Linköping University Medical Dissertation No. 1633

\title{
Subsyndromal Depression in Very Old Persons
}

\author{
Mikael Ludvigsson
}

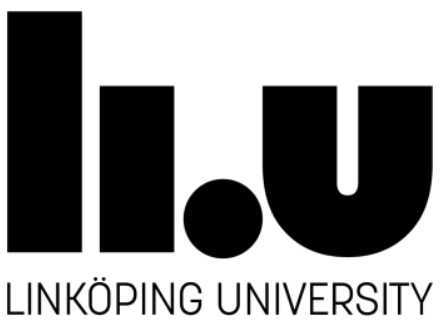

Department of Clinical and Experimental Medicine,

Division of Neuro and Inflammation Sciences Linköping University, SE-581 83 Linköping, Sweden Linköping 2018 
(C) Mikael Ludvigsson, 2018

Front cover: Shutterstock images. Printed with permission. The symbolism of the iceberg is explained in connection with Figure 11 in the thesis frame.

Published articles have been reprinted with the permission of the copyright holders.

Printed in Sweden by LiU-Tryck, Linköping, Sweden, 2018

ISSN $0345-0082$

ISBN 978-91-7685-253-8 


\title{
Subsyndromal Depression in Very Old Persons
}

\author{
By \\ Mikael Ludvigsson \\ June 2018 \\ ISBN 978-91-7685-253-8 \\ Linköping University Medical Dissertation \\ No.1633 \\ ISSN 0345-0082
}

Department of Clinical and Experimental Medicine, Division of Neuro and Inflammation Sciences

Linköping University, SE-581 83 Linköping, Sweden 

O Captain, my Captain! our fearful trip is done;

The ship has weather'd every rack, the prize we sought is won; The port is near, the bells I hear, the people all exulting, while follow eyes the steady keel, the vessel grim and daring:

But O heart! heart! heart! $O$ the bleeding drops of red, Where on the deck my Captain lies, Fallen cold and dead.

Walt Whitman (1819-1892). Leaves of Grass. 1900 



\section{List of contents}

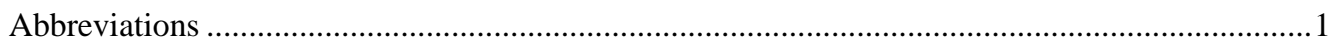

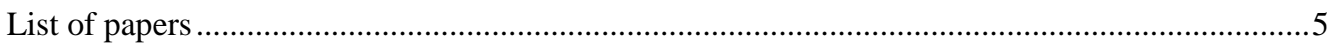

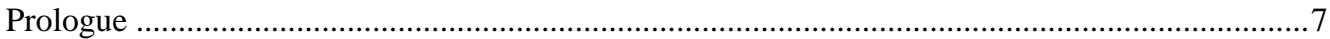

1. Introduction: Depression, subsyndromal depression (SSD) and very old persons ...............9

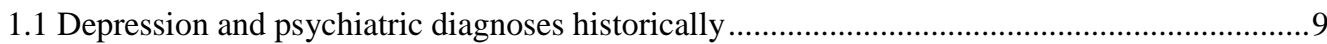

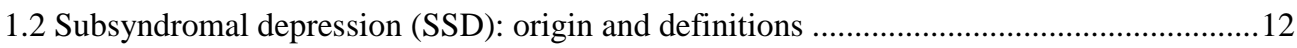

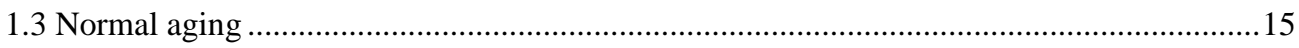

1.4 Prevalence and causes of depression in very old persons ............................................. 17

1.5 Treatment of depressiveness in very old persons ............................................................. 18

1.6 The complex area between normal aging and syndromal depression ...............................19

1.7 The identified knowledge gap, as a motive for this thesis................................................ 19

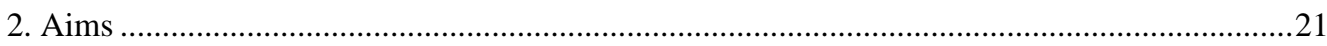

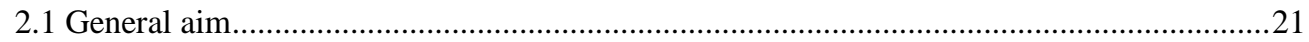

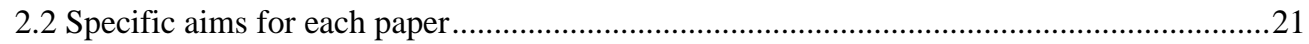

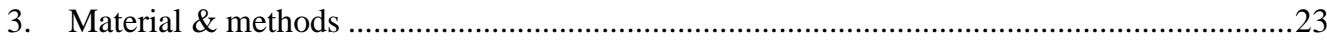

3.1 The population study ELSA85 and the relation to the thesis project ................................23

3.2 Definition of SSD, syndromal depression, ND and normal aging for the thesis project......24

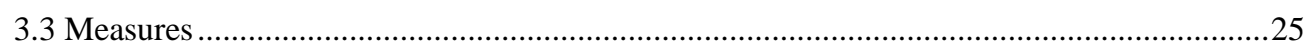

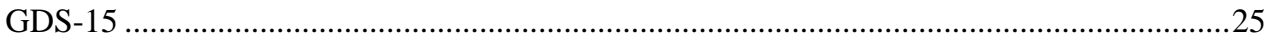

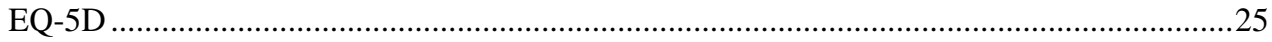

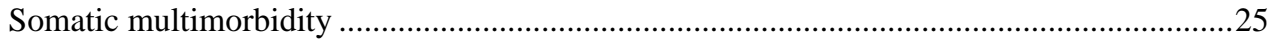

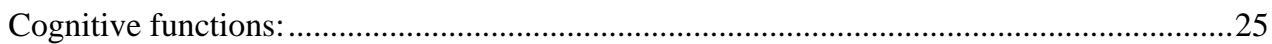

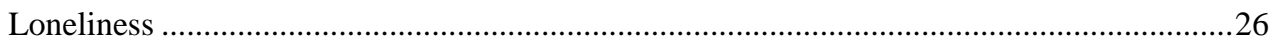

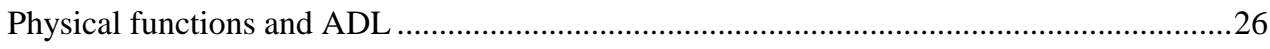

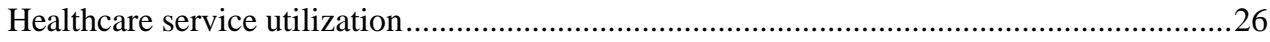

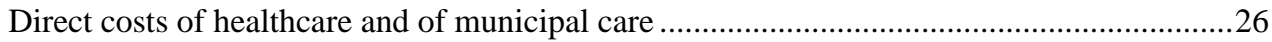

3.4 Design, sampling and analytical procedures for the different papers................................27

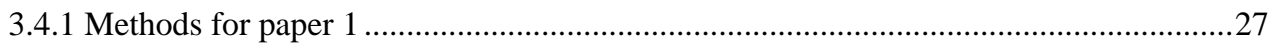

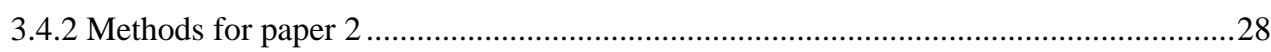




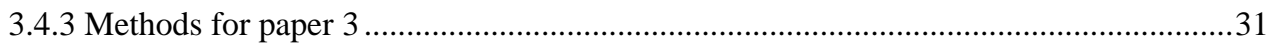

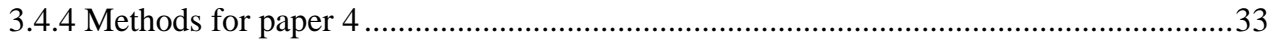

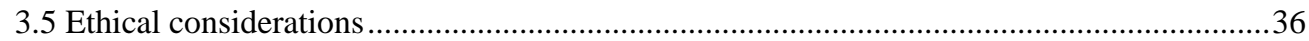

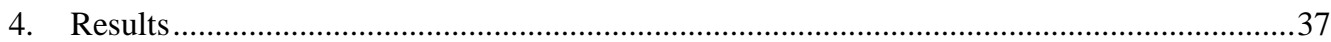

4.1 Results from paper 1. Normal aging, SSD or depression: a qualitative analysis ................37

4.2 Results from paper 2: Markers of subsyndromal depression .............................................40

4.3 Results from paper 3: Direct costs of persons with subsyndromal depression ...................42

4.4 Results from paper 4: Morbidity and mortality in persons with SSD ..............................48

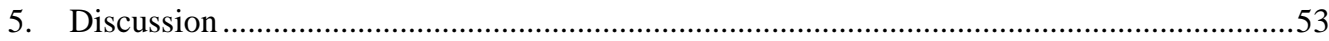

5.1 Cross-sectional pictures of the complex area between normal aging and depression ..........53

5.1.1 Experiences of being in very old age, and the heterogeneity of depressiveness ...........53

5.1.2 Presentations of depressiveness in very old persons, typical or atypical? ....................55

5.2 Longitudinal aspects of SSD in very old persons ............................................................57

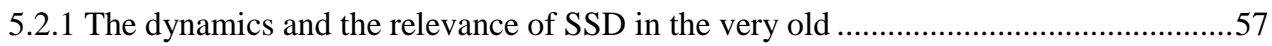

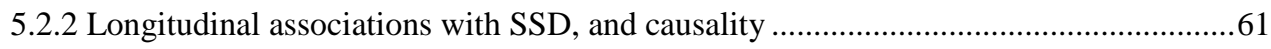

5.3 Significance of SSD in the very old, and the risks of medicalization ................................63

5.3.1 Significance of SSD in very old persons for the patient, for healthcare and for society

5.3.2 Normality, medicalization and diagnostic practice ......................................................64

5.3.3 Prevention and treatment of SSD in very old persons ..............................................67

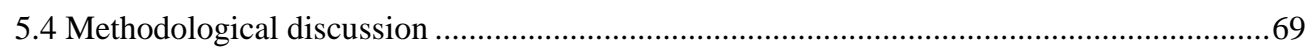

5.4.1 The validity of the definition of SSD in the thesis project ........................................69

5.4.2 Internal validity for the thesis project as a whole: ................................................... 70

5.4.3 External validity, generalizability or transferability: ................................................... 73

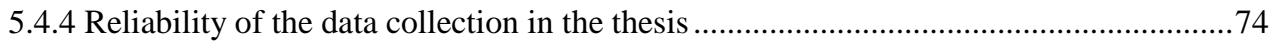

5.4.5 Some comments on causality for the thesis project ............................................... 74

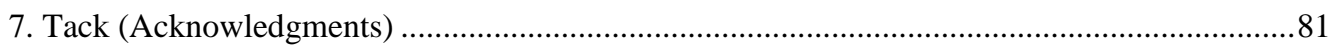

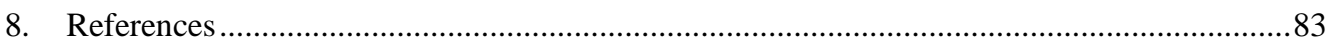

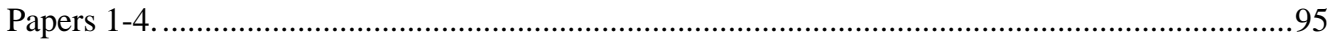


Appendix

Annex 1. The 15-item Geriatric Depression Scale (GDS-15) 



\section{Abbreviations}

$\begin{array}{ll}\text { ADL } & \text { Activities of Daily Living } \\ \text { CBT } & \text { Cognitive Behavioral Therapy } \\ \text { CDWÖ } & \text { the register Care Data Warehouse in Östergötland } \\ \text { CGA } & \text { Comprehensive Geriatric Assessment } \\ \text { CI } & \text { Confidence interval } \\ \text { COI } & \text { Cost-of-Illness } \\ \text { CPU } & \text { Cost Per User } \\ \text { Depr Ever } & \text { Syndromal depression at either of the two separate measurements } \\ \text { DSM } & \text { Diagnostic and Statistical Manual } \\ \text { ELSA85 } & \text { Elderly in Linköping Screening Assessment, 85 years at baseline } \\ \text { EQ-5D } & \text { The instrument EQ-5D, EuroQol - 5 Dimensions } \\ \text { EQ-VAS } & \text { EuroQol - Visual Analog Scale } \\ \text { GDS-15 } & \text { The 15-item version of the Geriatric Depression Scale } \\ \text { HR } & \text { Hazard Ratio } \\ \text { I-ADL } & \text { Instrumental ADL } \\ \text { IAM } & \text { Instrumental Activity Measure } \\ \text { ICD } & \text { International Classification of Diseases } \\ \text { MMSE } & \text { Mini Mental State Examination } \\ \text { ND } & \text { Non-depression } \\ \text { ND Both } & \text { Non-depression at both of two separate measurements } \\ \text { OR } & \text { Odds Ratio } \\ \text { PaSMO } & \text { Parallel Serial Mental Operations test } \\ \text { SD } & \text { Standard Deviation } \\ \text { SEK } & \text { The currency Swedish Krona (Svensk Ekonomisk Krona) } \\ \text { SSD } & \text { Subsyndromal depression } \\ \text { SSD Ever } & \text { SSD at either of the two separate measurements } \\ \text { SSRI } & \text { Selective serotonin reuptake inhibitors } \\ \text { TMT-A } & \text { Trail Making Test part A } \\ & \\ \text { SDT } & \\ \text { SD } & \end{array}$




\section{Abstract}

Background: Subsyndromal depression (SSD) or subthreshold depression is a common affective condition that can be described as depressiveness below the threshold of what is called a syndromal or a major depressive episode. The point prevalence for SSD has been reported to be about $10 \%$ in the community, or about two or three times higher than the prevalence for syndromal depression. In elderly persons, SSD compared to non-depression (ND) is associated with impaired activities of daily living (ADL), lower cognitive function, lower self-perceived health, worse psychiatric outcomes and higher mortality.

However, most studies on SSD in elderly persons have been done in the young old age group (age 60-80 years), while few studies have investigated SSD in very old persons (age 80+). As many aspects (e.g. multimorbidity, frailty, functional decline and social dependence) increase between the young old and the very old ages, there is a need for more knowledge about SSD in the very old. The overall aim of this doctoral thesis was to describe SSD, or the unclear area between syndromal depression and normal aging, in very old persons.

Method: Paper 1 was based on qualitative interviews $(n=27)$, while papers 2-4 were based largely on data from a prospective observational cohort study "Elderly in Linköping Screening Assessment" (ELSA85), with a population-based design following the participants from the age of 85 in three waves of follow-up. The 15-item Geriatric Depression Scale (GDS-15) was used for measuring depressiveness and to define SSD in the studies.

Results: The analysis of the qualitative interviews (paper 1) resulted in four themes (life curve and the body go down, to manage on one's own, to keep up with life, and taking one day at a time), giving a comprehensive picture of SSD in very old age. In a comparison among SSD, ND and syndromal depression, SSD differed qualitatively from syndromal depression, but not clearly from ND.

A cross-sectional analysis of data from baseline (paper 2) identified factors associated with SSD in very old persons, and according to analyses with multiple logistic and linear regressions, four domains (sociodemographic factors, declining physical functioning, neuropsychiatric factors, and existential factors) were significantly associated with SSD.

A five-year longitudinal follow-up (paper 3) showed that direct healthcare costs per month of survival for persons with SSD exceeded those of persons with ND by a ratio of 1.45 (€634 vs $€ 436$ ), a difference that was significant even after controlling for somatic multimorbidity.

An eight-year longitudinal follow-up (paper 4) showed that morbidity was elevated for persons with SSD compared to ND regarding basic ADL, I-ADL, loneliness, self-perceived health and depressiveness, whereas cognitive speed, executive functions and global cognitive function were not significantly lower when adjusting for covariates. Contrary to our hypotheses, mortality over 
nine years was not elevated for very old persons with SSD compared to ND, when adjusting for relevant covariates.

Conclusion: SSD in very old persons has a different presentation in different persons, and healthcare personnel should be attentive to other depressive signs beside the classical ones in the diagnostic classification registries. SSD in the very old is associated with elevated direct healthcare costs, morbidity and lower self-perceived health. Considering the high prevalence of SSD and the demographic development of increasing numbers of very old people, the findings highlight the need to develop clinical and societal strategies to prevent SSD and associated negative outcomes. 


\section{List of papers}

1) Ludvigsson Mikael, Milberg Anna, Marcusson Jan, Wressle Ewa. Normal aging or depression? A qualitative study on the differences between subsyndromal depression and depression in very old people. Gerontologist. 2015 Oct;55(5):760-9. doi: 10.1093/geront/gnt162. Epub 2014 Jan 7.

2) Ludvigsson Mikael, Marcusson Jan, Wressle Ewa, Milberg Anna. Markers of subsyndromal depression in very old persons. Int J Geriatr Psychiatry. 2016 Jun;31(6):619-28. doi: 10.1002/gps.4369. Epub 2015 Oct 21.

3) Ludvigsson Mikael, Bernfort Lars, Marcusson Jan, Wressle Ewa, Milberg Anna. Direct costs of very old persons with subsyndromal depression: a five-year prospective study. Am J Geriatr Psychiatry. 2018 Jul;26(7):741-751. doi: 10.1016/j.jagp.2018.03.007. Epub 2018 Mar 15.

4) Ludvigsson Mikael, Marcusson Jan, Wressle Ewa, Milberg Anna. Morbidity and mortality in very old persons with subsyndromal depression: An eight-year prospective study. Submitted. 


\section{Prologue}

For a long time I have personally had a commitment to elderly people, and more specifically to elderly persons with mental illness, for example signs of depression. I am not quite sure about the origin of this commitment, but maybe my basic social pathos has contributed to this, when I have recurrently experienced that elderly persons as a group (compared to younger persons) and persons with mental illness as a group (compared to those with physical illness) have been systematically overlooked or neglected in the planning and design of social life and healthcare. I have been involved in this issue through my work as a specialist in geriatrics, and through my internship in psychiatry, including providing psychotherapy to patients.

When I conducted my first interview in a sample of elderly persons I noticed especially how response bias complicated the interpretation when using rating scales or in anamnestic interviews, which increased my interest. Not only did physical comorbidity and transcultural aspects contribute to the complicated interpretation of psychiatric signs and symptoms during the conversations, but also the detail that elderly persons (as well as younger persons) sometimes denied depressive symptoms when answering my questions, at the same time as they communicated such symptoms through their alternative formulations, through non-verbal speech and through body language.

For example, if I asked them if they experienced persistent low mood, they could perhaps answer "no, not low mood, but I sometimes feel gloomy" at the same time as their body language expressed low mood in a clear way as in depressiveness. In a verbatim interpretation, as an example of response bias, these answers would have been interpreted as a denial of the question about low mood, while a more open-minded interpretation (including the non-verbal communication) instead confirmed a persistent low mood.

When I learned more about depressive signs and mild depressiveness in elderly persons, I eventually came into contact with the concept of subsyndromal depression. I felt a desire to better understand the interface between major or syndromal depression and normal aging. A colleague of mine warned that research in this subject area of discrete psychiatric symptoms would be like "doing research on phantoms" (i.e. it is hard to do research on phantoms or ghosts, as they do not have a physical body [my personal interpretation of the warning]). However, later I was strengthened in my intentions to do research on subsyndromal depression, when talking to a senior physician in old age psychiatry. He instead emphasized the great relevance of subsyndromal psychiatric conditions in the clinical work to help with mental illness in old age [1]. The desire to help older people with mental illness by contributing to scientific development eventually led me to this $\mathrm{PhD}$ project.

At the beginning of this dissertation a poem by Walt Whitman was cited. This poem reminds me, on the basis of my personal interpretation, of how we human beings tend to complicate life very much, for example through dysfunctional patterns of thinking, misunderstandings and conflicts. 
This tendency to complicate things in life so much has consequences such as different forms of mental illness or - as in the poem - death. The captain of the poem, which in my interpretation would be the captain of ourselves (the self, or the frontal lobe of the brain) and our values, is lying on the deck because we did not give him his proper leadership of life. Instead we often let temporary impulses, dysfunctional thinking and external circumstances take the leadership of our lives, while the captain was pushed into a corner. If instead we gave the proper leadership back to our captain of life and did not complicate things so much, then we would probably suffer less from mental illness, and be able to enjoy the journey of life more. If we thus could prevent mental illness and instead live a more meaningful life, then we would perhaps be able to stand together with the main character in the poem - close to the harbor - and enjoy the bells and the exultation of the people.

The frame of the thesis is primarily written in English, but a Swedish version was also produced in order to facilitate the public outreach. The Swedish version is found in the appendix (annex 2) at the end of this book, or as a separate file in the digital version of the thesis. 


\section{Introduction: Depression, subsyndromal depression (SSD) and very old persons}

\subsection{Depression and psychiatric diagnoses historically}

Depression or melancholy as an affective condition was described as early as in the ancient Greek period, and the founder of medicine, Hippocrates (c.460-c.370 BCE), wrote that "fear or sadness that lasts a long time means melancholia", and that melancholy was caused by an excess of black bile in relation to the other three humors (yellow bile, blood and phlegm; Figure 1) [2].

A few centuries later, Galen of Pergamum (129 AD - c. 200/c. 216) further developed the humoral theory about how different medical disorders were caused by an imbalance between the humors, which for many centuries was the rationale for treating melancholy with herbs and other treatment methods in order to restore balance in the body $[3,4]$.

Even though other scientists such as Carl von Linné in Sweden made a commitment to classify psychiatric disorders in the $18^{\text {th }}$ century, the humoral theory was influential in theory and practice right up until the $19^{\text {th }}$ century [5].

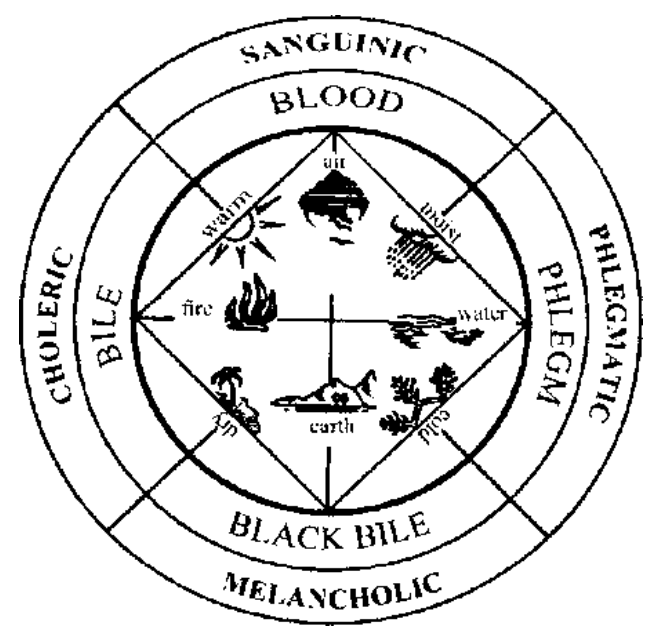

Figure 1. Schematic view of depression or melancholy according to the ancient humoral theory. Adapted from Schipperges 1970 according to Bujalkova et al. 2001 [6], with permission. 
Since then, the evolution of psychiatric classification of diseases (nosology) has undergone gradual or punctuated changes in certain steps, by clinicians and thinkers such as Sigmund Freud (1856-1939) at the beginning of the $20^{\text {th }}$ century, and his peer Emil Kraepelin (1856-1926) who slightly earlier founded modern nosology in psychiatry with a fundamental effort to systematically and empirically chart psychiatric signs and symptoms over time [2]. In 1952 the Diagnostic and Statistical Manual: Mental Disorders (DSM-I) was published by the American Psychiatric Association, which was influenced mainly by the psychoanalytical theories of Freud. In parallel with the diagnostic classification of DSM in psychiatry, there was also the more comprehensive registry, the International Classification of Diseases (ICD)[7] on both psychiatric and somatic disorders, and the second revised edition of the DSM which was published in 1968 had a structure that was closer to the ICD and the somatic disease categories included. The third edition of the DSM was developed in the 1970s and it included a radical change of the description of depression built on the so-called Feighner criteria for depression, which was the result of an endeavor toward a basis of validity and reliability of diagnoses rather than an unsecure etiological basis. Still today in the DSM registry in its fifth edition, the Feighner criteria are used in a fairly similar manner [8-11].

According to the current edition of the DSM a diagnosis of major depression means at least five of the following nine symptoms must be present most of the day, nearly every day, for at least two weeks: depressed mood, anhedonia (diminished interest or pleasure), change in appetite, sleep disturbance, psychomotor change, loss of energy, feelings of worthlessness or excessive or inappropriate guilt, diminished ability to think or concentrate or indecisiveness, and recurrent thoughts of death [10]. These symptoms or signs together are regarded as the psychiatric syndrome, or the symptom complex, of major depression. Two of Feighner's colleagues, Robins and Guze, criticized the prevailing psychoanalytical paradigm, and made a careful description of the validity concept in psychiatric diagnostic practice, which was important for the revision of the DSM $[12,13]$. Their model to validate diagnoses was based on five steps (of which the Feighner criteria for depression correspond to the first): identification of 1) clinical characteristics for the syndrome (including symptoms, demographical characteristics), 2) exclusion criteria for differentiating from other syndromes, 3) family history, 4) laboratory data and 5) follow-up (development of the symptoms over time, treatment response).

Establishing diagnostic criteria was an expression of the endeavor to describe and define reliably what the disorder means, and the DSM criteria for depression have for a long time been considered a gold standard in different aspects of diagnosing depression. They have also, in connection to Plato's allegory of the cave, been described as the shadow in reality from a more complex independent existence, or as our empirical indicators of the underlying disorder [14]. A simplified illustration of the evolution of the concept of depression or melancholy in history is depicted in Figure 2. 


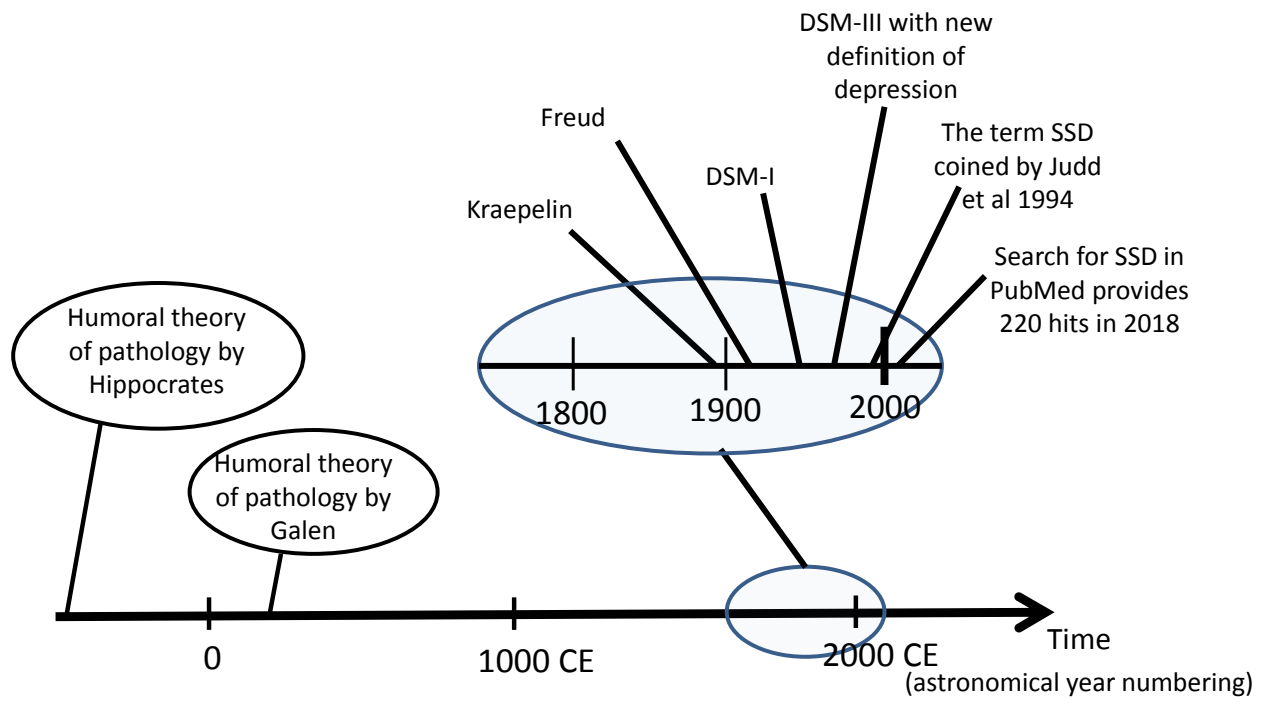

Figure 2. Depression or melancholia, and SSD from the perspective of the history of ideas in Western culture.

A recurrent academic debate in regard to psychiatric disorders concerns the way varying degrees of a disorder relate to normality and to other disorders. The current DSM-5 and ICD-10 (of which the latter is used for administrative purposes in Sweden today) both build mostly on a categorical perspective in which different disorders are regarded as independent of each other, similar to buckets next to each other [7, 10]. An alternative perspective on psychiatric disorders is the dimensional perspective, from which every disorder relates to normality and to other psychiatric disorders in a continuum of several dimensions or qualities [14-16]. A comparison of the categorical and the dimensional perspectives on depressive conditions and normality is depicted in Figure 3. 


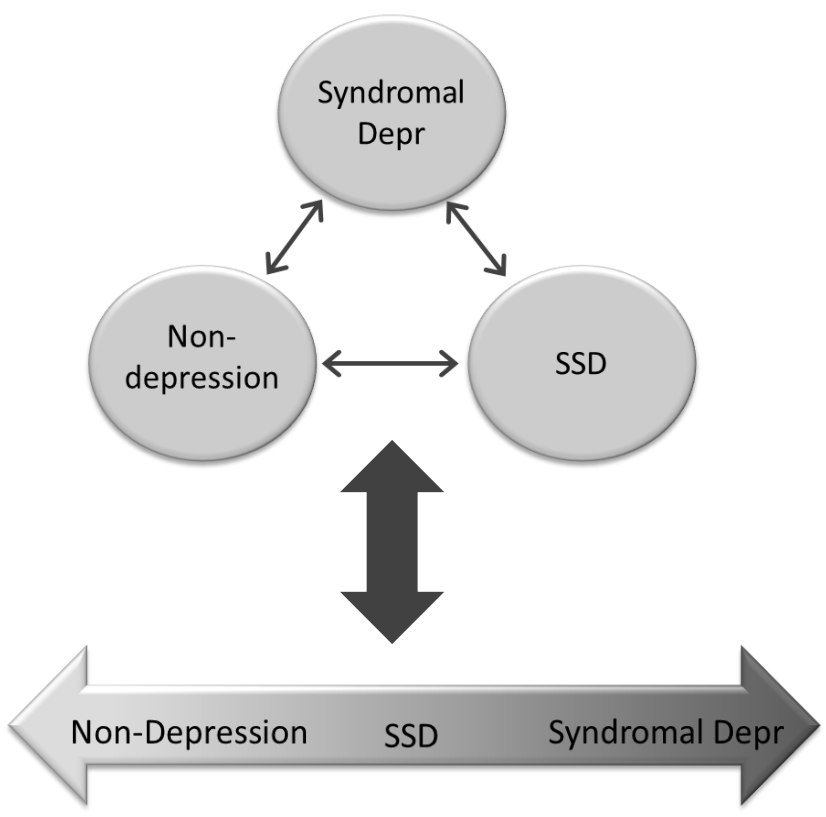

Figure 3. Schematic differences between categorical (above) and dimensional (below) perspectives on depressive conditions and normality.

\subsection{Subsyndromal depression (SSD): origin and definitions}

The fourth edition of DSM distinguished three extra subgroups of depressiveness except for major or syndromal depression, and they were called dysthymia, minor depression and recurrent brief depression. In addition, Judd et al. 1994 described a condition they called subsyndromal symptomatic depression, which subsequently, and more briefly, has been called subsyndromal depression $[17,18]$.

Judd et al. 1994 initially defined SSD by at least two or more current depressive symptoms (with the absence of the core symptoms of depressed mood and anhedonia) present most of the time and every day for at least two weeks, and with consequent suffering or functional impairment $[17,19]$. Since then, alternative definitions and operationalizations of SSD have been used, and these varying definitions might in part be a result of the fact that the American Psychiatric Association has not yet incorporated the condition in the DSM. Consequently, scientific studies with different definitions of SSD have shown a wide range of prevalence numbers, associated factors and outcomes of SSD [20-22]. Table 1 shows a compilation of how different states of depressiveness are defined in DSM-5, and how SSD is defined in contrast to ND or normal aging in this thesis. 
Table 1. A compilation of different states of depressiveness according to DSM-5 definitions, and the definitions of SSD and ND or normal aging as defined in this thesis.

\begin{tabular}{|c|c|c|c|}
\hline $\begin{array}{l}\text { Diagnosis of different states } \\
\text { of depressiveness }\end{array}$ & Symptom criteria & $\begin{array}{l}\text { Duration of } \\
\text { symptoms }\end{array}$ & $\begin{array}{l}\text { Other diagnostic } \\
\text { criteria }\end{array}$ \\
\hline $\begin{array}{l}\text { Syndromal or major } \\
\text { depressive disorder }\end{array}$ & $\begin{array}{l}\text { Five or more out of } \\
\text { nine depressive } \\
\text { symptoms, and at least } \\
\text { one of the core } \\
\text { symptoms of } \\
\text { depressed mood or } \\
\text { anhedonia }\end{array}$ & $\begin{array}{l}\text { Most of the day, } \\
\text { nearly every } \\
\text { day, for } 14 \text { days } \\
\text { or more }\end{array}$ & $\begin{array}{l}\text { Cause clinically } \\
\text { significant distress } \\
\text { or impairment, and } \\
\text { is not better } \\
\text { explained by } \\
\text { another disorder }\end{array}$ \\
\hline Recurrent brief depression $^{b}$ & $\begin{array}{l}\text { Five or more } \\
\text { symptoms, including } \\
\text { depressed mood }\end{array}$ & $\begin{array}{l}\text { Duration } 2-13 \\
\text { days per month, } \\
\text { at least } 12 \\
\text { consecutive } \\
\text { months }\end{array}$ & Ibidem \\
\hline $\begin{array}{l}\text { Persistent depressive } \\
\text { disorder (dysthymia) }\end{array}$ & $\begin{array}{l}\text { Three or more out of } \\
\text { seven symptoms, } \\
\text { including depressed } \\
\text { mood }\end{array}$ & Duration 2 years & Ibidem \\
\hline $\begin{array}{l}\text { Unspecified depressive } \\
\text { disorder, mild and } \\
\text { moderate severity }\end{array}$ & $\begin{array}{l}\text { Two to four } \\
\text { depressive symptoms }\end{array}$ & Not specified & Ibidem \\
\hline $\begin{array}{l}\text { SSD according to Judd et } \\
\text { al. } 1994\end{array}$ & $\begin{array}{l}\text { Two or more out of } \\
\text { nine symptoms, and } \\
\text { absence of the core } \\
\text { symptoms depressed }_{\text {mood and anhedonia }}{ }^{\mathrm{c}}\end{array}$ & $\begin{array}{l}\text { Most of the day } \\
\text { and every day, } \\
\text { for } 14 \text { days or } \\
\text { more }\end{array}$ & Ibidem \\
\hline $\begin{array}{l}\text { SSD in DSM-5, not } \\
\text { mentioned }\end{array}$ & Not defined & Not defined & Not defined \\
\hline SSD as defined in this thesis & $\begin{array}{l}\text { Specific range of } \\
\text { points from the scale } \\
\text { GDS }-15^{\mathrm{d}}\end{array}$ & Not defined & Not defined \\
\hline $\begin{array}{l}\text { ND or normal aging as } \\
\text { defined in this thesis }\end{array}$ & $\begin{array}{l}\text { Specific range of } \\
\text { points from the scale } \\
\text { GDS }-15^{\mathrm{d}}\end{array}$ & Not defined & Not defined \\
\hline
\end{tabular}

Notes: ${ }^{a}=$ Compared to the DSM-5 the following diagnoses have been left out from the table in order to simplify the presentation: disruptive mood dysregulation disorder, premenstrual dysphoric disorder, substance/medication-induced depressive disorder, depressive disorder due to another medical disorder, other specified depressive disorder (except recurrent brief depression), and unspecified depressive disorder $.^{b}=$ this condition is included in the category "other specified depressive disorder" in the DSM-5. ${ }^{c}=$ the specification about absence of core symptoms by Judd et al. 1994 was added in the light of the similar diagnosis of minor depression 
which included at least one core symptom. For the current edition of DSM, the term 'minor depression' was left out. ${ }^{d}=$ The scale GDS-15 (15-item Geriatric Depression Scale) is described in more detail in the methods section 3.3.

In general, definitions of SSD are based on either self-assessment scales or structured diagnostic interviews (or both in a so-called two-phase design), which tend to give slightly different diagnostic results including different prevalence numbers [23]. For example SSD was defined as results of $0-5 p$ on the 15 -item Geriatric Depression Scale (GDS-15; [24]) in a study of Chachamovic et al. 2008, while it was defined with both a screening scale and alternative structured interview in a study of Lyness et al. 2007 [20, 25]. Screening scales generally have advantages of being easily administered and more closely related to the dimensional paradigm of psychiatric disorders, while structured interviews on the other hand are better for describing symptom development over time as well as comorbidity [26]. Another factor that substantially influences prevalence numbers in psychiatric epidemiology is (except for varying definitions of study phenomenon and varying study samples) also the decision about exclusion criteria for a study. Including or excluding comorbid disorders makes a big difference as the covariation or comorbidity of psychiatric disorders is great $[16,27]$.

The prevalence of SSD among elderly persons thus varies greatly between different studies, with a median point prevalence of $9.8 \%$ (range $4.0-22.9 \%$ ) in the community, according to a review from 2011 [21], and the pattern from different investigations with screening scales is, naturally, that the prevalence estimates are greater the lower (fewer or milder symptoms) the threshold is. Mild disorders have been called subclinical disorders in both psychiatric and somatic research, and a recurrent notion is that the subclinical forms of a disorder should be included in scientific studies on etiology in order not to miss important aspects when trying to understand and prevent a disease $[28,29]$.

A principal difference for depressive disorders, compared with other medical disorders with similar patterns of gradually increasing morbidity effects with degree of disorder but still a categorical cutoff for the diagnosis (i.e. diabetes mellitus, hypertension, hyperlipidemia), is that there is no consensus regarding which measure to use in depressive disorders. This makes the question about cutoff between disorder or disease and normality more complicated in the case of depression.

However, for depressiveness, as for the above-mentioned other medical conditions, there is a common problem of arbitrariness in the decisions of where to draw the line between normality and pathology, and a consequent risk for medicalization and over- or under-treatment [30]. Almost independently of where to draw the line between ND and SSD, or between SSD and syndromal depression, a recurrent finding has been that SSD is associated with an impairment of different functions and of quality of life on a level between that of ND and syndromal depression $[21,31]$. For example, production losses in work, cognitive test results, degree of anxiety, quality 
of life and the risk of future depression for persons with SSD are at a level between those of persons with ND and depression respectively [25, 32-37].

\subsection{Normal aging}

Even if aging in some aspects biologically begins at about the age of 30 , the accumulated signs of aging only exceed bodily buffers to a measurable degree at 60-70 years of age [38]. The aging of the central nervous system means a reduced weight of the brain anatomically, a reduced cerebral blood flow, the accumulation of amyloid plaques and neurofibrillary tangles at a cellular level, and a reduced number of receptors for dopamine and acetylcholine neurochemically [39-41]. These and other changes lead to functional impairment in different cognitive functions, but also in volitional and emotional functions [42, 43]. The line between normal aging and dementia is diffuse, and pathological changes in dementia are often present to a lesser degree also in normal aging $[39,44]$.

In addition to the biological changes, aging is associated with psychosocial changes which also affect well-being, for example in cases of mourning because of loss of friends or loss of physical functions, in more difficult economic conditions after retirement, in social isolation, or in the effort of caring for a relative [45]. In this way, old age is a life span that naturally contains many challenges, which explains why many people also live with a notion that a heavy load of negative experiences and feelings belongs to old age. However, there are several studies showing that selfperceived health or quality of life is not so bad in old age, on average in the population. Even if the quality of life on a population level decreases with age after a peak at age 65-80, it never decreases to the level of persons between age 40-60 [46, 47]. The fact that quality of life or wellbeing thus is relatively high during old age compared to other periods of life on a population level despite the fact that normal aging contains so many losses or challenges, has been called the health paradox of old age [48].

The cause of this health paradox is not completely understood, but two subjects that might explain part of it are coping and resilience. Coping stands for different kinds of efforts to overcome challenges in life, while resilience similarly is about the resistance or the capacity to bounce back or recover from stress [49-56].

Resilience has been investigated in elderly persons, and has been shown to be associated with a lower degree of depressiveness, and with reduced mortality [57-59]. Other theoretical concepts that similarly describe a health-promoting lifestyle or salutogenic coping styles include inner strength, hardiness, and sense of coherence [50,60,61]. These salutogenic processes have mostly been investigated within the disciplines of nursing, sociology and psychology, while the opposite directed pathogenic or disease-causing processes on the other hand have been investigated mostly within the medical discipline.

In addition to coping and resilience on an individual level, the health paradox and well-being in old age have been investigated from a larger macro perspective on cultural and societal levels. 
The movement from an individual to a societal level roughly corresponds to a movement from the perspectives of psychology to the perspectives of nursing and sociology from which aging has been described more on a group level and population level. Some of the more influential sociological theories about what gives health and quality of life while aging are activity theory, disengagement theory and the theory of gerotranscendence.

According to activity theory, good aging is based on being active and maintaining activity patterns typical of middle age also in old age, despite the changing conditions of life such as retirement and social losses [62]. According to this theory, high quality of life can be achieved through an active lifestyle across the lifespan. The disengagement theory on the contrary has described persons in old age as having a natural tendency to withdraw from previous roles and activities, and to engage less in social life $[62,63]$. By withdrawing from society and instead engaging in introspection and reflection, old persons can achieve good aging and good health, according to this theory. The theory of gerotranscendence resembles the disengagement theory in the matter of withdrawal, but involves more existential and spiritual aspects. It states that the old person has a growing need for reflection, and that there is a natural personal development of transcendence in three dimensions: in the cosmic, in the self and in social relations [64].

Much of the research on health promotion or salutogenic factors in aging has used the concept of successful aging to describe what promotes good quality of life in aging and in old age (even if some people have stated that "optimal aging" would be a more culturally neutral description than successful aging) $[63,65,66]$. The research about successful aging was accelerated during the 1980s and the 1990s by researchers with connections to the MacArthur Foundation in the US, and the concept has been investigated extensively as an aspect of health promotion in normal aging $[63,67,68]$. A more recent theory that integrated many parts of the theories on resilience, coping and health promotion in aging is Strength and Vulnerability Integration (SAVI) [69]. Together, these theories offer a comprehensive picture of how it is to grow older and of normal aging, with preconditions that on one hand are common in chronological, biological and physical age, in generation (secular trend), culture and subculture [70-73], and with preconditions that on the other hand are individually different.

Even if many normal aging processes thus begin earlier in life, it is common in scientific studies to set a lower limit for old age or elderly persons at the age of 60 or 65 . As life on a group level continues to change substantially in several aspects (socially, psychologically, biologically) also after this lower limit with large differences between 65-year-olds and 85-year-olds, a chronological limit is set for scientific purposes also between young old persons (age 60-80) and very old or the oldest old persons (age $80+$ or $85+$ ) [74, 75]. From a psychosocial perspective an alternative limit has been described between a third and a fourth age of life [76]. While persons of the third age (roughly corresponding to the chronological group young old) still have good physical, social and economic resources with independence and fairly good health, the preconditions generally change in the fourth age (corresponding to the group of very old persons) with progressive multimorbidity, frailty, and functional impairments with social and economic 
dependence. Even if this psychosocial division into the categories of the third and the fourth ages does not necessarily have to correlate to the chronological division into the young old and the very old, there is a clear similarity between the two.

The current demographic development worldwide means that the proportion of old persons - and in particular of very old persons - is steadily increasing, which is why there is a growing need to scientifically understand and describe the needs, the preferences, the thinking patterns and behavioral patterns of very old persons. At the same time there is also a need to identify and to describe salutogenic and pathogenic processes in aging [74].

\subsection{Prevalence and causes of depression in very old persons}

Depressiveness is an extensive social problem; for example, depression has been estimated to become the largest contributing factor to disease burden in high-income countries by 2030, while currently (next to low back pain) it is the second largest contributing factor to the global burden of disease $[77,78])$.

On an individual level it causes great suffering and negative consequences for both psychological and somatic health, including impaired functions [79, 80]. Even if depression in many cases heals spontaneously, there are a large number of treatment alternatives which speed up and increase recovery, with associated reduction of suffering, functional impairments and disease. Some common alternatives for depression treatment according to current medical guidelines are cognitive behavioral therapy (CBT), interpersonal psychotherapy, antidepressive medications, electroconvulsive therapy (ECT) and physical activity $[81,82])$.

As in younger adults, depressiveness or depressive signs are common in elderly persons. It is estimated that about $1-5 \%$ of the older population suffer (12-month prevalence) from syndromal depression in Sweden and in other countries (with some minor variations between countries) [8387], while at least two to three times as many people suffer from clinically significant depressive symptoms or subsyndromal depression [88-91].

Neuroanatomical and neurochemical changes have been found in elderly people with depression compared with ND, and depression in aging people have statistically slightly different causes than in younger people, with organic brain damage and somatic comorbidity contributing to the clinical picture [92-96]. Recurrently it has been stated that the clinical picture of depression in the elderly is different than that of younger ages, which has been called age-colored depression. This statement or hypothesis has been investigated scientifically several times, and some of the findings of such research are that there are a heavier load of cognitive impairment, a higher frequency of suicide, and a lesser degree of sadness in depression in the elderly compared to younger ages [97-102]. Instead of comparing depression between different chronological ages, an alternative approach has been to compare depression in elderly persons with early onset in life and late onset in life, in order to find a correlate to the clinical impression of age-colored depression [43, 103, 104]. Nevertheless, some authors have argued that there is no empirical 
evidence of differences between depression in younger and older populations, as long as comorbidity is corrected for, and as long as methodological diversities between studies are considered [89, 105].

\subsection{Treatment of depressiveness in very old persons}

Recommendations for treatment of depression in the elderly are in general based on less evidence than depression in younger adults, as most studies have been carried out on subjects of younger ages. Furthermore, there is no universally accepted treatment model for SSD in any age, which is probably partly due to the lack of consensus on definitions of SSD, and partly due to the lack of treatment studies for the condition [21]. The few previous studies have indicated that regular treatment alternatives for depression (for example CBT and antidepressive medications) seem to work also for SSD, even though effect sizes in general are smaller for SSD than for syndromal depression [106-108]. There are no guidelines for treatment of syndromal depression in the specific age group of very old persons, but on the other hand such do exist for depression in elderly persons more in general (i.e. age 65+) [109].

Common treatments that have shown an effect on depression in the elderly are CBT and the subgroup of problem-solving therapy, antidepressive medication, physical activity and collaborative care $[109,110]$. Collaborative care is a treatment model for depressiveness that is uncommon in Sweden at present. A main component in the treatment model is the usage of a case manager as a link between the patient, healthcare providers, municipal care and family, and collaborative care has been shown to be treatment-effective and cost-effective [110-113].

In recent years a new model for assessing and treating disorders of elderly persons called Comprehensive Geriatric Assessment (CGA) has been developed in geriatric healthcare, which corresponds to a multiprofessional and systematically holistic and person-centered way of assessment and treatment of elderly patients $[114,115]$. Such principles for assessment and treatment have previously been recommended for the treatment of depression in old age, but as far as I know the model has not been investigated in controlled trials for depression yet [116]. Another treatment model for different degrees of depressiveness, advocated in British national guidelines, is a so-called stepped care model: on one hand low-intensity interventions for those with discrete problems of depressiveness and on the other hand higher intensity interventions for those with more problems (with the metaphor of a staircase of depression intensity and treatment intensity) $[27,82,117]$. Both collaborative care, CGA and stepped-care models give attention to the complex multifactorial etiology of depressiveness. This is also the case in CBT in so called tailored interventions [118] and in augmentation strategies in pharmacology $[119,120]$. Considering the complex and multifactorial aspects of depressiveness is often recommended in old age psychiatry, as this corresponds to the nature of the disorders of old age [121]. Further on, it is common in clinical practice to extrapolate treatment evidence from depression of younger ages to older ages, although this is often done on weak grounds [109, 122, 123]. 


\subsection{The complex area between normal aging and syndromal depression}

Thus, since the days of Hippocrates there has been a growing body of knowledge about melancholy or syndromal depression (even if the relation between the two terms have changed over time) [2, 124], and since Judd et al. described SSD in 1994 [17], SSD or subclinical depression has been described in different aspects from a large number of studies. Also how normal or non-depressive life, SSD, and depression change with aging has been investigated.

However, the general pattern in the subject area for depressiveness, as well as for other subjects of psychiatry and medicine in general, is that most studies on old age have been carried out on samples of the young old age group [21, 116, 125]. For example in the previously mentioned review of Meeks et al. 2011 on SSD in the elderly, only 18\% (7/38) of presented studies had samples of a mean age 80+ [21]. As certain aspects of life and depressiveness change (e.g. the frequency of cerebral lesions, somatic diseases and degree of social dependence) between young old and very old persons, and as the population proportion of the latter group is growing there is a need for more knowledge about depressiveness in very old persons. Diagnostics and design of treatment specifically for persons with SSD in very old age could be improved with more knowledge in the subject field, and divergent treatment strategies for SSD in very old ages compared with younger ages could be identified.

SSD corresponds to a somewhat diffuse and complex area between normal aging and syndromal depression. It is an interface between, on one hand, the constant normal variations in mental activity, and on the other hand the abnormal depressive states for which help can be needed [126]. Critics have commented on this complex area, expressing that psychiatry has failed to adjust its diagnostic practices to handle the problem of false positives and that normal reactions to stress therefore are mistakenly classified as mental disorders, in concepts like subsyndromal depression [127]. On the other hand, depression has been described as underdiagnosed and undertreated [128, 129]. Thus, this unclear area between mental health and pathology leads to both false positives and false negatives, and a parallel sense of lacking specificity in the process of diagnostic practice.

\subsection{The identified knowledge gap, as a motive for this thesis}

On the basis of the text above, the unclear and complex area between syndromal depression and normal aging seems relevant to the well-being of elderly persons, and this complex area corresponds to SSD which is common in the population. In addition, there is a knowledge gap regarding SSD in very old persons, which seems particularly relevant in the light of the current demographic development. 


\section{Aims}

\subsection{General aim}

An overarching aim of this doctoral thesis was to investigate the unclear area between syndromal depression and ND in very old persons. That is, to investigate subsyndromal depression or subthreshold depression in the very elderly. Through investigation and deeper understanding of subsyndromal depression with its different aspects and components, clinicians might provide more relevant prevention or treatment to those who need such. Through deeper understanding of this unclear area, clinicians might also develop skills to better differentiate between pathology and normal affective states in very old ages - to increase accuracy in diagnostic practice and reduce the number of false positives and false negatives.

Specific issues:

- What is SSD in relation to ND and syndromal depression among very old persons?

- What does SSD in very old persons look like, i.e. how do very old persons with SSD experience their being or life in general, and what factors are associated with SSD?

- What are the consequences of SSD for very old persons? Does SSD differ from ND or syndromal depression regarding healthcare costs? Does SSD differ from ND regarding morbidity or mortality?

\subsection{Specific aims for each paper}

- Paper 1: to make a qualitative comparison of experiences of being in very old people with SSD, in relation to the experiences of very old people with syndromal depression or ND.

- Paper 2: to investigate factors associated with SSD in very old persons, and to develop a model for prediction of SSD among very old persons.

Based on previous literature and the results from paper 1 we hypothesized that SSD in very old persons would be related to sociodemographic characteristics (e.g. female sex, lower education), declining physical functioning (e.g. problems with mobility), or neuropsychiatric factors (e.g. history of affective psychiatric disorder, cognitive dysfunctioning) [21]. We also hypothesized that existential factors (e.g. lack of meaningfulness in life) would be associated with SSD in very old persons, because such aspects have previously been reported to be associated with syndromal depression [130]. 
- Paper 3: to provide a comparison between the prospective direct healthcare costs and service utilization for persons with SSD compared with non-depressive persons in a Swedish population of very old persons over a five-year period. A second aim was to develop a model that predicts direct healthcare costs in very old persons with SSD.

○ Based on previous literature on persons of lower ages we hypothesized that the direct costs of very old persons with SSD would be higher than for non-depressive persons [131, 132], independently of somatic multimorbidity, and that the factors of somatic multimorbidity, cognitive dysfunction [133], physical functioning and impaired activities of daily living (ADL) [134], chronic pain [135] , and loneliness [136] would also predict increased direct costs.

- Paper 4: to investigate eight-year longitudinal outcomes of morbidity and mortality for very old persons with SSD compared to ND.

- Based on previous studies on SSD in the young old, and on syndromal depression in very old age we hypothesized that in very old persons, SSD, compared to ND, would be associated with lower ADL function [137], worse self-perceived health [138], lower cognitive functions [36], a higher degree of loneliness [139], depressiveness [35] and higher mortality [23]. 


\section{Material \& methods}

\subsection{The population study ELSA85 and the relation to the thesis project}

During the years of 2007 and 2008 the first measure wave of the population-based observational cohort study ELSA85 was undertaken. All persons born in 1922 and living in Linköping municipality in Sweden $(n=650)$ in 2007 were invited to participate [140]. The overall purpose of the study was to create an evidence-based basis for health and social care of very old persons, with more specific purposes a) to describe physical, psychological, cognitive and social functioning in the population, b) to identify different subgroups regarding needs of health and social care, c) to identify discriminative factors in order to create a definition for the group "elderly with complex care needs", and d) to follow the cohort over time in order to analyze possible changes in the needs for health and social care. The first measure wave at baseline consisted of a postal questionnaire, a home visit by an occupational therapist, and a subsequent reception visit where a physician and a nurse asked extra questions in connection with a medical examination.

The postal questionnaire contained questions about sociodemographic data such as living conditions, educational level, but also the instrument EQ-5D about self-perceived health [141], questions about medications, disease history, loneliness, sense of meaning in life. At the home visit the depression screening instrument GDS-15 [24] was used, as well as questions about ADL including the Instrumental Activity Measure (IAM; [142]). At the reception visit different cognitive tests were undertaken in addition to the medical examination: Mini Mental State Examination (MMSE [143]), Victoria Stroop test [144], Trail Making Test part A (TMT-A [145]), Parallel Serial Mental Operations test (PaSMO [146]).

At the one-year follow-up, the postal questionnaire, the ADL assessment as well as GDS-15 and cognitive tests were repeated. The cohort study ELSA85 was initially planned to continue for one year, but new issues were raised which justified an extension of the study over time, with new measure waves after five years and eight years of follow-up. This doctoral thesis grew in connection with ELSA85, and Figure 4 shows how the different papers of the thesis investigated participants of ELSA85 in different stages of the cohort study and with partly different samples. 


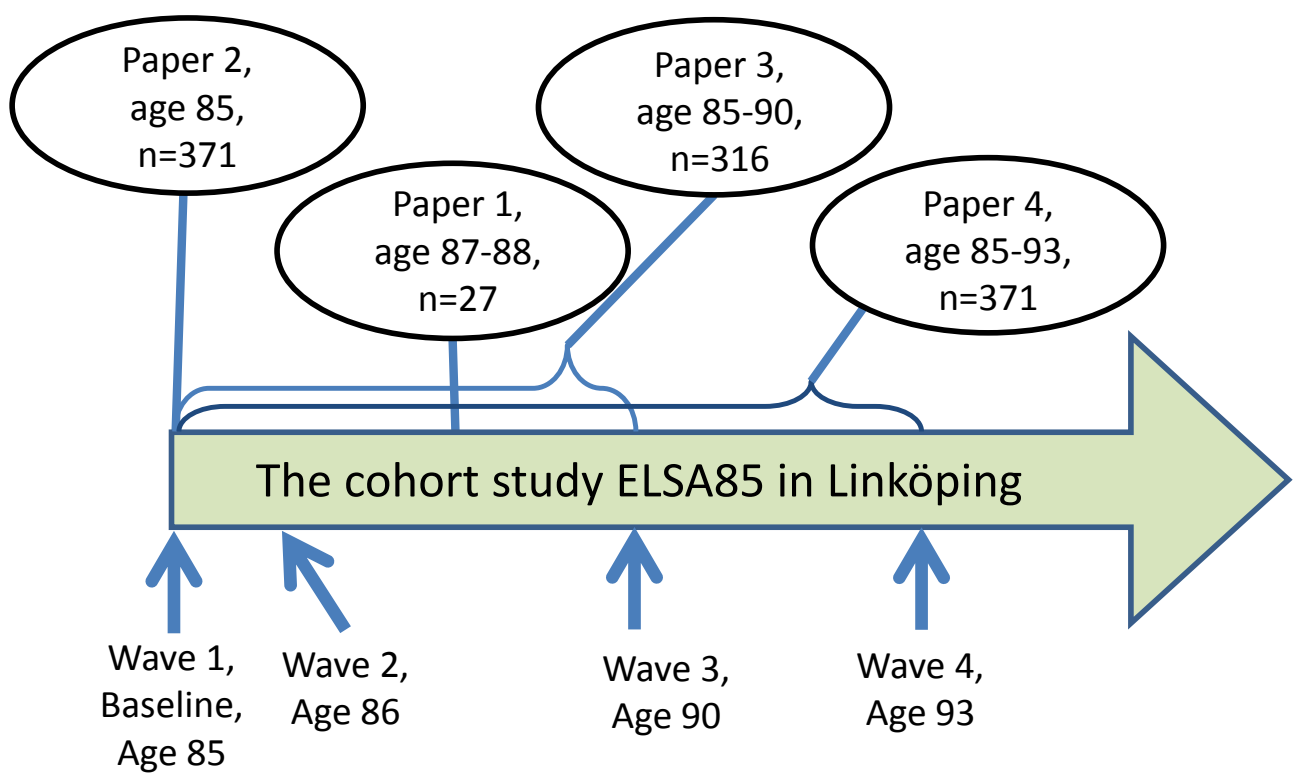

Figure 4. Schematic image of how the different papers of this thesis were connected to the cohort study ELSA85 in Linköping, Sweden, in the years of 2007-2016.

\subsection{Definition of SSD, syndromal depression, ND and normal aging for the thesis project}

As mentioned in the introduction it is common to define categories of depressiveness either by a self-assessment scale or by a structured interview or both. For this thesis SSD, ND and syndromal depression were defined by the results from the depression screening assessment scale GDS-15 [24], which is a common procedure in geriatric psychiatric studies. According to de Craen et al. 2003 it is important to consider which cutoff to choose according to the purpose of the study [147]. As a cutoff between SSD and syndromal depression, 5/6p was chosen, which is a common cutoff corresponding to a fair sensitivity and specificity [148].

However, there is no generally accepted cutoff between ND and SSD, and for paper 1 we chose $1 / 2 p$ as a cutoff, which meant that at least two (and less than six) answers indicating depressiveness were defined as SSD. For papers 2-4 the cutoff 2/3p was chosen instead between ND and SSD, as this latter limit was considered to give a better criterion validity, and had been used before [149]. A contributing factor to this decision was also the way the cutoff affected the prevalence numbers of SSD. The lower cutoff $(1 / 2 \mathrm{p})$ between ND and SSD resulted in a point prevalence for SSD of 50\%, whereas the higher cutoff resulted in the lower level of $27 \%$. This latter level seemed reasonable in order to increase comparability with other studies, of which few 
studies have shown a point prevalence of SSD above 30\%. Normal aging has been defined as the same as ND for the thesis, according to the GDS-15 cutoff numbers above.

\subsection{Measures}

\section{GDS-15}

There are many depression scales to measure depressiveness, and they are generally used in order to screen for depressive symptoms for diagnostic purposes, or to follow the degree of depressiveness over time. Such a self-assessment screening depression scale is the Geriatric Depression Scale (GDS) with 30 questions (GDS-30; [150, 151]), which was constructed with the purpose of creating an instrument that was particularly suited to measuring depressive symptoms in old people. For example the scale was constructed to be less dependent on multimorbidity and physical aging processes than other scales, and the individual items were given yes/no answers (instead of more complex answering alternatives, such as six-level scale answers) in order to facilitate its use by persons with cognitive decline due to aging. Eventually, a short version GDS with only 15 items, GDS-15 (appendix, annex 1) was created, as GDS-30 had been relatively time-consuming to use [24]. The GDS-15 contains 15 items with yes/no answers, in which one point is given for each question. The instrument has been shown to be valid for identifying depression, with a sensitivity of 0.89 (95\% Confidence interval (CI) $0.80-0.94$ ) and a specificity of 0.77 (CI 0.65-0.86) at a cutoff of 5/6p according to a recent meta-analysis [148], and the instrument has been found to work well even for very old persons, though the decision on cutoff should be made with regard to the sample and purpose in each separate study [147].

\section{EQ-5D}

EQ-5D is a generic instrument that assesses health-related quality of life in terms of an EQ visual analog scale (EQ-VAS) and a descriptive system of the five dimensions of usual activities, selfcare, mobility, pain/discomfort, and anxiety/depression [141, 152]. Each of the five dimensions of the descriptive system is self-evaluated using three levels: no problems, some problems, and severe problems, while the EQ-VAS is a self-assessment of overall health graded between the endpoints labeled 'best imaginable health state' (100) and 'worst imaginable health state'(0).

\section{Somatic multimorbidity}

Somatic multimorbidity or multiple coexistence of chronic diseases, was operationalized (papers 3 and 4) as the number of the number of chronic diseases from an author-constructed (with inspiration from the subject field [153]) predetermined list of 12 disease categories: arrhythmic heart disease, chronic heart failure or myocardial infarction, other vascular disease, hypertension or hyperlipidemia, diabetes mellitus, thyroid disease, respiratory disease, joint disease, central nervous system disease, gastrointestinal disease, urinary incontinence, and malignancy.

\section{Cognitive functions:}

Overall cognitive function was assessed with the MMSE (Mini Mental State Examination; paper 1-4), which is a scale that assesses overall cognitive functioning with a maximum result of 30 
points [143]. In papers $1-3$, results $<25 \mathrm{p}$ were regarded as indicating cognitive dysfunction, and in paper 4 the result was instead used as a continuous function in the calculations [154].

Executive functions were assessed with the Victoria version of the Stroop test, part 3, and the Parallel Serial Mental Operations test (PaSMO) [144, 146]. In paper 2, results $>70$ s on the Stroop test were regarded as indicating executive dysfunction. Paper 4 used a composite measure of the sum of the standardized values from part three of the Stroop test and the PaSMO.

Cognitive speed (paper 4) was assessed with a similar composite measure of the sum of the standardized values from the Trail Making Test part A (TMT-A; [145]) and part one of the Victoria version of the Stroop test [144].

\section{Loneliness}

Loneliness was measured with a single item author-constructed question (with inspiration from the subject field [155]) about feelings of loneliness on a four-level scale of frequency (often (4), sometimes, seldom or never (1)).

\section{Physical functions and ADL}

The postal questionnaire in ELSA85 contained a self-assessment instrument, the Instrumental Activity Measure (IAM; [142]) for measuring instrumental ADL (I-ADL; (paper 4)) through perceived difficulty in the performance of eight different activities on a four-level scale (too difficult (1), great difficulties, some difficulties, and no difficulties (4)): locomotion outdoors, preparing a simple meal, cooking, using public transportation, small-scale shopping, large-scale shopping, cleaning and washing. These eight values were converted into a single summary score (8-32p) of I-ADL. Basic ADL (paper 4) was assessed through questions about perceived need of assistance in four different activities (bathing/showering, dressing, toilet visits, and eating) on a three-level scale (need for no (3), little, or much assistance (1)). These four values were converted into a single summary score (4-12p) of Basic ADL. Other measures of physical functions and ADL used (paper 2-3) were the single dimensions of EQ-5D as described above.

\section{Healthcare service utilization}

Data on health care utilization were derived from the population-based administrative healthcare register care data warehouse in Östergötland (CDWÖ), containing data from both public care, and from the vast majority of private care services in the region [156]. The number of healthcare contacts were summed per individual, and sorted into inpatient or outpatient care, and subcategories of primary and secondary outpatient care. Private healthcare contacts were registered separately, as was specific psychiatric care. For an overview of the different components of service utilization, please see Table 6 .

\section{Direct costs of healthcare and of municipal care}

Data about the direct costs of the individual healthcare consumption over the period five years from baseline were obtained from the national database Cost Per Patient (CPP) via the county 
council of Östergötland, Sweden. Standard costs for different care components, e.g. a specific examination or a surgical treatment, are used to calculate CPP. The standard costs for specific care components are attributed to a specific healthcare contact (derived from the CDWÖ) and summarized to CPP. Direct costs of municipal care were derived from the local database Cost Per User (CPU). The principles for calculating CPU are the same as for the database CPP above, though the municipal costs instead of healthcare correspond to costs for living at nursing homes, domestic care services, transportation services, as well as ordered meals. Indirect costs, i.e. production losses or the economic value of family care, can be of great relevance for the overall societal costs of illness, but they were not included in the analyses.

\subsection{Design, sampling and analytical procedures for the different papers}

\subsubsection{Methods for paper 1}

About two years after the baseline of ELSA85, a smaller sample of participants were contacted for an interview study. Purposeful sampling was used in the pursuit of maximum variation regarding degree of depressiveness and of sex, in order to get information-rich manifestations of the study object [157]. Inclusion criteria were participants of ELSA85 who had expressed their support for continued participation after the one-year follow-up, while exclusion criteria were a) conversation difficulties due to difficulties with the Swedish language, or due to speech impairment or hearing impairment; b) cognitive impairment at a level that complicated the interview; and c) cognitive impairment of $<25 \mathrm{p}$ in the MMSE at the earlier one-year follow-up.

Invitation letters with consent forms were sent to a few persons at a time, to 40 persons altogether, of which 28 persons agreed to participate in an interview. One person was excluded after the interview because of cognitive impairment at a level that invalidated the answers. The sample size was determined according to estimates based on the study purpose, and on the gradually accumulated interview data. Semi-structured qualitative interviews were undertaken using a prepared interview guide with four topics (life in general, psychological well-being, coping, aging). These included associated open-ended questions, such as "What is life like at 88 years old?"; "What are the positive and negative sides?"; "How do you look upon the past/ the future?". The topics and associated questions served as a reminder of topics to be covered, and did not determine the structure of the interview. Supplementary and probing questions were also asked. The GDS-15 was filled in after the interview, and the result was later used to sort the participants into categories of depressiveness. The interviews were audio-recorded and transcribed verbatim. Field notes and reflexive notes were written continuously in order to minimize the risk of reproducing preconceptions, and to maximize the trustworthiness of the study [157].

The analysis of the interviews was conducted in accordance with latent content analysis, as described in Graneheim and Lundman 2004 [158], and the process was divided into six different 
steps: 1) repeated preliminary reading of unique interviews to get a sense of the whole; 2 ) dividing the text into units of meaning; 3 ) giving codes to condensed meaning units; 4) within each category of depressiveness (ND, SSD and syndromal depression), abstraction within and between interviews by aggregating codes into tentative subthemes/themes (latent interpretive content) at a higher logical level; 5) within each category of depressiveness, discussion of tentative codes and subthemes/themes, and reflection on them, after which they were revised into more definitive ones, and 6) between the categories of depressiveness, comparing patterns of analysis categories and themes of SSD informants with the findings from the other two categories of depressiveness (ND, syndromal depression).

In order to enable comparisons between the categories of depressiveness but also avoid reproduction of preconceptions, steps 1-3 were undertaken with the researchers blinded to which category the informant belonged to, while steps 4-5 were undertaken within each category, before the final comparison between categories in step 6 . This procedure for enabling qualitative comparisons between the categories was designed with inspiration from gender theory [159, 160]. The analysis contained both a search for convergent dominant patterns in the text, and a mirror analytical strategy to examine divergence (consideration of data which did not fit into the dominant patterns), as an expression of the pursuit of reflexivity [157]. The qualitative content analysis is a method which can be adapted according to the researcher's theoretical standpoints, and in our study the method was used from a hermeneutic point of view [161]. The software program Nvivo Revision 1.3. was used as a tool for the analysis.

\subsubsection{Methods for paper 2}

In paper 2, a cross-sectional quantitative analysis was conducted on data from the baseline of ELSA85. The GDS-15 was answered by 371 subjects, which represented the sample of the study (Figure 5). 


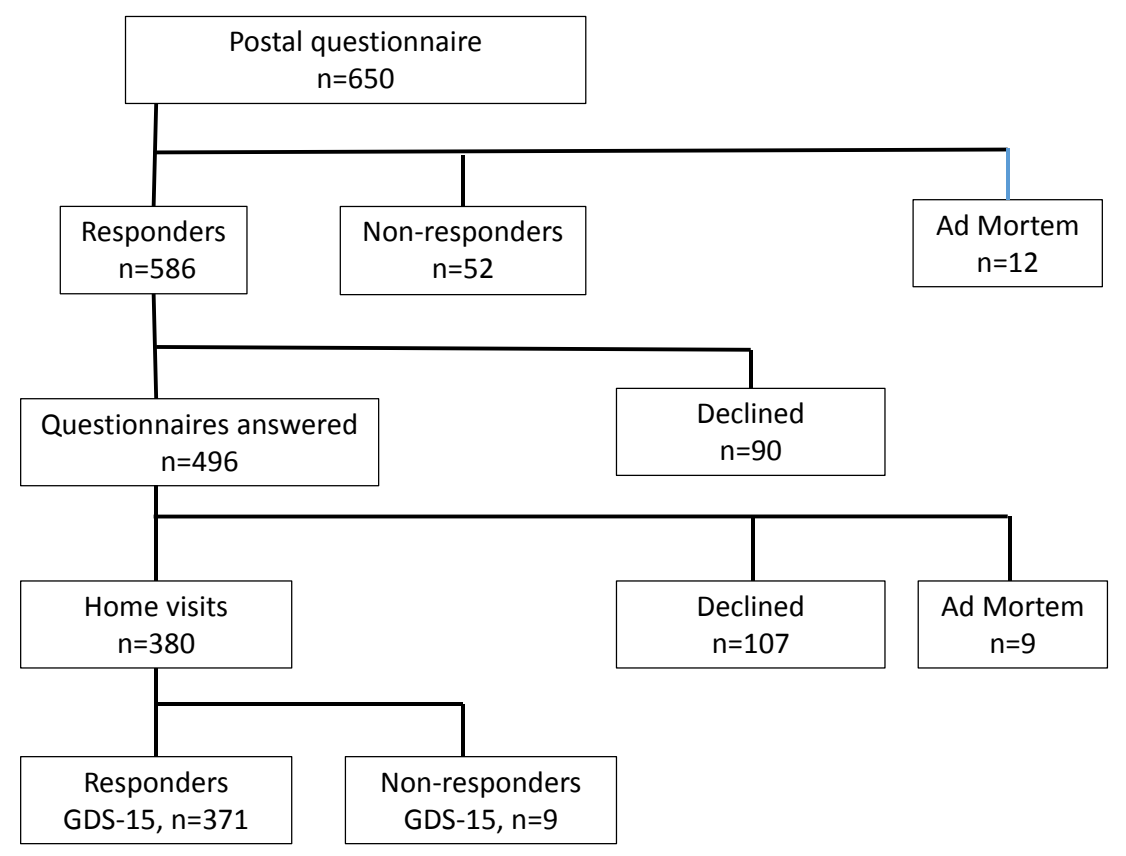

Figure 5. Derivation of the analytical sample from the ELSA85 study

The hypotheses (according to previous literature and to paper 1) was that SSD would be associated with four different domains (sociodemographic factors, declining physical functioning, neuropsychiatric factors, and existential factors), which were operationalized in 23 different variables (Table 2). Multicollinearity was controlled for by correlation analyses, including calculations of the Variance Inflation Factor. For the subsequent logistic regressions all independent variables were dichotomized. Non-responders to GDS-15 (125/496) were analyzed in comparison to responders $(371 / 496)$ with $\chi^{2}$-tests (Table 3), while item non-response were excluded listwise for the analyses.

According to the baseline characteristics (Table 2) the responders of GDS-15 in general had a high level of morbidity and impairment of bodily functions and of ADL, as a natural consequence of aging and diseases. There was also a general pattern of covariation between degree of depressiveness and lower functioning. 
Table 2. Baseline characteristics for responders ( $n=371)$ of GDS-15, sorted into categories of depressiveness (ND, SSD and syndromal depression).

\begin{tabular}{|c|c|c|c|c|}
\hline & & $\begin{array}{c}\text { ND } \\
(\mathrm{n}=249) \text { No. of } \\
\text { subj (valid } \\
\text { percent) }\end{array}$ & $\begin{array}{c}\text { SSD } \\
\text { (n=99) No. of } \\
\text { subj (valid } \\
\text { percent) }\end{array}$ & $\begin{array}{c}\begin{array}{c}\text { Syndr } \\
\text { Depr }\end{array} \\
(\mathrm{n}=23) \\
\text { No. of } \\
\text { subj (valid } \\
\text { percent) }\end{array}$ \\
\hline \multirow{5}{*}{$\begin{array}{l}\text { Sociodemo } \\
\text {-graphic } \\
\text { factors }\end{array}$} & Female sex & $136(54.6)$ & $66(66.7)$ & $16(69.6)$ \\
\hline & $\begin{array}{l}\text { Adapted housing: i.e. } \\
\text { sheltered housing, nursing } \\
\text { home or dementia care }\end{array}$ & $9(3.6)$ & $17(17.2)$ & $5(21.7)$ \\
\hline & Living alone & $138(55.4)$ & $59(59.6)$ & $18(78.3)$ \\
\hline & Low education & $168(67.7)$ & $70(70.7)$ & $16(69.6)$ \\
\hline & No contact with neighbors & $20(8.1)$ & $16(16.7)$ & $6(26.1)$ \\
\hline \multirow{7}{*}{$\begin{array}{l}\text { Declining } \\
\text { physical } \\
\text { function- } \\
\text { ing }\end{array}$} & $\begin{array}{l}\text { Use of mobility } \\
\text { assistive devices }\end{array}$ & 92 (36.9) & $72(72.7)$ & $19(82.6)$ \\
\hline & Visual impairment & $190(76.3)$ & $82(82.3)$ & $21(91.3)$ \\
\hline & $\begin{array}{l}\text { Usual activities (EQ-5D), } \\
\text { some or severe problems }\end{array}$ & $27(10.8)$ & $45(45.5)$ & $15(65.2)$ \\
\hline & $\begin{array}{l}\text { Self-Care (EQ-5D), } \\
\text { some or severe problems }\end{array}$ & $12(4.8)$ & $26(26.3)$ & $6(26.1)$ \\
\hline & $\begin{array}{l}\text { Mobility (EQ-5D), } \\
\text { some or severe problems }\end{array}$ & $84(34.1)$ & $68(68.7)$ & $18(78.3)$ \\
\hline & $\begin{array}{l}\text { Pain/ Discomfort (EQ-5D), } \\
\text { moderate or extreme }\end{array}$ & $140(56.9)$ & $68(69.4)$ & $20(87.0)$ \\
\hline & $\begin{array}{l}\text { History of Heart Failure } \\
\text { or Myocardial infarction }\end{array}$ & $60(24.1)$ & $32(32.3)$ & $4(17.4)$ \\
\hline \multirow[t]{6}{*}{$\begin{array}{l}\text { Neuro- } \\
\text { psychiatric } \\
\text { factors }\end{array}$} & $\begin{array}{l}\text { History of Affective } \\
\text { psychiatric disorder }\end{array}$ & $18(7.2)$ & $20(20.2)$ & $8(34.8)$ \\
\hline & History of Anxiety disorder & $7(2.8)$ & $11(11.1)$ & $4(17.4)$ \\
\hline & $\begin{array}{l}\text { Actual Anxiety/Depression } \\
\text { (EQ-5D), moderate or } \\
\text { extreme }\end{array}$ & $57(23.0)$ & $50(50.5)$ & $21(91.3)$ \\
\hline & $\begin{array}{l}\text { Use of Tranquilizing } \\
\text { medication }\end{array}$ & $8(3.3)$ & $15(15.5)$ & $5(21.7)$ \\
\hline & History of Stroke & $20(8.0)$ & $22(22.2)$ & $6(26.1)$ \\
\hline & $\begin{array}{l}\text { Cognitive dysfunction } \\
\text { (MMSE < 25p) }\end{array}$ & $27(10.9)$ & $25(25.8)$ & $7(31.8)$ \\
\hline
\end{tabular}




\begin{tabular}{|l|l|c|c|c|} 
& $\begin{array}{l}\text { Executive dysfunction } \\
\text { (Victoria Stroop test >70 s) }\end{array}$ & $58(23.3)$ & $42(42.4)$ & $12(52.2)$ \\
\hline $\begin{array}{l}\text { Existential } \\
\text { factors }\end{array}$ & $\begin{array}{l}\text { Self-perceived loneliness, } \\
\text { sometimes or often }\end{array}$ & $74(29.4)$ & $52(52.5)$ & $20(87.0)$ \\
& $\begin{array}{l}\text { Worries about the future, } \\
\text { sometimes or often }\end{array}$ & $3(1.2)$ & $11(11.1)$ & $8(34.8)$ \\
& $\begin{array}{l}\text { Lower self-perceived health } \\
\text { (EQ-VAS <70) }\end{array}$ & $63(26.7)$ & $72(75.0)$ & $21(91.3)$ \\
& Life not meaningful & $17(7.3)$ & $25(27.8)$ & $13(65.0)$ \\
\hline
\end{tabular}

Associations between presence of SSD (instead of ND or syndromal depression) and the four domains of our hypotheses were investigated first with univariate binary logistic regression including estimation of odds ratio (OR) and $95 \%$ CI. For this, all the independent variables were dichotomized according to Table 2. After these first regressions, a prediction model for identifying SSD was calculated through multivariate binary regression, and the same set of independent variables was used.

Because there has been a discussion previously on whether psychiatric conditions relate to normality and other psychiatric disorders categorically or dimensionally, we chose to redo the multiple regressions with the ordinal logistic and linear regression procedure (corresponding to the dimensional perspective) in addition to the previous binary logistic regressions (categorical perspective). For all regressions we used stepwise automatic selection which was supplemented with a manual stepwise procedure, in order to predict SSD in relation to ND or syndromal depression. We used SPSS software version 21 for the statistical analyses, and differences were deemed significant at $\mathrm{p}$-values $<0.05$.

\subsubsection{Methods for paper 3}

Data from baseline and the one-year follow-up of ELSA85 were used for paper 3. With the insight that depressive conditions vary much in intensity over time, we chose to sort the depressive conditions into categories on the basis of two different measures. The following categories were used: ND at both measure waves (ND Both), SSD at either wave (SSD Ever) and syndromal depression at either wave (Depr Ever). In order to more easily distinguish the effects of each category we decided to exclude from the SSD category those few individuals who had SSD at one measure wave and syndromal depression at another, and altogether it resulted in a sample of $n=316$ for the analyses (Figure 6). Data about direct costs for healthcare were obtained from the CPP database [162]) for each individual and for a five-year period after baseline. Data about healthcare service utilization (e.g. number of primary care visits) were obtained from the CDWÖ database [156], and the direct costs of municipal care were obtained from the CPU database. As the CPU registry was started rather recently, the quality of data was not judged sufficient until the year 2011, and therefore data of the direct costs of municipal care were 
collected only for a one-year period between 2011 and 2012, when only $n=270$ of the original $\mathrm{n}=371$ were still alive.

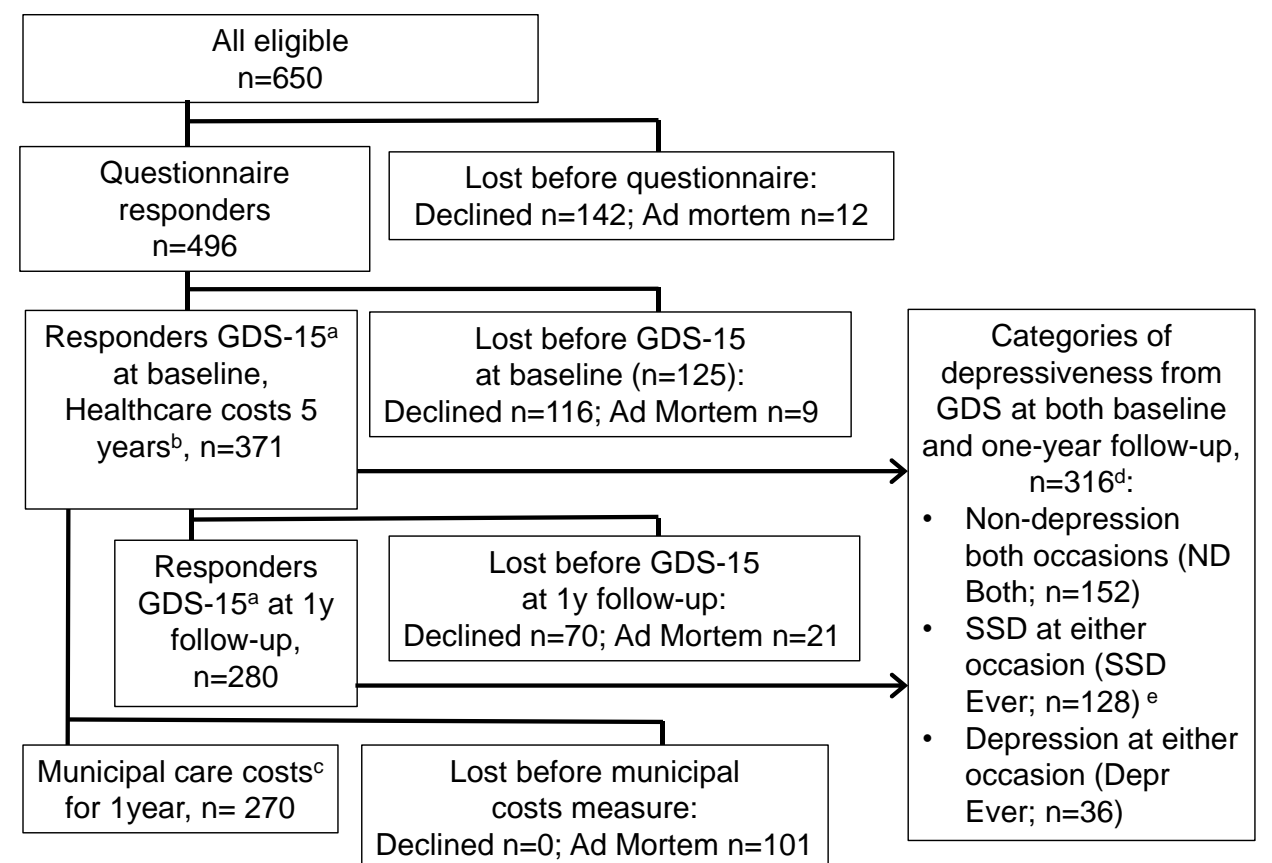

Figure 6. Derivation of the analytical samples from the ELSA85 study. Notes: ${ }^{a}=G D S-15$ assessment through interview at a home visit. ${ }^{b}=$ The five prospective years per individual from baseline 2007-2008 according to birth date. ${ }^{c}=$ Municipal data collected between four and five years after baseline, during 2011-2012. ${ }^{d}=$ The difference between the analytical sample $n=316$ and the responders at baseline $n=371$ consisted of individuals $(n=55)$ with ND at baseline and who declined before one-year follow-up. ${ }^{e}=$ Sixteen individuals corresponded to both the categories SSD ever and Depr Ever, but for the calculations for the study these persons were excluded from the category of SSD Ever, in order to better distinguish the effects per category.

Because many participants died during the study period, the analyses were based on costs per month of survival. The costs were transformed into price levels of September 2016 according to the Consumer Price Index, and to Euros $(€)$ in order to facilitate comparisons with previous studies. According to the recommendations of the Swedish Council on Health Technology Assessment (SBU) we used a discount rate of three percent [163]. In addition, sensibility analyses were undertaken for alternative discount rates of zero percent and five percent for the primary outcome variable of total healthcare costs. Missing data were analyzed in the same way 
for paper 2 as in paper 1, although some variables were analyzed with two-sided t-tests instead of $\chi^{2}$-tests. As the cost and service utilization data had a positively skewed non-normal distribution (as is common in healthcare expenditures ) comparisons were done with Mann-Whitney U-tests, and $\log$ transformation of cost values was done before performing linear regressions [164]. Unstandardized B-coefficients were calculated, as were 95\% CI and p-values, and correction for multiple comparisons was made using the method False discovery rate (FDR; [165]). A multiple regression including sex, educational level and all independent variables according to the hypotheses was performed in order to identify a model for prediction of total healthcare costs. Automatic stepwise selection was used to identify an adequate final multivariate regression model.

\subsubsection{Methods for paper 4}

Data from all four measure waves (baseline and follow-up at years 1, 5 and 8) of ELSA85 were used for paper 4. As in many longitudinal studies of very old persons, there was a substantial proportion of loss to follow-up in each step [166], which is why the number of persons filling in GDS-15 decreased stepwise from $n=371$ at baseline to $n=55$ (15\% of 371$)$ at the eight-year follow-up (Figure 7).

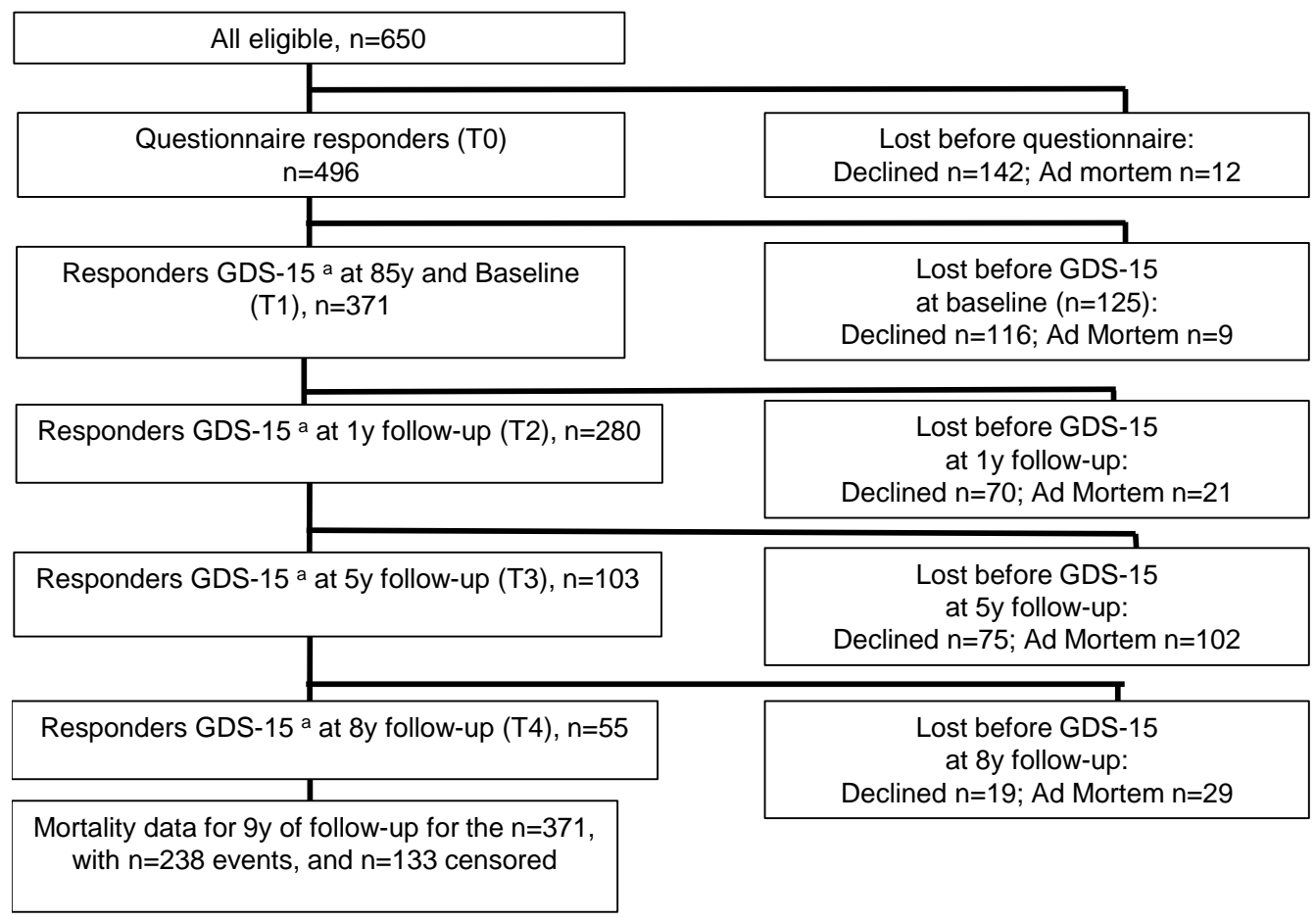

Figure 7. Derivation of the analytical samples for paper 4. 
In addition to the data from ELSA85, information about mortality status and date of death for deceased participants was obtained from the national tax agency from baseline and up to nine years later, when only $n=133(36 \%)$ of the original $n=371$ responders to GDS-15 were still alive. In order to extract maximum information from the data in spite of the substantial and non-random loss to follow-up, Linear mixed models (instead of analysis of variance with repeated measures) was chosen for the statistical analyses of morbidity. We used a diagonal covariance structure (based on the assumption of autocorrelation) with calculation of parameter estimates, $95 \% \mathrm{CI}$ and p-values $(\alpha=0.05)$ [167]. As an independent variable SSD versus ND was used, with category values from all measure waves, and with correction for sex, somatic multimorbidity, time from baseline, and ADL functioning.

Mortality was analyzed with univariate and multivariate Cox regressions and calculation of hazard ratio (HR), 95\% CI and p-values. The independent variable for the Cox regressions was the presence of SSD versus ND according to GDS values at baseline, while the sum of survival days was the dependent variable.

Loss to follow-up was analyzed with two-sided t-tests and $\chi^{2}$-tests with comparison of those lost between each measure wave, compared to the rest of responders at the previous wave (Table 3).

Item non-response was substantial for two of the variables of cognitive functions $(17 \%(64 / 371)$ in cognitive speed, and $36 \%$ (132/371) in executive function), which were handled by multiple imputations before the Cox regressions. All independent variables corresponding to our hypotheses and sex and educational level were selected for the multivariate Cox regression, with entry mode for variable selection. 
Table 3. Analyses with two-sided t-tests or $\chi^{2}$-tests of participants lost to follow-up compared with the rest of the participants of the previous measure wave.

\begin{tabular}{|c|c|c|c|c|c|c|c|c|c|}
\hline \multirow[b]{2}{*}{$\begin{array}{l}\text { Outcome } \\
\text { variables }\end{array}$} & & \multicolumn{2}{|c|}{$\begin{array}{l}\text { Loss to follow-up } \\
\text { between T0-T1 } \\
(n=125) \text { vs the rest } \\
\text { of participants at } \\
\text { T0 }(n=371)\end{array}$} & \multicolumn{2}{|c|}{$\begin{array}{l}\text { Loss to follow-up } \\
\text { between T1-T2 } \\
\text { (n=91) vs the rest of } \\
\text { participants at T1 } \\
(\mathrm{n}=280)\end{array}$} & \multicolumn{2}{|c|}{$\begin{array}{l}\text { Loss to follow-up } \\
\text { between T2-T3 } \\
(\mathrm{n}=177) \text { vs the rest of } \\
\text { participants at } \mathrm{T} 2 \\
(\mathrm{n}=103)\end{array}$} & \multicolumn{2}{|c|}{$\begin{array}{l}\text { Loss to follow-up } \\
\text { between T3-T4 } \\
(n=48) \text { at T3-T4 vs } \\
\text { the rest of } \\
\text { participants at T3 } \\
(n=55)\end{array}$} \\
\hline & & $\begin{array}{c}\text { Mean } \\
\text { difference } \\
\text { (CI) or } \chi^{2}- \\
\text { value }\end{array}$ & $\begin{array}{c}\text { p- } \\
\text { value }\end{array}$ & $\begin{array}{c}\text { Mean } \\
\text { difference } \\
\text { (CI) or } \chi^{2}- \\
\text { value }\end{array}$ & $\begin{array}{c}\text { p- } \\
\text { value }\end{array}$ & $\begin{array}{c}\text { Mean } \\
\text { difference } \\
\text { (CI) or } \chi^{2}- \\
\text { value }\end{array}$ & $\begin{array}{c}\text { p- } \\
\text { value }\end{array}$ & $\begin{array}{c}\text { Mean } \\
\text { difference } \\
\text { (CI) or } \chi^{2}- \\
\text { value }\end{array}$ & $\begin{array}{c}\text { p- } \\
\text { value }\end{array}$ \\
\hline Male sex & & $6.1^{\mathrm{a}}$ & 0.013 & 0.75 & 0.387 & 1.1 & 0.290 & 1.7 & 0.192 \\
\hline $\begin{array}{l}\text { Education- } \\
\text { al level, n } \\
\text { years }\end{array}$ & & $\begin{array}{c}-0.89 \\
(-1.5- \\
(-0.30))\end{array}$ & 0.003 & $\begin{array}{c}-0.18 \\
(-1.0-0.65)\end{array}$ & 0.421 & $\begin{array}{c}-0.82 \\
(-1.8-0.11)\end{array}$ & 0.084 & $\begin{array}{c}-1.2 \\
(-2.7-0.40)\end{array}$ & 0.142 \\
\hline $\begin{array}{c}\text { Adapted } \\
\text { housing at } \\
\text { previous } \\
\text { wave }\end{array}$ & & $11^{\mathrm{b}}$ & 0.001 & $7.8^{\mathrm{b}}$ & 0.005 & $4.0^{\mathrm{b}}$ & 0.046 & $5.3^{\mathrm{b}}$ & 0.021 \\
\hline $\begin{array}{c}\text { Somatic } \\
\text { multi- } \\
\text { morbidity }\end{array}$ & $\begin{array}{c}\mathrm{n} \text { number of } \\
\text { diseases }\end{array}$ & $--^{c}$ & --- & $\begin{array}{c}-0.44 \\
(-0.80- \\
(-0.084)\end{array}$ & 0.016 & $\begin{array}{c}0.37 \\
(-0.015- \\
0.75)\end{array}$ & 0.059 & $\begin{array}{c}0.018 \\
(-0.60-0.63)\end{array}$ & 0.953 \\
\hline $\begin{array}{c}\text { Functional } \\
\text { abilities }\end{array}$ & Basic ADL & $--^{c}$ & --- & $\begin{array}{c}-0.44 \\
(-0.77- \\
(-0.11))\end{array}$ & 0.009 & $\begin{array}{c}-0.36 \\
(-0.61- \\
(-0.11))\end{array}$ & 0.005 & $\begin{array}{c}-0.94 \\
(-1.5- \\
(-0.36))\end{array}$ & 0.002 \\
\hline & I-ADL & $--^{c}$ & --- & $\begin{array}{c}-2.3 \\
(-4.0-(-0.51)\end{array}$ & 0.012 & $\begin{array}{c}-4.0 \\
(-5.6-(-2.5))\end{array}$ & $<0.001$ & $\begin{array}{c}-6.1 \\
(-8.8-(-3.4)\end{array}$ & $<0.001$ \\
\hline $\begin{array}{l}\text { Self-rated } \\
\text { health } \\
\text { status }\end{array}$ & EQ-VAS & $\begin{array}{c}-5.4 \\
(-11-0.066)\end{array}$ & 0.053 & $\begin{array}{c}-4.4 \\
(-9.5-0.78)\end{array}$ & 0.095 & $\begin{array}{c}-2.9 \\
(-7.0-1.1)\end{array}$ & 0.148 & $\begin{array}{c}-7.5 \\
(-15-0.046)\end{array}$ & 0.051 \\
\hline \multirow[t]{3}{*}{$\begin{array}{l}\text { Cognitive } \\
\text { functions }\end{array}$} & MMSE & $--^{c}$ & --- & $\begin{array}{c}-0.85 \\
(-1.9-0.23)\end{array}$ & 0.123 & $\begin{array}{c}-2.0 \\
(-2.7-(-1.2))\end{array}$ & $<0.001$ & $\begin{array}{c}-1.9 \\
(-3.1- \\
(-0.69))\end{array}$ & 0.003 \\
\hline & $\begin{array}{l}\text { Cognitive } \\
\text { Speed }\end{array}$ & $--^{c}$ & --- & $\begin{array}{c}-0.14 \\
(-0.52-0.24)\end{array}$ & 0.464 & $\begin{array}{c}-0.94 \\
(-1.3- \\
(-0.59))\end{array}$ & $<0.001$ & $\begin{array}{c}-0.52 \\
(-1.2-0.18)\end{array}$ & 0.145 \\
\hline & $\begin{array}{l}\text { Executive } \\
\text { function }\end{array}$ & $--^{c}$ & --- & $\begin{array}{c}-0.45 \\
(-0.99-0.10)\end{array}$ & 0.108 & $\begin{array}{c}-0.77 \\
(-1.2- \\
(-0.38))\end{array}$ & $<0.001$ & $\begin{array}{c}-0.74 \\
(-1.7-0.28)\end{array}$ & 0.149 \\
\hline $\begin{array}{c}\text { Social } \\
\text { functions }\end{array}$ & $\begin{array}{c}\text { Frequency } \\
\text { of } \\
\text { loneliness }\end{array}$ & $\begin{array}{c}0.14 \\
(-0.077- \\
0.35)\end{array}$ & 0.209 & $\begin{array}{c}0.21 \\
(-0.014-0.43)\end{array}$ & 0.066 & $\begin{array}{c}0.17 \\
(-0.061- \\
0.41)\end{array}$ & 0.146 & $\begin{array}{c}0.11 \\
(-0.29-0.51)\end{array}$ & 0.586 \\
\hline \multirow[t]{2}{*}{$\begin{array}{c}\text { Mental } \\
\text { health } \\
\text { function }\end{array}$} & $\begin{array}{c}\text { Depressive- } \\
\text { ness, GDS- } \\
15 \text { score }\end{array}$ & $--^{c}$ & --- & $\begin{array}{c}0.59 \\
(0.027-1.1)\end{array}$ & 0.040 & $\begin{array}{c}0.62 \\
(0.15-1.1)\end{array}$ & 0.010 & $\begin{array}{c}0.86 \\
(-0.067-1.8)\end{array}$ & 0.069 \\
\hline & SSD vs ND & $--^{c}$ & --- & 0.19 & 0.665 & $10^{\mathrm{d}}$ & 0.001 & 1.7 & 0.197 \\
\hline
\end{tabular}


Notes: ${ }^{a}=$ More women and fewer men among those lost to follow-up, a recurrent tendency in all the measure waves, though the association was significant only between T0-T1. ${ }^{b}=$ More persons with adapted housing and fewer with independent housing among those lost to follow-up. ${ }^{c}=N o$ comparison possible, as the first measure wave of this variable was at T1. ${ }^{d}=$ More with SSD and fewer with ND among those lost to follow-up.

\subsection{Ethical considerations}

All studies complied with the Declaration of Helsinki [168]. The studies were approved by the Regional Ethical Review Board at Linköping University (paper 1 [M 226-09], papers 2 and 3 [141-06], paper 4 [141-06, 2012/332-31 and 2014/455-31]). Written informed consent was obtained from each participant or legal surrogate, including information about the right to cancel participation at any time.

Written informed consent can be a problem in both geriatric and psychiatric research as many patients in those research areas have reduced capacities for autonomy and making decisions. For this reason, relatives were involved in the consent process in some cases $[169,170]$. All data were unidentified and presented on a group level except for a few citations in paper 1, and specific individuals could therefore not be identified. The risk for harm was considered low in general in all the studies, while there was a benefit for many persons in getting a free medical examination with referral to another healthcare provider as needed. In addition, scientific development in the research field was considered valuable from a societal perspective, as better understanding of SSD among very old persons could promote precision in diagnostics and treatment in the future. Also the studies were considered valuable from a justice perspective, as previous research on affective diseases in the specific age group is scarce. 


\section{Results}

\subsection{Results from paper 1. Normal aging, SSD or depression: a qualitative analysis}

The aim of paper 1 was to make a qualitative comparison of experiences of being in very old people with SSD, in relation to the experiences of very old people with syndromal depression or ND. Qualitative analysis of the interviews (ND $n=6$; SSD $n=13$; syndromal depression $n=8$ ) generated four themes in persons with SSD, which together describe different aspects of their being in very old age: declining life curve and physical health; managing on their own; keeping up with life; taking one day at a time (Table 4). Taken together, the four themes can be formulated as although my physical health is declining, I still want to live a little longer - as long as I'm relatively well and can manage on my own.

Table 4. Subthemes and themes from the qualitative content analysis of interviews with very old persons with SSD, ND and syndromal depression $(n=27)$.

\begin{tabular}{|c|c|}
\hline Subthemes & Themes \\
\hline Loss of significant others & \multirow{3}{*}{$\begin{array}{l}\text { Life curve and the body go } \\
\text { down }\end{array}$} \\
\hline Declining bodily functions & \\
\hline End of life, old age & \\
\hline Maintaining everyday life & \multirow{4}{*}{ To keep up with life } \\
\hline Meaningfulness from joys and values of life & \\
\hline Meaningfulness from participation & \\
\hline $\begin{array}{l}\text { Loneliness, sense of exclusion, abandoned } \\
\text { Alien frightening world }\end{array}$ & \\
\hline Avoid dwelling, living in the present & \multirow{2}{*}{ Taking one day at a time } \\
\hline $\begin{array}{l}\text { Rolling up the sleeves } \\
\text { Shifting perspectives }\end{array}$ & \\
\hline Self-determination & \multirow[t]{2}{*}{ To manage on one's own } \\
\hline Managing on one's own, independence & \\
\hline
\end{tabular}

One theme was the experience that bodily functions (e.g. hearing, vision, physical stamina and movement) and other things decline in old age. The decline was accompanied by increasing stiffness and pain in the body, with a consequent reduction of activities and increase of social isolation, all of which was reinforced by the fact that contacts with peers, acquaintances and relatives were lost through death or dementia. Thoughts of aging and death were described as less 
stressful, while loss of self-determination involved in end of life processes and further bodily decline were more emotionally charged.

I: ... Now that you're old, in what ways have you been affected?

$R$ : Well, this is something that comes with life in a way, so it's probably something you come to terms with gradually, I think. What can you do about it anyway? Jump? No one wants that.

I: You come to terms with it ...?

(Interview 8)

R: Yes, of course. Because there's nothing else to do. You can't slow down the aging process.

A second theme was the desire to keep up with life. "Keeping up with everything" was a common expression in the interviews, and meant remaining active and involved in life and society, and being a part of a greater whole, despite their physical decline. Instead of strenuous activities the informants said that they engaged more in sedentary activities such as solving crosswords, Sudoku, reading, conversations with friends and family at home or on the phone, listening to audio books and music, watching TV, growing pot plants or sitting on a park bench.

A third theme was taking one day at a time: the unavoidable decline in physical functions, activities and social interaction, together with other adversities occasionally made these very old persons with SSD sad. In spite of these moments of sadness, they considered themselves to have a good life, all in all, and they tried not to dwell on their adversity or bury themselves in it. Instead, they took things as they came, one day at a time, or alternatively, a year at a time.

R: Well, I take one day at a time ... I don't look forward or have ideas far into the future, but you just take one day at a time, and if you survive that, it's ... (Interview 23).

Taking things as they come was a complex expression with different meanings, related to cognitive coping strategies. It meant living in the present and not mourning in advance, allowing the future to remain uncertain. It also meant maintaining their everyday life, running the household or doing just as they liked for the time being.

In the face of adversity, they renewed their efforts, rolled up their sleeves and forced themselves to do a little more, or just take one day at a time. Through a shift away from negative experiences in their present personal situation to a more general or interpersonal perspective, they also managed to reduce the effects of adversity and pain. The very old informants considered that life had been quite good after all, when comparing themselves to their friends, to times past or to what they had expected.

The fourth and final theme was about the experience of managing on one's own. The informants with SSD mostly considered themselves to be doing fine, because they could still manage on their own and live independently, even though the life curve and the body were going down. 
Managing on their own could mean running the household, getting dressed, making the bed independently, or it could alternatively be an expression of self-determination, with a more basic desire to control their time and activities The experience of managing on one's own seemed crucial to their overall well-being, and this experience seemed, paradoxically, relatively independent of the individual's level of function or care needs. Even when their physical functions were restricted, and their need for social services was greater, the informants emphasized that they were doing fine because they were still managing relatively well on their own.

R: The only important thing is to avoid lying in bed, or giving in to difficulties. I: $\mathrm{Hmm}, \mathrm{hmm}$.

R: You wouldn't want that, because you just wouldn't want that. I mean, I've lived such a long time. I'd rather end my life than be bedridden ... and I think most people think that way. They would rather end their lives than be bedridden, or be a nuisance to others and ... (Interview 6)

The informants with SSD also expressed a fear of losing this ability to manage on their own, becoming dependent or losing their self-determination. For example, those who were able to walk were afraid of having to sit down all the time, and those who had to sit down all the time were afraid of becoming bedridden in the future.

There were similarities between informants with SSD and syndromal depression. For example all the above themes were represented in the interviews from both categories, and they gave similar descriptions regarding the decline in their life curve and bodily functions. Their descriptions mentioned pain, balance and hearing impairment, fear of falling, decreasing mobility and the effects of loneliness. However, there were differences between the interviews of those with SSD and those with syndromal depression. Among persons with syndromal depression compared to SSD, the experience of bodily decline and associated consequences were more prominent in the interviews, with descriptions of suffering due to a heavily restricted lifestyle, either physically, socially or both. The theme of managing on their own was less prominent in the interviews with people suffering from depression, and instead they recurrently expressed a need for more support than they already had. Also, the theme of taking one day at a time was more prominent in the interviews of persons with SSD, while people suffering from depression spoke more about negative memories as well as worries for the future.

Between the categories of SSD and ND the similarities were even greater (than between SSD and syndromal depression), and persons from both categories described the importance of managing on one's own and of self-determination for well-being. They described the need to adjust the activity level to new preconditions of bodily decline and of losses of old age, and the coping strategies presented for meeting challenges were similar between the categories. Differences between the stories of persons with SSD and ND were small; the most obvious being that persons 
with SSD compared to ND described the intensity and the extent of suffering more clearly. For example, persons with SSD spoke of severe pain as a constant companion, and of pronounced hearing impairment which reduced the whole world to something rather small, while people with ND experienced the decline of old age to a lesser degree, reflected in expressions like "it's fine, as long as you're reasonably healthy".

In summary, rich descriptions of experiences of being in SSD in very old age were obtained, and similarities were extensive between all three categories of depressiveness, while the differences were a little greater between SSD and syndromal depression compared to SSD and ND.

\subsection{Results from paper 2: Markers of subsyndromal depression}

The aims of this second study were to investigate factors associated with SSD in very old persons, and to develop a model for prediction of SSD among very old persons.

The hypotheses and the corresponding domains were operationalized in 23 different variables (Table 2 in the methods section), and 20 of these proved to be significantly related to the comparison between SSD and ND according to the univariate binary logistic regressions. On the other hand, only four of the variables were significantly associated with the comparison between SSD and depression. The 20 variables that were associated with SSD versus ND corresponded to all of the four domains; thus, all null hypotheses were rejected.

In the following multivariate binary logistic regressions, seven independent variables from all the four domains were significantly associated with SSD versus ND, while only two variables were associated with SSD versus depression (Table 5). The seven independent variables associated with SSD versus ND were the following, presented in descending order of OR: lower selfperceived health (EQ-VAS), life not meaningful, problems with self-care, no contact with neighbors, use of tranquilizing medication, personal history of affective disorder, and history of stroke. The two variables that were associated with SSD versus depression were non-meaningful life and higher current anxiety/depression according to the EQ-5D. 
Table 5. Multivariate binary logistic regressions for the associations between SSD versus ND, and SSD versus depression, and corresponding multivariate ordinal logistic and linear regressions from paper $2(\mathrm{n}=371)$

\begin{tabular}{|c|c|c|c|c|c|c|c|c|c|}
\hline \multirow[b]{2}{*}{ Domain } & \multirow[b]{2}{*}{ Variables } & \multicolumn{2}{|c|}{$\begin{array}{l}\text { Multivariate Log } \\
\text { Reg }^{a}, \text { Likelihood of } \\
\text { SSD vs ND }\end{array}$} & \multicolumn{2}{|c|}{$\begin{array}{l}\text { Multivariate Log } \\
\text { Reg }{ }^{b} \text {,Likelihood } \\
\text { of Depr vs SSD }\end{array}$} & \multicolumn{2}{|c|}{$\begin{array}{l}\text { Ordinal Log Regr } \\
\text { including ND, SSD } \\
\text { and Depr }\end{array}$} & \multicolumn{2}{|c|}{$\begin{array}{l}\text { Linear } \text { Regr }^{d}, G D S- \\
\text { score as a continuous } \\
\text { function }\end{array}$} \\
\hline & & $\begin{array}{c}\text { OR } \\
(95 \% \mathrm{CI} \\
)\end{array}$ & $\mathbf{P}$ & $\begin{array}{c}\text { OR } \\
(95 \% \mathrm{CI} \\
)\end{array}$ & $\mathbf{P}$ & $\begin{array}{c}\text { OR } \\
(95 \% \mathrm{CI} \\
)\end{array}$ & $\mathbf{P}$ & $\begin{array}{c}\text { Unstan- } \\
\text { dardized B } \\
(95 \% \mathrm{CI})\end{array}$ & $\mathbf{P}$ \\
\hline $\begin{array}{l}\text { Socio- } \\
\text { demo- } \\
\text { graphic } \\
\text { Factors }\end{array}$ & $\begin{array}{l}\text { No contact } \\
\text { with } \\
\text { neighbours }\end{array}$ & $\begin{array}{c}4.0 \\
(1.6-10)\end{array}$ & 0.003 & & ns & $\begin{array}{c}3.8 \\
(1.7-8.2)\end{array}$ & 0.001 & $\begin{array}{c}0.91(0.41- \\
1.4)\end{array}$ & $<0.001$ \\
\hline \multirow[t]{2}{*}{$\begin{array}{l}\text { Declining } \\
\text { physical } \\
\text { func- } \\
\text { tioning }\end{array}$} & $\begin{array}{l}\text { Usual } \\
\text { activities (EQ- } \\
\text { 5D), some or } \\
\text { severe } \\
\text { problems }\end{array}$ & & ns & & ns & $\begin{array}{c}3.5 \\
(1.9-6.6)\end{array}$ & $<0.001$ & $\begin{array}{c}1.0 \\
(0.60-1.4)\end{array}$ & $<0.001$ \\
\hline & $\begin{array}{l}\text { Self-Care (EQ- } \\
\text { 5D), some or } \\
\text { severe } \\
\text { problems }\end{array}$ & $\begin{array}{c}5.5 \\
(2.1-14)\end{array}$ & 0.001 & & ns & & ns & & ns \\
\hline \multirow[t]{4}{*}{$\begin{array}{l}\text { Neuro- } \\
\text { psychi- } \\
\text { atric } \\
\text { factors }\end{array}$} & $\begin{array}{l}\text { History of } \\
\text { affective } \\
\text { psychiatric } \\
\text { disorder }\end{array}$ & $\begin{array}{c}3.5 \\
(1.3-9.4)\end{array}$ & 0.015 & & ns & & ns & & ns \\
\hline & $\begin{array}{l}\text { Current } \\
\text { anxiety/De- } \\
\text { pression (EQ- } \\
\text { 5D), moderate } \\
\text { or extreme }\end{array}$ & & ns & $\begin{array}{c}6.9 \\
(1.5-32)\end{array}$ & 0.014 & & ns & & ns \\
\hline & $\begin{array}{l}\text { Use of } \\
\text { tranquilizing } \\
\text { medication }\end{array}$ & $\begin{array}{c}3.9 \\
(1.1-14)\end{array}$ & 0.037 & & ns & $\begin{array}{c}3.6 \\
(1.5-9.0)\end{array}$ & 0.006 & $\begin{array}{c}1.1 \\
(0.45-1.7)\end{array}$ & 0.001 \\
\hline & $\begin{array}{l}\text { History of } \\
\text { Stroke }\end{array}$ & $\begin{array}{c}2.9 \\
(1.2-7.1)\end{array}$ & 0.022 & & ns & $\begin{array}{c}2.4 \\
(1.1-5.2) \\
\end{array}$ & 0.021 & $\begin{array}{c}0.90 \\
(0.42-1.4)\end{array}$ & $<0.001$ \\
\hline \multirow[t]{3}{*}{$\begin{array}{l}\text { Existen- } \\
\text { tial } \\
\text { factors }\end{array}$} & $\begin{array}{l}\text { Worries about } \\
\text { the future, } \\
\text { sometimes or } \\
\text { often }\end{array}$ & & ns & & ns & $\begin{array}{c}2.3 \\
(1.3-4.3)\end{array}$ & 0.006 & $\begin{array}{c}0.60 \\
(0.26-0.94)\end{array}$ & 0.001 \\
\hline & $\begin{array}{l}\text { Lower self- } \\
\text { perceived } \\
\text { health (EQ- } \\
\text { VAS) }\end{array}$ & $\begin{array}{c}6.9 \\
(3.5-13)\end{array}$ & $<0.001$ & & ns & $\begin{array}{c}5.1 \\
(2.7-9.6)\end{array}$ & $<0.001$ & $\begin{array}{c}0.79 \\
(0.43-1.2)\end{array}$ & $<0.001$ \\
\hline & $\begin{array}{l}\text { Life not } \\
\text { meaningful }\end{array}$ & $\begin{array}{c}5.9 \\
(2.4-14)\end{array}$ & $<0.001$ & $\begin{array}{c}3.8 \\
(1.3-11)\end{array}$ & 0.015 & $\begin{array}{c}5.9 \\
(2.9-12)\end{array}$ & $<0.001$ & $\begin{array}{c}1.6 \\
(1.1-2.0)\end{array}$ & $<0.001$ \\
\hline
\end{tabular}


Notes: ${ }^{a}=$ Nagelkerke $R^{2}=0.464 ;{ }^{b}=$ Nagelkerke $R^{2}=0.246 ;{ }^{c}=$ Nagelkerke Pseudo- $R^{2}=0.506$; test of parallel lines: $p=0.842$, indicating an ordinal logistic model is fair to the data; ${ }^{d}=$ Adjusted $R^{2}=$ 0.478 .

In the following multivariate ordinal logistic and linear regressions, there were instead seven partly different factors significantly associated with the dependent variable degree of depressiveness (categories of depressiveness in the ordinal logistic regression, and score on GDS15 in the linear regression respectively). The factors of the ordinal logistic regression are presented in descending order of OR: life not meaningful, lower self-perceived health, no contact with neighbors, use of tranquilizing medication, problems with usual activities, personal history of stroke, worries about the future.

A detail finding was that the three variables of problems with self-care, history of affective disorder and current anxiety/depression were significantly associated with the outcome in the binary logistic regressions, but not in the ordinal logistic or the linear regressions. On the other hand, the two variables problems with usual activities and worries about the future were significantly associated with the outcome in ordinal logistic and linear regressions, but not in the previous binary logistic regression.

Analyses of differences between GDS-responders $(n=371)$ and non-responders $(n=125)$ of the $\mathrm{n}=496$ who had filled in the postal questionnaire at baseline showed systematic differences, with non-responders more often being women, living in adapted housing, having problems with mobility, usual activities, self-care and self-perceived health according to the EQ-5D-items. The non-responders on the other hand had significantly less visual impairment, history of stroke and history of heart failure or myocardial infarction compared to the responders.

\subsection{Results from paper 3: Direct costs of persons with subsyndromal depression}

The aim of paper 3 was to provide a comparison, over a five-year period, between the prospective direct healthcare costs and service utilization for persons with SSD compared with nondepressive persons in a Swedish population of very old persons. A second aim was to develop a model that predicts direct healthcare costs in very old persons with SSD. Based on previous literature on persons of lower ages we hypothesized that the direct costs of very old persons with SSD would be higher than for non-depressive persons, independent of somatic multimorbidity, and that the factors of somatic multimorbidity, cognitive dysfunction, physical functioning and impaired ADL, chronic pain, and loneliness would also predict increased direct costs [135][135](135)(135)(135)(135)[131, 132, 135-137].

Revised categories of depressiveness were used for the analyses in paper 3, namely ND Both $(n=152)$, SSD Ever $(n=128)$ and Depr Ever $(n=36)$, which together constituted the sample of $\mathrm{n}=316$. The mean total healthcare costs per month of survival were $€ 608( \pm 628)$ for all GDSresponders $(n=371)$, which, extrapolated to annual costs, was $€ 7301$ ( \pm 7539 ; Table 6$)$. The mean 
total healthcare cost per month for the smaller sample, $n=316$, was instead $€ 545( \pm 539)$. Inpatient care accounted for almost half of the total healthcare costs, while primary and secondary outpatient care accounted for similar proportions of the rest. 
Table 6. Comparison with Mann-Whitney U-tests of prospective healthcare direct costs and service use between the categories ND Both, SSD Ever and Depr Ever.

\begin{tabular}{|c|c|c|c|c|c|c|c|c|}
\hline & & & $\begin{array}{l}\text { NDBoth } \\
(n=152)\end{array}$ & $\begin{array}{c}\text { SSDEver } \\
(\mathrm{n}=128)\end{array}$ & $\begin{array}{c}\text { DeprEver } \\
(n=36)\end{array}$ & $\begin{array}{c}\text { All } \\
(n=316)\end{array}$ & $\begin{array}{c}\text { p-value } \\
\text { (U- } \\
\text { test), }, \text { b } \\
\text { SSD } \\
\text { Ever vs } \\
\text { ND } \\
\text { Both }\end{array}$ & $\begin{array}{c}\text { p-value } \\
\text { (U- } \\
\text { test), }{ }^{\text {, b }} \\
\text { Depr } \\
\text { Ever vs } \\
\text { ND } \\
\text { Both }\end{array}$ \\
\hline \multirow{7}{*}{$\begin{array}{c}\text { Health- } \\
\text { care } \\
\text { direct } \\
\text { costs } \\
\text { per } \\
\text { capita } \\
\text { monthly } \\
(€)^{c}\end{array}$} & $\begin{array}{c}\text { Total } \\
\text { Healthcare } \\
\text { costs, mean } \\
\text { (SD) }\end{array}$ & & $436(367)^{d}$ & $634(611)^{d}$ & (693 (759) & $545(539)^{\mathrm{e}}$ & 0.048 & 0.018 \\
\hline & $\begin{array}{c}\text { Inpatient } \\
\text { care, } \\
\text { mean }(\mathrm{SD})\end{array}$ & & $171(234)$ & 290 (396) & $280(336)$ & $224(319)^{\mathrm{f}}$ & 0.014 & 0.068 \\
\hline & $\begin{array}{l}\text { Outpatient } \\
\text { care }\end{array}$ & $\begin{array}{c}\text { Primary } \\
\text { care, } \\
\text { mean (SD) }\end{array}$ & 148 (104) & 197 (189) & 348 (591) & $184(239)^{\mathrm{f}}$ & 0.005 & 0.003 \\
\hline & & $\begin{array}{l}\text { Secondary } \\
\text { outpatient } \\
\text { care, } \\
\text { mean (SD) }\end{array}$ & $141(220)$ & 149 (206) & $106(81)$ & $136(196)^{\mathrm{f}}$ & 0.311 & 0.707 \\
\hline & $\begin{array}{l}\text { Pharma- } \\
\text { ceuticals, } \\
\text { mean }(\mathrm{SD})\end{array}$ & & 67 (107) & 82 (69) & $83(51)$ & $77(90)$ & 0.005 & 0.113 \\
\hline & $\begin{array}{c}\text { Non- } \\
\text { pharma- } \\
\text { ceutical } \\
\text { components } \\
\text { g } \\
\text { mean (SD) }\end{array}$ & & 343 (330) & $516(543)$ & 525 (449) & 446 (467) & 0.005 & 0.013 \\
\hline & $\begin{array}{c}\text { Private } \\
\text { healthcare, } \\
\text { mean }(\mathrm{SD})\end{array}$ & & $49(77)$ & $40(90)$ & $126(571)$ & $56(208)$ & 0.048 & 0.675 \\
\hline \multirow{2}{*}{$\begin{array}{l}\text { Munici- } \\
\text { pal care } \\
\text { direct } \\
\text { costs } \\
\text { per } \\
\text { capita } \\
\text { monthly } \\
(€)^{i}\end{array}$} & $\begin{array}{l}\text { Total costs, } \\
\text { mean (SD) }\end{array}$ & & $\begin{array}{c}402 \\
(1078)\end{array}$ & $\begin{array}{c}975 \\
(1398)\end{array}$ & $\begin{array}{c}2298 \\
(1593)\end{array}$ & $\begin{array}{c}820 \\
(1411)\end{array}$ & 0.005 & 0.003 \\
\hline & $\begin{array}{l}\text { Adapted } \\
\text { housing, }{ }^{\mathrm{j}} \\
\text { mean }(\mathrm{SD})\end{array}$ & & 37 (166) & 109 (248) & 225 (277) & 90 (246) & 0.005 & 0.003 \\
\hline
\end{tabular}

Notes: ${ }^{a}=$ Correction for multiple comparisons with help of the method False Discovery Rate according to Benjamini and Hochberg [165] via online calculator at SDM project web (https://www.sdmproject.com/utilities/?show=FDR; the 23 ${ }^{\text {rd }}$ of January, 2018; Neuroimaging software library). These calculations were made separately for costs and healthcare service use. 
Continuation table 6.

\begin{tabular}{|c|c|c|c|c|c|c|c|c|}
\hline & & & $\begin{array}{l}\text { NDBoth } \\
(\mathbf{n}=152)\end{array}$ & $\begin{array}{c}\text { SSDEver } \\
(\mathbf{n}=\mathbf{1 2 8})\end{array}$ & $\begin{array}{c}\text { DeprEver } \\
(\mathbf{n}=36)\end{array}$ & $\underset{(n=316)}{\text { All }}$ & $\begin{array}{c}\text { p-value } \\
\text { (U- } \\
\text { test), a, b } \\
\text { SSD } \\
\text { Ever vs } \\
\text { ND } \\
\text { Both } \\
\end{array}$ & $\begin{array}{l}\text { p-value } \\
\text { (U- } \\
\text { test), } \\
\text { Depr } \\
\text { Ever vs } \\
\text { ND } \\
\text { Both } \\
\end{array}$ \\
\hline \multirow{8}{*}{$\begin{array}{l}\text { Health- } \\
\text { care } \\
\text { service } \\
\text { use per } \\
\text { capita } \\
\text { monthly }\end{array}$} & $\begin{array}{c}\text { Total } \mathrm{n} \\
\text { healthcare } \\
\text { visits, } \\
\text { mean (SD) }\end{array}$ & & $1.6(1.5)$ & $1.8(3.1)$ & $2.8(7.4)$ & $1,8(3,3)^{\mathrm{K}}$ & 0.620 & 0.469 \\
\hline & $\begin{array}{l}\mathrm{N} \text { visits to a } \\
\text { physician in } \\
\text { all, }{ }^{1} \\
\text { mean (SD) }\end{array}$ & & $\begin{array}{c}0.50 \\
(0.38)\end{array}$ & $\begin{array}{c}0.48 \\
(0.56)\end{array}$ & $\begin{array}{l}0.74 \\
(2.2)\end{array}$ & $\begin{array}{c}0.52 \\
(0.87)\end{array}$ & 0.240 & 0.364 \\
\hline & \multirow[t]{2}{*}{$\begin{array}{l}\text { Inpatient } \\
\text { care }\end{array}$} & $\begin{array}{l}\text { All inpatient } \\
\text { care, } \mathrm{n} \\
\text { occasions; } \\
\text { mean }(\mathrm{SD})\end{array}$ & $\begin{array}{c}1.9 * 10^{-2} \\
(3.6 \\
\left.* 10^{-2}\right)\end{array}$ & $\begin{array}{c}1.4 * 10^{-2} \\
\left(3.8 * 10^{-2}\right)\end{array}$ & $\begin{array}{c}2.3 * 10^{-2} \\
\left(6.4 * 10^{-2}\right)\end{array}$ & $\begin{array}{c}1.7 * 10^{-2} \\
\left(4.0 * 10^{-2}\right)\end{array}$ & 0.104 & 0.626 \\
\hline & & $\begin{array}{c}\text { Specific } \\
\text { psychiatric } \\
\text { inpatient } \\
\text { care, } \mathrm{n} \\
\text { occasions; }^{\mathrm{m}} \\
\text { mean (SD) }^{\text {non }}\end{array}$ & $\begin{array}{c}1.0^{*} 10^{-4} \\
(1.4 \\
\left.* 10^{-3}\right)\end{array}$ & $\begin{array}{c}0.00 \\
(0.00)\end{array}$ & $0.00(0.0)$ & $\begin{array}{c}1.0^{*} 10^{-4} \\
\left(9.4 * 10^{-4}\right)\end{array}$ & 0.620 & 0.626 \\
\hline & \multirow[t]{4}{*}{$\begin{array}{l}\text { Outpatient } \\
\text { care }\end{array}$} & $\begin{array}{c}\text { Primary } \\
\text { care n } \\
\text { visits; } \\
\text { mean (SD) }\end{array}$ & $1.3(1.3)$ & $1.5(3.0)$ & $2.6(7.3)$ & $1.5(3.2)$ & 0.670 & 0.626 \\
\hline & & $\begin{array}{l}\text { Emergency } \\
\text { room, } \mathrm{n} \\
\text { visits; }^{\mathrm{n}} \\
\text { mean }(\mathrm{SD})\end{array}$ & $\begin{array}{c}3.9 * 10^{-2} \\
(4.6 \\
\left.* 10^{-2}\right)\end{array}$ & $\begin{array}{c}4.8^{*} * 10^{-2} \\
\left(7.0^{*} 10^{-2}\right)\end{array}$ & $\begin{array}{c}3.5^{*} 10^{-2} \\
\left(4.5 * 10^{-2}\right)\end{array}$ & $\begin{array}{c}4.2 * 10^{-2} \\
\left(5.7 * 10^{-2}\right)\end{array}$ & 0.690 & 0.626 \\
\hline & & $\begin{array}{c}\text { All } \\
\text { secondary } \\
\text { outpatient } \\
\text { care, } \mathrm{n} \\
\text { visits; } \\
\text { mean (SD) }\end{array}$ & $\begin{array}{c}0.31 \\
(0.37)\end{array}$ & $\begin{array}{c}0.30 \\
(0.71)\end{array}$ & $\begin{array}{c}0.15 \\
(0.17)\end{array}$ & $\begin{array}{c}0.28 \\
(0.53)\end{array}$ & 0.104 & 0.008 \\
\hline & & $\begin{array}{c}\text { Specific } \\
\text { psychiatric } \\
\text { outpatient } \\
\text { care, } \mathrm{n} \\
\text { visits; }^{\mathrm{m}} \\
\text { mean (SD) }\end{array}$ & $\begin{array}{c}1.0^{*} 10^{-2} \\
(1.2 \\
\left.* 10^{-2}\right)\end{array}$ & $\begin{array}{c}1.6^{*} 10^{-3} \\
\left(1.6^{*} 10^{-2}\right)\end{array}$ & $\begin{array}{c}0.00 \\
(0.00)\end{array}$ & $\begin{array}{c}1.7 * 10^{-2} \\
\left(2.2 * 10^{-2}\right)\end{array}$ & 0.620 & 0.626 \\
\hline
\end{tabular}

Notes: ${ }^{b}=d f$ for the Mann-Whitney U-tests were equal to the smallest group size of the comparison, i. e. df 128 ( $n=128$ for SSD Ever) in the comparison between SSD Ever vs ND Both, and $d f 36$ ( $n=36$ for Depr Ever) in the comparison between Depr Ever vs ND Both. ${ }^{c}=$ Adjusted 
for the number of months of survival. ${ }^{d}=$ The ratio between the mean values for SSD Ever/ND Both was 1.45, while the corresponding ratio between the median values was 1.48. Median total healthcare costs were $€ 433$ ( $q 1=211, q 3=842)$ for SSD Ever and $€ 293$ ( $q 1=190, q 3=579)$ for ND Both. Sensitivity analyses with varying discount rates did not change the ratio between the mean values. ${ }^{e}=$ The mean total healthcare cost was $€ 608$ ( \pm 628$)$ for the whole sample of $n=371$, and $\epsilon 545$ ( \pm 539$)$ for the smaller sample of $n=316$. The median total healthcare cost for the whole sample of $n=371$ was $€ 412$ ( $q 1=216, q 3=781)$, instead of the median $€ 371(q 1=201, q 3=718)$ for the $n=316$. In sensitivity analyses, the mean value for the whole sample of $n=371$ was $€ 645$ ( \pm 666$)$ at $0 \%$ discount rate, and $€ 586( \pm 605)$ at $5 \%$ discount rate. ${ }^{f}=$ Compared to the numbers for the $n=316$ individuals of the table, the mean total costs for the whole sample $n=371$ were $€ 267$ ( \pm 381$)$ for inpatient care, $€ 191$ ( \pm 250$)$ for primary outpatient care, and $€ 149( \pm 230)$ for secondary outpatient care. ${ }^{g}=$ These numbers were only built on public costs data. ${ }^{h}=$ Only $n=160$ had any private healthcare during the study period. ${ }^{i}=$ Municipal costs were built only on data from a one year period between 2011-12, and those still surviving by the time $n=242$, of which $n=134$ (ND+ND), $n=82$ (SSD Ever) and $n=26$ (Depr Ever). ${ }^{j}=$ Only $n=38$ of the 242 individuals with municipal costs lived in adapted housing. ${ }^{k}=$ The mean number of healthcare visits was $1.8( \pm 3.2)$ for the whole sample of $n=371$, and $1.8( \pm 3.3)$ for the smaller sample of $n=316$. The median total number of healthcare visits for the whole sample of $n=371$ was 1.0 $(q 1=0.42, q 3=2.1)$, instead of the median $1.2(q 1=0.52, q 3=2.3)$ for the $n=316 .{ }^{l}=$ Number of visits to a physician is only based on data from four years of the study period. ${ }^{m}=$ There were only 1 psychiatric inpatient occasion, and only 31 psychiatric outpatient visits of the total 28626 visits for all the 371 persons during the five-year study period. ${ }^{n}=$ Visits at the emergency room was only to a physician.

Private healthcare accounted for only about ten percent of the healthcare costs. Even though only $16 \%$ (51/316) had adapted housing (as a major cost component), still the mean total municipal costs were clearly higher than the mean total healthcare costs per capita. A positively skewed distribution of healthcare costs corresponded to the fact that a small number of people had extremely high costs (corresponding to persons with multimorbidity), while a large number of persons had costs way below the mean.

The comparisons between the categories of depressiveness showed that SSD Ever had a 45\% higher mean total cost per month (€634 versus $€ 436)$ for healthcare compared with ND Both, which was a significant difference according to the u-tests. Such a difference was also significant for the components of inpatient care and primary care, but not for secondary outpatient care. Also, the mean costs per month for municipal care were significantly higher for SSD Ever (€975) compared to ND Both (€402). In contrast to these differences in mean costs, the service utilization measured as the number of healthcare visits or inpatient occasions was not significantly different between the categories of depressiveness. Persons with Depr Ever had higher mean total costs for healthcare and municipal care, compared to ND Both, though most cost components did not differ significantly. 
In the following multivariate linear regression a final model of five independent variables significantly predicted direct healthcare costs per month over five years: male sex, ADL functions, loneliness, presence of SSD, and somatic multimorbidity (Table 7). The effect size of the predictive model as a whole was small though, indicating that other factors contributed to the amount of direct healthcare costs in the very old persons.

Table 7. Univariate and multivariate linear regressions with log direct healthcare costs per month of survival as the dependent variable.

\begin{tabular}{|c|c|c|c|c|}
\hline \multirow[b]{2}{*}{$\begin{array}{l}\text { Independent } \\
\text { predictor variable }\end{array}$} & \multicolumn{2}{|c|}{$\begin{array}{l}\text { Univariate regression, } \\
\text { Log healthcare costs }\end{array}$} & \multicolumn{2}{|c|}{$\begin{array}{l}\text { Multivariate regression }{ }^{\mathrm{a}, \mathrm{b}} \text {, } \\
\text { Log healthcare costs }\end{array}$} \\
\hline & $\begin{array}{l}\text { Coefficient } \\
(95 \% \mathrm{CI})\end{array}$ & $\begin{array}{c}\text { t; df; } \\
\text { p-value; }\end{array}$ & $\begin{array}{l}\text { Coefficient } \\
(95 \% \text { CI })\end{array}$ & $\begin{array}{c}\text { t; df; } \\
\text { p-value }\end{array}$ \\
\hline Male sex (yes/no) & $\begin{array}{c}0.08 \\
(-0.02-0.18)\end{array}$ & $\begin{array}{c}1.65 ; 353 \\
0.100\end{array}$ & $\begin{array}{c}0.16 \\
(0.06-0.25)\end{array}$ & $\begin{array}{l}3.25 ; 264 ; \\
\boldsymbol{0 . 0 0 1}^{\mathrm{c}}\end{array}$ \\
\hline $\begin{array}{l}\text { Low education, } \\
<9 \text { years (yes/no) }\end{array}$ & $\begin{array}{c}-0.064 \\
(-0.16-0.04)\end{array}$ & $\begin{array}{c}1.25 ; 347 \\
0.211\end{array}$ & $\begin{array}{c}-0.04 \\
(-0.14-0.05)\end{array}$ & $\begin{array}{c}0.89 ; 260 \\
0.374^{\mathrm{d}}\end{array}$ \\
\hline $\begin{array}{l}\text { Loneliness, sometimes or } \\
\text { often (yes/no) }\end{array}$ & $\begin{array}{c}0.11 \\
(0.02-0.20)\end{array}$ & $\begin{array}{l}\text { 2.37; } 338 ; \\
\quad \mathbf{0 . 0 1 8}\end{array}$ & $\begin{array}{c}0.14 \\
(0.03-0.24)\end{array}$ & $\begin{array}{l}2.62 ; 264 ; \\
0.009\end{array}$ \\
\hline $\begin{array}{l}\text { Use of mobility assistive } \\
\text { devices (yes/no) }\end{array}$ & $\begin{array}{c}0.08 \\
(-0.02-0.17)\end{array}$ & $\begin{array}{l}1.57 ; 353 \\
0.118\end{array}$ & $\begin{array}{c}0.03 \\
(-0.08-0.14)\end{array}$ & $\begin{array}{l}0.52 ; 260 \\
0.604^{d}\end{array}$ \\
\hline $\begin{array}{l}\text { Lower ADL functions } \\
\text { (EQ-5D), (yes/no) }\end{array}$ & $\begin{array}{c}0.04 \\
(-0.08-0.15)\end{array}$ & $\begin{array}{l}0.61 ; 353 ; \\
0.541\end{array}$ & $\begin{array}{c}-0.15 \\
(-0.28-(-0.02)\end{array}$ & $\begin{array}{l}-2.27 ; 264 ; \\
\quad 0.024\end{array}$ \\
\hline $\begin{array}{l}\text { Pain/ Discomfort (EQ- } \\
\text { 5D), moderate or extreme } \\
\text { (yes/no) }\end{array}$ & $\begin{array}{c}0.00 \\
(-0.10-0.10)\end{array}$ & $\begin{array}{c}0.05 ; 353 ; \\
0.964\end{array}$ & $\begin{array}{c}0.02 \\
(-0.08-0.12)\end{array}$ & $\begin{array}{c}0.36 ; 260 \\
0.718^{\mathrm{d}}\end{array}$ \\
\hline $\begin{array}{l}\text { Cognitive dysfunction } \\
\text { (MMSE<25p, yes/no) }\end{array}$ & $\begin{array}{c}0.03 \\
(-0.11-0.16)\end{array}$ & $\begin{array}{l}0.40 ; 353 ; \\
0.687\end{array}$ & $\begin{array}{c}-0.06 \\
(-0.21-0.08)\end{array}$ & $\begin{array}{c}-0.85 ; 260 \\
0.394^{\mathrm{d}}\end{array}$ \\
\hline $\begin{array}{l}\text { Somatic multimorbidity } \\
\text { (n chronic diseases) }\end{array}$ & $\begin{array}{c}0.05 \\
(0.01-0.08)\end{array}$ & $\begin{array}{l}2.88 ; 353 ; \\
\quad 0.004\end{array}$ & $\begin{array}{c}0.04 \\
(0.01-0.08)\end{array}$ & $\begin{array}{l}2.81 ; 264 ; \\
\quad 0.005\end{array}$ \\
\hline $\begin{array}{l}\text { Presence of SSD Ever vs } \\
\text { ND Both }\end{array}$ & $\begin{array}{c}0.13 \\
(0.03-0.23)\end{array}$ & $\begin{array}{c}2.58 ; 278 \\
\quad 0.011\end{array}$ & $\begin{array}{c}0.11 \\
(0.01-0.21)\end{array}$ & $\begin{array}{l}2.20 ; 264 \\
\text { 0.029 }\end{array}$ \\
\hline
\end{tabular}

Notes: ${ }^{a}=$ Adjusted $R^{2}=0.083$ for the stepwise linear regression, and $F=5.88, d f=5,264$ for the model of five significant predictors female sex, loneliness, usual activities, somatic multimorbidity, and presence of SSD. ${ }^{b}=$ The multivariate regression analyses were based on $n=280$ out of the $n=316$ sample, as all other than the categories ND both $(n=152)$ and SSD Ever $(n=128)$ were excluded listwise. ${ }^{c}=$ Mean total healthcare cost per month of survival was $€ 611$ ( \pm 593$)$ for men, and $€ 500( \pm 495)$ for women, which means a $19 \%$ lower mean total healthcare cost for women. ${ }^{d}=$ The coefficient, $95 \% \mathrm{CI}$ and associated p-value of the multivariate regression for this variable were taken from the first stepwise model, corresponding to an entry procedure for all the variables together. In the final stepwise backward automatic regression model this 
variable was actually removed as it was non-significant. ${ }^{e}=$ In the sensitivity analyses the p-value for this variable was 0.042 with a discount rate of $0 \%$, and 0.029 with a discount rate of $5 \%$.

\subsection{Results from paper 4: Morbidity and mortality in persons with SSD}

The aim of the present study was to investigate longitudinal outcomes of SSD in very old persons. Based on previous studies on SSD in the young old, and on syndromal depression in very old ages we hypothesized that SSD compared to ND in very old persons would be associated with lower ADL function [137], worse self-perceived health [138], lower cognitive functions [36], a higher degree of loneliness [139], depressiveness [35] and higher mortality [23].

For the morbidity analyses, GDS-15 measurements from all four measure waves (at ages 85 (T1), 86 (T2), 90 (T3) and 93 (T4) over eight years were used, while only the baseline measurement was used for the survival analysis. The focus for the analyses was to separate the effects of SSD from ND, so the category of syndromal depression (23/371 at baseline) was excluded from the morbidity analyses. Thus, the morbidity analyses were built on the sample of $n=348$, while the mortality analyses were built on the original sample of $n=371$. Because of death, disease and other causes of attrition, the number of participants diminished substantially in every wave, which is common in longitudinal studies of very old persons. Separate analyses showed that the loss to follow-up was significantly associated with female sex, adapted housing, lower ADL function and global cognitive function, and a higher degree of depressiveness, all of which is of relevance for the interpretation of the other results (Table 3 in the methods section).

Morbidity analyses with linear mixed models showed that SSD compared to ND was associated with a higher morbidity, in line with most hypotheses. For example the presence of SSD was associated with a mean decrease of I-ADL score of 23\% (5.4 of the range $24 \mathrm{p}$ ) in each measure wave, after adjustment had been made for potential confounders (Table 8 ). 
Table 8. Effect of SSD and time on different outcome variables over four measure waves and eight years, according to calculations using Linear Mixed Model analysis ${ }^{\mathrm{a}}, \mathrm{n}=348$.

\begin{tabular}{|c|c|c|c|c|c|c|c|}
\hline & & \multicolumn{2}{|c|}{$\begin{array}{c}\text { Effect of SSD vs ND, } \\
\text { unadjusted }\end{array}$} & \multicolumn{2}{|c|}{$\begin{array}{l}\text { Effect of SSD vs ND, } \\
\text { adjusted }^{\mathrm{b}}\end{array}$} & \multicolumn{2}{|c|}{ Effect of time $e^{b, c}$} \\
\hline \multicolumn{2}{|c|}{$\begin{array}{c}\text { Outcome variables } \\
\text { longitudinally measured }\end{array}$} & $\begin{array}{l}\text { Parameter } \\
\text { estimate }(\mathrm{CI})\end{array}$ & $\begin{array}{c}\text { p- } \\
\text { value }\end{array}$ & $\begin{array}{l}\text { Parameter } \\
\text { estimate }(\mathbf{C I})\end{array}$ & $\begin{array}{c}\text { p- } \\
\text { value }\end{array}$ & $\begin{array}{l}\text { Parameter } \\
\text { estimate }\end{array}$ & $\begin{array}{c}\text { p- } \\
\text { value }\end{array}$ \\
\hline \multirow[t]{2}{*}{$\begin{array}{l}\text { Functional } \\
\text { abilities }\end{array}$} & Basic ADL & $\begin{array}{c}-0.62 \\
(-0.80-(-0.44))\end{array}$ & $<0.001$ & $\begin{array}{c}-0.58 \\
(-0.76-(- \\
0.40))\end{array}$ & $<0.001$ & $\begin{array}{c}\text { T1-T4: }-0.56 \\
(-1.1-(- \\
0.050))\end{array}$ & 0.032 \\
\hline & I-ADL & $\begin{array}{c}-6.1 \\
(-7.1-(-5.1))\end{array}$ & $<0.001$ & $\begin{array}{c}-5.4 \\
(-6.4-(-4.4))\end{array}$ & $<0.001$ & $\begin{array}{l}\text { T1-T4: }-5.4 \\
(-7.4-(-3.4))\end{array}$ & $<0.001$ \\
\hline $\begin{array}{l}\text { Self-rated } \\
\text { health }\end{array}$ & EQ-VAS & $\begin{array}{c}-15 \\
(-17-(-12))\end{array}$ & $<0.001$ & $\begin{array}{c}-8.2 \\
(-11-(-5.5))\end{array}$ & $<0.001$ & $\begin{array}{l}\text { T1-T4: } 3.8 \\
(-0.19-7.7)\end{array}$ & 0.062 \\
\hline \multirow[t]{3}{*}{$\begin{array}{l}\text { Cognitive } \\
\text { functions }\end{array}$} & MMSE & $\begin{array}{c}-1.5 \\
(-2.1-(-0.089))\end{array}$ & $<0.001$ & $\begin{array}{c}-0.17 \\
(-0.42-0.75)\end{array}$ & 0.581 & $\begin{array}{l}\text { T1-T4: } 1.2 \\
(0.43-2.0)\end{array}$ & 0.003 \\
\hline & Cog. Speed & $\begin{array}{c}-0.19 \\
(-0.32-(-0.052))\end{array}$ & 0.006 & $\begin{array}{c}0.0086 \\
(-0.13-0.15)\end{array}$ & 0.902 & $\begin{array}{c}\text { T1-T4: } 0.19 \\
(-0.041-0.42)\end{array}$ & 0.106 \\
\hline & $\begin{array}{l}\text { Executive } \\
\text { function }\end{array}$ & $\begin{array}{c}-0.21 \\
(-0.37-(-0.053))\end{array}$ & 0.009 & $\begin{array}{c}-0.016 \\
(-0.18-0.15)\end{array}$ & 0.846 & $\begin{array}{c}\text { T1-T4: }-0.025 \\
(-0.25-0.30)\end{array}$ & 0.857 \\
\hline $\begin{array}{c}\text { Social } \\
\text { functions }\end{array}$ & $\begin{array}{l}\text { Frequency } \\
\text { loneliness }\end{array}$ & $\begin{array}{c}0.44 \\
(0.30-0.59)\end{array}$ & $<0.001$ & $\begin{array}{c}0.30 \\
(0.15-0.46)\end{array}$ & $<0.001$ & $\begin{array}{c}\text { T1-T4: } \\
0.00069 \\
(-0.32-0.32)\end{array}$ & 0.997 \\
\hline $\begin{array}{l}\text { Mental } \\
\text { health } \\
\text { function }\end{array}$ & $\begin{array}{c}\text { Depressive- } \\
\text { ness, } \\
\text { GDS-15 } \\
\text { score }\end{array}$ & $\begin{array}{c}1.8 \\
(1.5-2.2)\end{array}$ & $<0.001$ & $\begin{array}{c}1.1 \\
(0.62-1.6)\end{array}$ & $<0.001$ & $\begin{array}{l}\text { T2-T4: } 0.48 \\
(-0.13-1.1)\end{array}$ & 0.124 \\
\hline
\end{tabular}

Notes: ${ }^{a}=$ Diagonal covariance structure $;{ }^{b}=$ Adjusted for sex, somatic multimorbidity and time. Variables other than Basic ADL and I-ADL also adjusted for I-ADL; ${ }^{c}=$ Ordinal data for measure waves T1 to T4, except for the variable Depressiveness for which the longitudinal outcome corresponds only to measure waves T2 to T4, as the T1 value was the independent variable in the analysis.

The variable of time (or age) was also associated with a significant decrease of I-ADL (23\% or $5.4 / 24 p$ ), which, however, was adjusted for in the previous association for SSD. The presence of SSD was significantly associated with a decrease of cognitive functions (MMSE, cognitive speed and executive functions) over time. However, contrary to our hypotheses the associations between SSD and the decreases of cognitive functions were no longer significant when adjusting for I-ADL and other potential confounders.

In addition to the fact that the presence of SSD at baseline was associated with a 7.3\% (1.1p of the range 15p) higher GDS-15 score in the following measure waves, separate analyses at a categorical level showed that the presence of SSD instead of ND at baseline was associated with 
an increase of the combined probability for SSD or syndromal depression in the following waves (Figure 8)

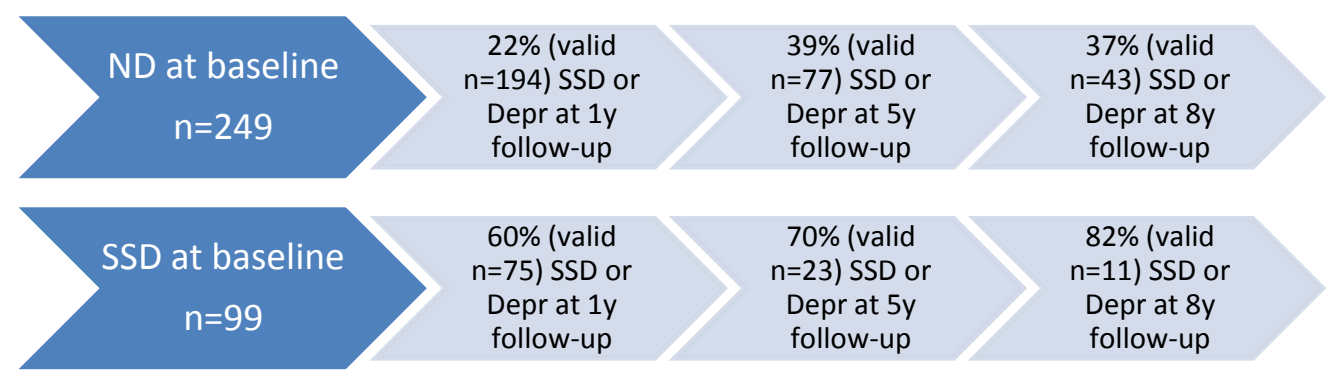

Figure 8. The combined proportion of SSD and Depression at each measure wave, for persons with ND or SSD at baseline. Note: The proportions differed significantly between ND at baseline and SSD at baseline for each measure wave, with $\chi^{2}=37(p<0.001)$ at one-year follow-up, $\chi^{2}=6.7$ $(p=0.010)$ at five-year follow-up, and $\chi^{2}=7.0(p=0.008)$ at eight-year follow-up .

Regarding mortality, the univariate Cox regression showed that the presence of SSD at baseline was associated with a $60 \%$ increased risk of mortality (Table 9). However, when adjusting for relevant covariates in a multivariate regression only three independent factors were significantly associated with survival time or mortality, in the following presented in descending order of HR: male sex, lower cognitive speed, and lower I-ADL. 
Table 9. Univariate and multivariate Cox regressions with baseline data as independent variables, $\mathrm{n}=371^{\mathrm{a}}$.

\begin{tabular}{|c|c|c|c|c|}
\hline & \multicolumn{2}{|c|}{ Univariate regression } & \multicolumn{2}{|c|}{ Multivariate regression } \\
\hline & Hazard Ratio (CI) & p-value & Hazard Ratio (CI) & p-value \\
\hline Male sex & $1.21(0.936-1.56)$ & 0.146 & $1.38(1.02-1.86)$ & 0.035 \\
\hline Education n years & $0.999(0.965-1.04)$ & 0.963 & $1.01(0.969-1.05)$ & 0.698 \\
\hline $\begin{array}{c}\text { Somatic } \\
\text { multimorbidity (n } \\
\text { diseases) }\end{array}$ & $1.13(1.05-1.22)$ & 0.002 & $1.07(0.981-1.16)$ & 0.130 \\
\hline SSD_vs_ND & $1.56(1.14-2.12)^{b}$ & 0.005 & $0.915(0.298-2.81)^{\mathrm{c}}$ & 0.867 \\
\hline Depr_vs_ND & $1.31(0.753-2.29)^{\mathrm{d}}$ & 0.329 & $1.25(0.426-3.67)^{\mathrm{c}}$ & 0.674 \\
\hline Basic ADL & $0.737(0.668-0.813)$ & $<0.001$ & $0.930(0.801-1.08)$ & 0.338 \\
\hline I-ADL & $0.941(0.924-0.958)$ & $<0.001$ & $0.952(0.926-0.980)$ & 0.001 \\
\hline EQ-VAS & $0.991(0.984-0.998)$ & 0.012 & $1.08(0.997-1.02)$ & 0.161 \\
\hline MMSE & $0.952(0.929-0.976)$ & $<0.001$ & $1.03(0.978-1.09)$ & 0.238 \\
\hline Cognitive speed & $0.701(0.609-0.806)$ & $<0.001$ & $0.764(0.634-0.919)$ & 0.004 \\
\hline Executive function & $0.777(0.676-0.894)$ & 0.001 & $0.939(0.736-1.20)$ & 0.599 \\
\hline Loneliness $1-2^{\mathrm{e}}$ & $1.23(0.874-1.72)$ & 0.238 & $1.20(0.837-1.71)$ & 0.326 \\
\hline Loneliness $1-3^{\mathrm{e}}$ & $1.52(1.01-2.11)$ & 0.012 & $1.38(0.939-2.02)$ & 0.101 \\
\hline Loneliness 1-4 $4^{\mathrm{e}}$ & $1.18(0.646-2.14)$ & 0.595 & $1.07(0.525-2.19)$ & 0.850 \\
\hline
\end{tabular}

Notes: ${ }^{a}=$ Final model built on $n=371$, whereof $238(64 \%)$ died, $133(36 \%)$ were censored. Five automatic imputations were done in every independent variable with missing data, according to the method Fully conditional specification in SPSS. Number of imputed values were 64 in the variable Cognitive speed, 132 in the variable Executive function, and lower numbers in the rest of variables. Cases available for the multiple Cox regression were 163/371 (44\%) before multiple imputation, and 371/371 (100\%) after multiple imputation. ${ }^{b}=$ Without imputations in this variable HR were 1.60 (1.21-2.11) and $p=0.001$ in the univariate regressions. ${ }^{c}=$ When using an alternative ordinal variable (including all the three categories ND, SSD and Depr; without any imputed values) instead of the dichotomous variables (SSD vs ND) and (Depr vs ND) the results of the multivariate regression were $H R=1.10(0.783-1.55)$ and $p=0.578$ for the categorical step $N D$-SSD, and $H R=1.03$ (0.508-2.09) and $p=0.936$ for the categorical step ND-Depr in the multivariate regression. ${ }^{d}=$ Without imputations in this variable HR were 1.35 (0.794-2.30) and $p=0.268$ in the univariate regressions. ${ }^{e}=$ The results for the variable loneliness are presented for each categorical step: 1-2 comparison never-seldom, 1-3 comparison never-sometimes, 1-4 comparison never-often. 


\section{Discussion}

\subsection{Cross-sectional pictures of the complex area between normal aging and depression}

The overarching aim of this thesis project was to investigate the unclear area between syndromal depression and non-depression (ND) in very old persons; that is, to investigate subsyndromal depression (SSD) or subthreshold depression in the oldest old. In the following discussion the results from the single studies will be discussed, with a subsequent overall discussion to put the results in context.

\subsubsection{Experiences of being in very old age, and the heterogeneity of depressiveness}

In paper 1, experiences of being in very old persons with SSD were described, and these experiences were compared with corresponding experiences in persons with ND or syndromal depression. The qualitative interviews gave detailed descriptions of living in old age with bodily decline and other challenges, and several persons said that they wanted to keep up with life, as long as they could manage on their own and remain relatively independent. Very old age, or the so-called fourth age of life, gives new preconditions for being that are necessary for very old persons to relate to. With the help of coping strategies, for example taking one day at a time (i.e. living in the present and not worrying about the future or the past), the subjects could experience well-being despite the physical decline, the functional impairments, and the social and psychological challenges they faced.

Previously, there have been done qualitative studies on what it is like to live with depression [171-174], and there are similarities between our study and the other ones. For example, there are obvious similarities between the theme of taking one day at a time and the forward motion from low mood and depressing environments as a part of a "personal responsibility" cultural model of depression, as described by Switzer et al 2006 [173]. Similar descriptions of the bodily decline were presented in Fischer et al 2008 [175], in which bodily changes were described as a sort of evidence of change while the main parts of the identity were stable in old persons. Divergent descriptions were on the other hand presented in Allan et al 2009 [174] where depression was described in terms of loathing and a struggle for life. Such latter differences between the qualitative studies may be a result of interviewing informants from different cultures, subcultures, or just different individuals, but they may also be a result of how the questions were formulated. In paper 1 open-ended questions about being were chosen, in order to gain a better understanding of SSD in an indirect way, while the questions in Allan et al 2009 were more direct about depression, and the different questions naturally provided different descriptions.

Descriptions in paper 1 of coping strategies in the very old persons were similar to previous studies on inner strength and resilience factors, and included varying cognitive and behavioral 
strategies of elderly people [50,60]. Coping and resilience, as well as adjoining psychological processes such as hardiness, sense of coherence, strength and vulnerability integration from psychology, and the activity theory, the disengagement theory and the theory of gerotranscendence from nursing and sociology have all been written about extensively [54, 55, $61,63,64,69]$.

In a comparison with the interviews of paper 1, these different theories seem to describe different aspects of aging and old age, rather than any theory being more universally valid than the others. Being in old age includes on one hand preconditions that are common for a specific chronological, biological and physical age, as well as for a generation (secular trend) and culture/subculture [70-72, 176]. On the other hand, being in old age is perceived differently between individuals because of their different perceptions, thoughts and values.

Through listening to the individual story we can get clues that are critical to the understanding of what gives quality of life, depressiveness, power, hope, or lack of the same for the individual. The individual story - besides the DSM-based counting of number of symptoms and durationgives important information to consider in the diagnostic assessment of the psychiatric patient during old age. At the same time it gives information that can be helpful in choosing treatment alternatives among CBT, medications, physical activity, reminiscence therapy and others. Through the attention to the individual story we can thus increase precision in psychiatric diagnostics and also ameliorate the treatment choice in a person-centered way, considering both the causes of depressiveness at individual level and the person's preferences and understanding of their own condition [177].

There were many similarities in the interviews between the categories of depressiveness, for example all four identified themes could be identified in each category. This indicates that preconditions, experiences of being, and coping with challenges are similar no matter whether a person has ND, SSD or syndromal depression. However, there were also differences between the categories. The differences between SSD and ND on one hand seemed to be discrete and quantitative, while the differences between SSD and depression on the other hand seemed to be both quantitative and qualitative. As an example of qualitative differences, the experiences of bodily decline and its negative consequences were more prominent in interviews with persons with syndromal depression compared to SSD, as they described severe restrictions socially and physically. The experience of self-determination was on the other hand less prominent in the interviews of syndromal depression compared to SSD. Conclusions from the study were, among other things, that there might be both quantitative and qualitative differences between SSD and syndromal depression, which might strengthen the perception of a natural boundary between normality and pathology that coincides with the limit between SSD and depression.

Also, previous studies have indicated qualitative differences with different symptom profiles between various degrees of depressiveness $[178,179]$. This is related to the discussion about the concurrent perspectives of dimensional or categorical perspective on disorders. The categorical 
perspective on affective diseases corresponds to the occurrence of qualitative differences, while the dimensional perspective instead corresponds to the idea of affective diseases and symptoms as degrees on a continuous scale (depicted in Figure 3 above).

The discussion about the categorical and the dimensional perspectives on affective diseases, or on single depressive symptoms, is also related to other aspects of heterogeneity in depressive conditions. The DSM system from versions III onwards was based on criteria that promote an acceptable reliability in the assessment of depressive symptoms. Still, there is a hope that future versions of the DSM will consider different etiologies, as conditions like SSD and syndromal depression are not homogenous, but rather composite parent groups of heterogeneous states. In this line, several authors have investigated subgroups of depressiveness [180]. For example, Carracher et al. 2009 found three subgroups of depression, while Fried and Nesse 2015 identified as many as 1030 different symptom profiles or variants of depression in the great $(n=3703)$ STAR*D study [181, 182]. Of course, results like these could lead a psychiatrist to despair if each symptom profile of depressiveness also corresponded to a specific treatment, as it would be hard to keep track of all these subgroups and treatments.

On the other hand, such study results can remind us that the present diagnostic strategies are still under development, and in need of revision and refining in order to guide our questions about prognosis and treatment in the future. In addition to the nine symptoms of the depression criteria of DSM there are other signs of depressiveness (presented for example in the Inventory of Depressive Symptomatology (IDS-30) with 30 different symptoms [183]). Except for classification on the basis of number of signs or symptoms, and of degree of suffering or functional impairment, other criteria for classification have been proposed or used. Some examples of such criteria are the presence of markers for complicated disorders [184], and different subtype trajectories (unipolar and bipolar affective variants $[185,186]$ ).

\subsubsection{Presentations of depressiveness in very old persons, typical or atypical?}

It has been repeatedly proposed that the elderly and very old persons with depressiveness have a different symptom profile compared to younger adults. For example, depression without sadness or a so-called "depletion syndrome" with prominent features of social disengagement and anhedonia has been described as typical for old age [187]. Also, vascular depression with characteristic features of apathy, retardation and cognitive impairment and other variants have been described [94].

However, the empirical basis has been weak for a generally different symptom profile among elderly persons, and in a recent critical review by Haigh et al. 2018 it was argued that such a different symptom profile could mainly be explained by a growing amount of comorbidity in old age [89]. When considering the transcultural perspective including different psychosocial differences between cultures, subcultures, and generations (secular trend), there are more explanations for the perception of age-colored depression in old age [71, 97-99, 102, 188]. In other words, the perception of a generally different and atypical symptom picture of 
depressiveness in elderly persons might be true only when embracing the hegemonic and simplified perspective of the depressive syndrome, and when overlooking physical comorbidity and transcultural aspects in the meeting with an individual. Perhaps it would thus be more appropriate to describe the picture of depressiveness in elderly persons as more variable than for younger persons, and comorbidity and transcultural aspects should be considered in the individual assessment.

Paper 1 thus reveals, on the basis of information-rich qualitative interviews, how aging and being are perceived in persons with SSD in very old age, which contributes to the understanding of $\mathrm{SSD}$, with consequences for our approach in healthcare and municipal care.

In this context, the results from paper 2 may be of particular relevance, as the identified factors associated with SSD could be phenomena or signs beside the DSM criteria that can help us to identify or at least increase our vigilance for SSD and depression in an old person. In the meeting with a patient with markers or factors associated with SSD (e.g. history of stroke, reduced ADL functioning and worries about the future as described in paper 2) we should thus increase our vigilance for depressive symptoms and pose questions accordingly. Together with our knowledge that it is not only the nine symptoms of the DSM criteria that count, and that comorbidity and transcultural aspects often complicate the picture of depressiveness in very old persons, our vigilance may increase the chances of adequately diagnosing significant depressiveness when present. In this way we can increase our sensitivity in healthcare and municipal care to identify depressiveness, and thus reduce the problems of under-diagnosis and under-treatment in old age [94, 109, 129].

In certain aspects, paper 2 built on the question from paper 1 of whether there are only quantitative or also qualitative differences between ND, SSD and syndromal depression. As some of the markers or factors were associated with the categories of depressiveness only in binary logistic regression (and not in the following ordinal logistic or linear regressions), a possible conclusion (in line with paper 1) would be that there may be both quantitative and qualitative differences between the categories. If there had been only quantitative differences (according to a strictly dimensional perspective), then all the associated factors from the binary logistic regression should have been significant also in ordinal logistic and linear regressions, which was not the case.

However, paper 2 had methodological limitations which mean that we cannot be sure of such a coexistence of qualitative and quantitative differences. For example, the number of individuals was smaller and the variance greater in the category of depression compared to ND and SSD respectively. This should have reduced the strength of associations, which in the long run may have contributed to the results indicating qualitative differences. On the other hand, the findings about qualitative differences between subtypes or categories of depressiveness seem reasonable when considering the discussion about heterogeneity in depressive conditions found by researchers such as Fried and Nesse [181]. 
In the above, papers 1 and 2 have been discussed, and even though they had completely different methods, both studies indicated the simultaneous occurrence of quantitative and qualitative differences between the categories ND, SSD and syndromal depression. In addition, they both revealed the ways in which SSD can be presented in very old persons, in a context of progressive bodily decline with associated functional impairment, need of care and elements of existential matters in the so-called fourth age of life. A possible interpretation of the findings could be that personnel in healthcare and municipal care should raise their eyes from the classical signs of depression, and consider also the individual story and preconditions, in order to identify when significant depressiveness is present.

Paper 2 could neither confirm nor refute the importance of the four themes identified in paper 1, as we chose to prioritize the investigation of factors with more robust evidence from previous literature. To further investigate the four identified themes from paper 1 with a quantitative and a deductive approach in the future would thus be valuable.

\subsection{Longitudinal aspects of SSD in very old persons}

\subsubsection{The dynamics and the relevance of SSD in the very old}

While both papers 1 and 2 investigated SSD in very old persons from a cross-sectional perspective on diagnostics and phenomenology, we shall now turn to a longitudinal perspective of SSD in papers 3 and 4. In order to understand SSD among very old persons better, we wanted to describe the predictive value of SSD in addition to this previous phenomenological approach. As affective conditions vary dynamically in symptom profile and intensity over time for an individual, it is important to study the conditions longitudinally. Is SSD really significant in a clinical healthcare meeting or from a societal perspective, if it is only a temporary ripple on the surface of a person's affects in life? An argument against longitudinal studies on SSD would be that the depressive categories cannot be studied longitudinally in a safe way, as the affects varies between the depressive categories for an individual over time ([15]; Figure 9 ). We have, however, chosen to undertake such studies, although we humbly realize that our method of a few observations over a long time period not fully can grasp the smallest details of the natural fast variations of mood. 


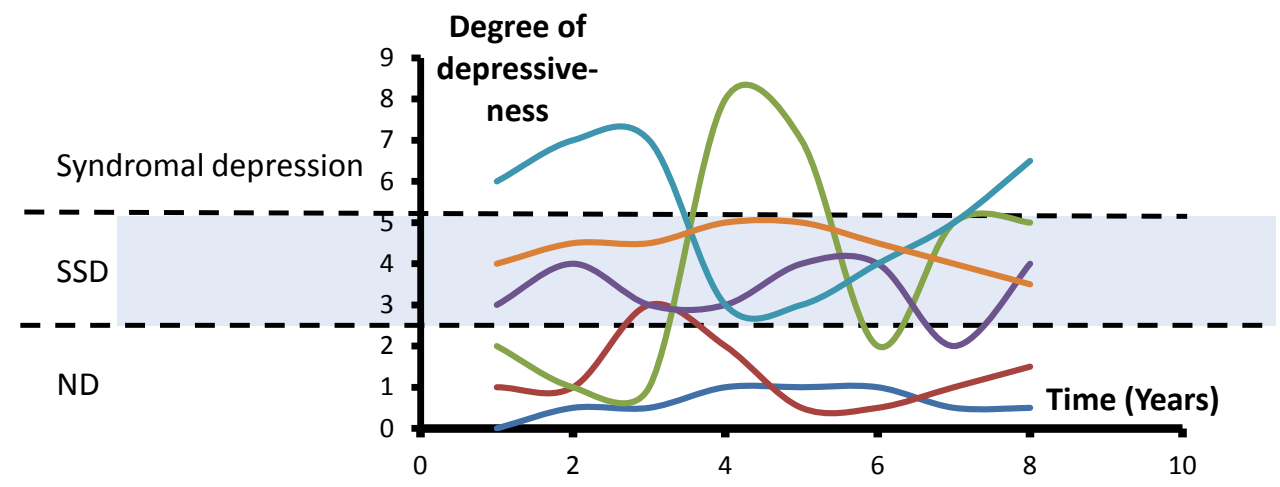

Figure 9. The dynamics of affective conditions: degree of depressiveness per individual over time.

In paper 3 we investigated the health economic effects of SSD and syndromal depression compared to ND, using register data on direct costs and service utilization over five years. A main finding was that persons with SSD at either baseline or at the one-year follow-up (SSD Ever) compared to those having ND at both measurements (ND Both), had a significantly higher mean total healthcare cost per individual and month of survival. In addition to the total costs, the following subcomponents of costs were also higher: primary care, inpatient care, medications, municipal care and more.

A very rough estimation of the sum of excess societal costs of SSD in very old persons in Sweden would be 4.3 billion SEK or 0.43 billion $€$ per year (given 258471 persons of age $85+$ and the associated cost of 81.3 billion SEK (or 8.16 billion $€$ ) in 2015 for the sum of healthcare and municipal care of these persons $)^{1}[189,190]$. Previous studies have shown similar results for

${ }^{1}$ The very rough estimation of excess societal costs of SSD in very old persons of Sweden is explained in detail in the following. The population of age 85+ was 258471 persons in Sweden by 2015. The number of persons per age group in more detail was 162108 (age 85-89)+76 013 (age 90-94)+18 454 (age 95-99)+1 896 (age 100+). The mean costs for the sum of healthcare and municipal care of the Västra Götaland county 2013-2015, was, per individual and year, 258400 SEK (mean of ages 85-89), 380800 SEK (mean of ages 90-94), 514000 SEK (mean of ages 9599), and 506000 SEK (mean of ages 100+). By multiplying the number of persons and mean costs for each age group, and then summing, the total cost for the whole population of age 85 was 81.279 billion SEK in 2015. With the assumption of a $12 \%$ prevalence of SSD I used the equation $(0.88 \mathrm{x}+0.12 \mathrm{y}=81.279)$ where $\mathrm{x}$ was the costs for ND while $\mathrm{y}$ was the costs of SSD. With the assumption of a factor 1.45 for excess costs of SSD compared to ND according to the 
younger persons with SSD [131, 132], and for very old persons with depression [191-193], while our study indicates that this pattern is also valid in the oldest ages. In the comparison between persons with syndromal depression at either of the two measure waves (Depr Ever) and ND, there were corresponding differences in total healthcare costs, but the associations were not significant for other subcomponents of than primary care, non-pharmaceutical components or municipal care. The fact that several associations were not significant in the comparison of syndromal depression and ND could possibly be explained by the smaller number of individuals and consequently less statistical power for the category of Depr Ever. Previous literature has discussed different explanations for why persons with depressive symptoms are associated with higher costs [193-197]. For example psychiatric symptoms themselves lead to extra treatments, and depressive symptoms are associated with the development of certain unspecific somatic symptoms. Also, depressive symptoms complicate the treatment of somatic disorders, for example through non-adherence to treatment.

A possible extended conclusion from our study would be that these higher societal costs for SSD in very old persons should motivate the allocation of extra resources to this group of persons in order to handle this societal problem of relatively great significance. However, it is important to note that cost-of-illness (COI)-studies should not necessarily guide the allocation of resources in society or healthcare, because the allocation should rather be guided by which interventions are of most use or are most effective. Through alternative cost-utility analyses (measured in the unity cost per QUALY) and cost-effectiveness analyses (with varying kinds of units) instead of COI, the use and effectiveness of interventions can be measured [163, 198]. However, COI-studies like paper 3 can contribute by demonstrating the relevance of mental health from a societal perspective: SSD is highly relevant from a societal perspective, although it does not correspond to any dramatic clinical picture. This societal relevance is particularly relevant when considering that the prevalence of SSD is two or three times higher than syndromal depression.

One more detail that indicates the relevance of SSD in very old persons in society is the fact that depressiveness among the elderly often goes unrecognized, which can mean higher costs than if recognized [89, 199, 200]. Consequently, a larger proportion of the COI for SSD and syndromal depression remains high in the elderly, while a smaller proportion remains high in younger adults as their depressiveness is recognized and treated [199, 201]. In paper 3 a detail that might support

results from paper 3 (which would be an underestimation for the municipal costs), I used the equation $y=1.45 x$. Together these equations gave $x=77.115$ and $y=111.817$. In a hypothetical situation with no SSD, but only ND in the population this would mean a total cost of 77.115 billion instead of 81.279 billion, which means that the prevalence of $12 \%$ SSD in society corresponds to excess costs of 4.164 (81.279-77.115) billion SEK. With consideration of inflation $2.80 \%$ according to the consumer price index and the year means of 2017 compared to 2015, the sum was 4.281 ( $4.164 \times 1.0280)$ with price levels of 2017. With the exchange rate of 9.96 $\mathrm{SEK}=1 €$ in June 2018 , the 4.281 SEK equals $0.430 €$. 
such a pattern of unrecognized depressiveness in the elderly was the fact that only 0.1 percent of all the healthcare contacts in five years for the participants consisted of visits to secondary psychiatric care, in contrast to a mean value of $9 \%$ in all adults of Sweden [202]. The National Board of Health and Welfare in Sweden wrote in a report in 2012 that a higher proportion of mental illness among the elderly compared to younger persons goes unrecognized, and if these elderly seek help, the help is given by primary care more often than for younger people [203]. In addition, according to the same report, elderly persons with mental illness get less adequate help if they do reach healthcare. In particular, they receive more medication and less psychotherapy regardless of their needs or preferences.

The fact the very old persons in our study had such a low frequency of contacts with secondary psychiatric care could have different valid explanations. Some explanations described in previous literature are that elderly persons with mental illness usually seek help for physical problems instead of their psychological problems, that there are barriers in the communication between old patients and healthcare personnel, and that psychiatric disorders give social stigma [196, 197, 204].

An inconsistency in the results of paper 3 was that the service utilization (measured as the number of healthcare visits or inpatient occasions) was not higher for persons with SSD Ever compared to ND Both, despite the pattern of higher direct costs in the same comparison. This inconsistency in the results might be explained by the different character of individual care contacts, as we did not consider which diagnosis was handled at each visit. For example single visits to healthcare could have been of longer duration or in other ways more expensive in persons with SSD Ever or Depr Ever, compared to ND.

Just as the results of paper 3 indicated the relevance of SSD in very old persons from a health economic perspective, paper 4, similarly, indicated the relevance of SSD in very old persons from physical and psychosocial perspectives. Paper 4 investigated the associations between SSD (in comparison to ND) and a variety of outcomes over eight years of follow-up. Some of the main results were that SSD was significantly associated with lower ADL, lower self-perceived health, lower cognitive functions, and higher degrees of loneliness and depressiveness, even though such associations with cognitive functions were no longer significant when adjusting for potential confounders. Mortality was higher for persons with SSD compared with ND according to the univariate regression, but this association subsided when adjusting for relevant covariates. Together these findings indicated that SSD compared with ND is associated with more serious health problems over a long period, although the symptomatology in SSD is seldom dramatic and although the duration of the affective episode might not be long.

Previous studies have shown that SSD and mild depressive conditions, just like syndromal depression, are associated with such negative outcomes in younger ages [35, 36, 138, 205, 206], but few studies have investigated this in very old age. Regarding the specific outcome of mortality for persons with SSD, the few previous studies have also shown diverging results, 
which makes our study particularly relevant. In the Leiden $85+$ study, SSD and depression were associated with mortality only for persons with loneliness [207], and in the BASE study the effects of SSD and depression on mortality were significant among the young old, but not among very old persons [208].

Blazer et al. 2001 argued that depressiveness among elderly persons may act on mortality only indirectly through multiple intermediate variables, why the pattern has been that the association between mortality and depression move towards unity when adjusting for relevant covariates [209]. Contrary to Rapp et al from the BASE study, we found that there was a significant association between SSD and mortality when adjusting only for sex and comorbidity.

Nevertheless, in our study the association subsided when adding the covariate I-ADL, and therefore our conclusion was (similar to the conclusion of Rapp et al) that there is an independent association between SSD and mortality in lower ages, but not in the very old [23, 208, 210]. This finding is also in agreement with those of Blazer et al, 2001, although their study was mostly on younger old persons [209].

\subsubsection{Longitudinal associations with SSD, and causality}

Regarding the associations between SSD and the different kinds of morbidity, one can also pose the question of whether these are causal associations or not - does this seemingly mild affective condition SSD really cause these strong negative effects in the long run? In order to answer this question, we will first discuss the concept of causality and its meaning. A frequently cited description of the concept of causality consists of the criteria presented by Sir Bradford Hill in 1965 [211]. The criteria indicating a causal relationship are 1) the strength of the association, 2) consistency between different studies, 3) the specificity of the association, 4) temporality, 5) biological gradient, 6) plausibility and 7) coherence with other studies. Since Hill's description was first given the criteria have been discussed and revised, and a modern condensed set of criteria can be found in Lewis 2011, where the above points three and seven have been excluded, and temporality is emphasized as the most elementary criterion [212]. There are four principal groups of causality, and most associations in nature belong to the group "non-necessary, nonsufficient" causal relations, while necessary but non-sufficient causal associations are rarer (with the tuberculosis bacteria and the tuberculosis infection as a concrete example) [28].

Commonly the term 'risk factor' is used instead of 'causal factor', as it is rare in nature to find factors meeting all the criteria of causality. Other concepts for expressing the complexity of causality in the context of mental health are "multiple levels of causation" (regarding when research spans across both larger social contexts and more detailed biological mechanisms) and "web of causation" in which a large number of factors interact in a web of multiple associations leading to an outcome ([213-215]; Figure 6). 


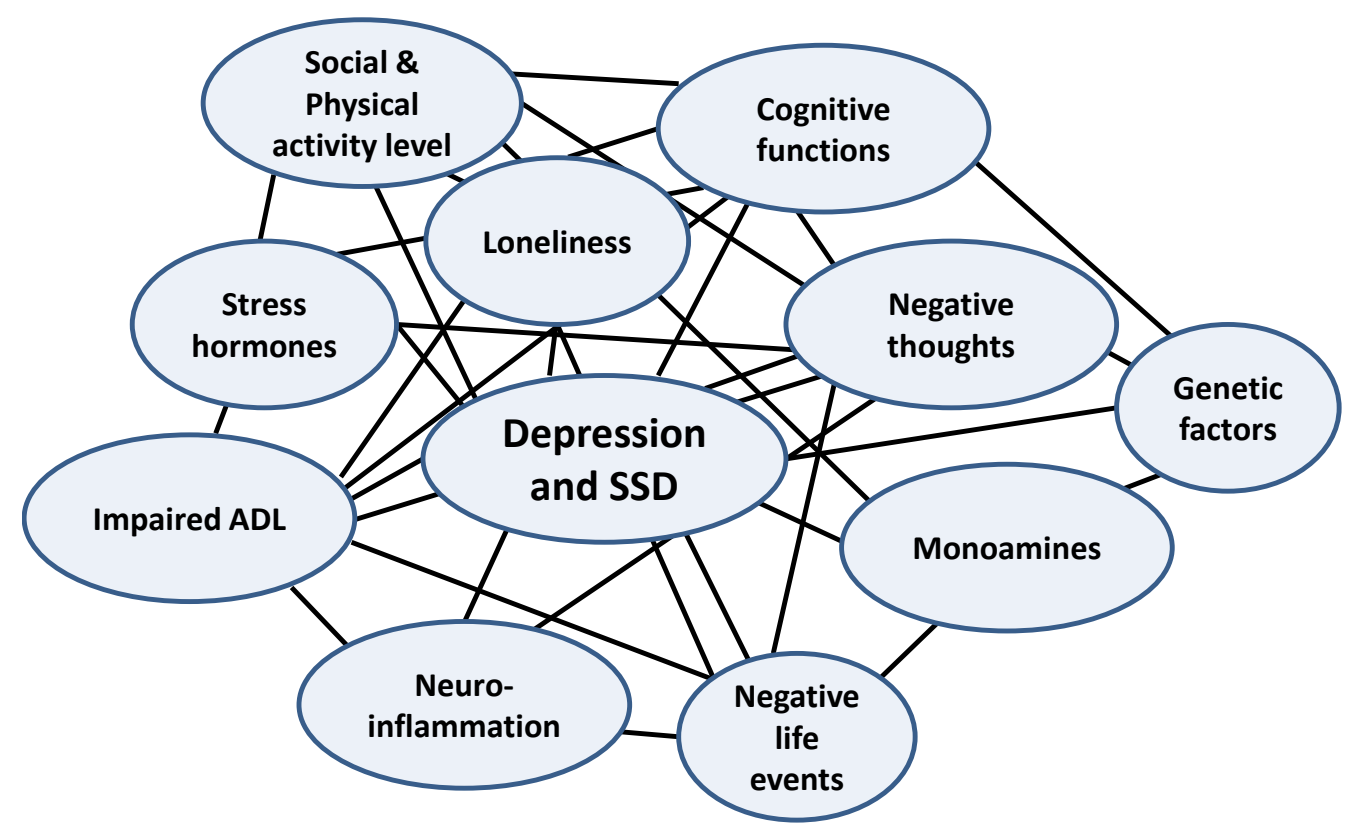

Figure 10. Schematic picture of the concept "web of causation", generally applied to the context of depressiveness with the conditions depression and SSD.

A criticism of equating risk factors and causal factors would be that some of the risk factors should be regarded as mediators (when they are just a link in a chain of processes in nature) rather than directly causative factors. Such remarks are hard to refute completely, which is why relevant covariates need to be included in the design and implementation of etiologic studies. The critical remarks about using the concept of causality in natural associations can in certain examples of depressiveness be answered by the finding that the specific association may be bidirectional or reciprocal between depressiveness and other factors [96, 216, 217].

If an association temporally goes in both directions, for example if a previous impairment of $\mathrm{ADL}$ is followed by an increase of depressiveness but also vice versa, then the complexity of the natural relationship appears clearly. An interpretation of our discussion above about causality would be that we can never be perfectly sure about whether specific associations correspond to causality, reverse causality or confounding. In this spirit it has been proposed that Hill's criteria and following revisions should be seen more as guidelines than criteria [212], as we can never reach complete certainty about causality in empirical studies of nature.

In our papers 3 and 4, temporality, plausibility and a certain relative strength in the associations could indicate causality, but as the time intervals were so long between the measurement of depressiveness and associated outcomes the temporality criteria can be questioned, and therefore we did not make such claims about causality. Through closer intervals between measurement of 
exposure and outcomes, and through more measure waves, one would have better possibilities to assess the question of causality. This has been exemplified in the thorough studies on the association between ADL and depression by Chen et al. 2012 with measurements every other year during a 10-year period [218], and on trajectories of depressiveness by Fishleder et al. 2016 with measurements every month during a six-month period [219].

Regarding causality and bidirectional associations, a surprising finding of our paper 4 was that the association between the presence of SSD and the outcome of cognitive impairment was not significant over time when adjusting for covariates. Previous studies on younger ages have indicated a generally bidirectional association between cognitions and depressiveness. Cognitive impairment is associated with an increased risk of depression, and depressive episodes are associated with cognitive decline and for example reduction of the size of hippocampus [96, 217, 220-222]. Why we did not find any such significant association could be explained by statistical interaction effects of comorbidity, or by differential loss of participants to follow-up (which is further commented upon in the methodological discussion 5.4).

In summary, papers 3 and 4 indicate that SSD compared to ND in very old persons is relevant for outcomes of economic costs in society, and for morbidity in the individual over a long period. In line with previous studies, we found a univariate association between SSD and mortality in very old age which subsided when adjusting for relevant covariates. As time intervals were long between measurements of depressiveness and the outcome variables, we cannot know whether the found associations were causal or not. In general, causal associations in nature are complex, and the picture of the web of causation for depressiveness is one way to describe this complexity.

\subsection{Significance of SSD in the very old, and the risks of medicalization}

\subsubsection{Significance of SSD in very old persons for the patient, for healthcare and for society}

The fact that the proportion of very old persons is growing in the demographic development worldwide, shows the particular importance of our study results from a societal perspective. Prevalence studies have indicated that SSD is two to three times more common than syndromal depression, so the sum of effects of each of these conditions might be equally great. Expressed in another way, the population-attributable fraction of health problems and quality of life might be equal for SSD and syndromal depression. A metaphor for the ratio between SSD and syndromal depression regarding clinical attention and the prevalence in the population is the picture of an iceberg (Figure 11). The syndromal or major depression that is diagnosed in clinical practice corresponds to the more visible but smaller part of the iceberg over the water surface, while the subsyndromal or subclinical depression that is usually not diagnosed in clinical practice corresponds to the less visible but larger part of the iceberg under the surface. 


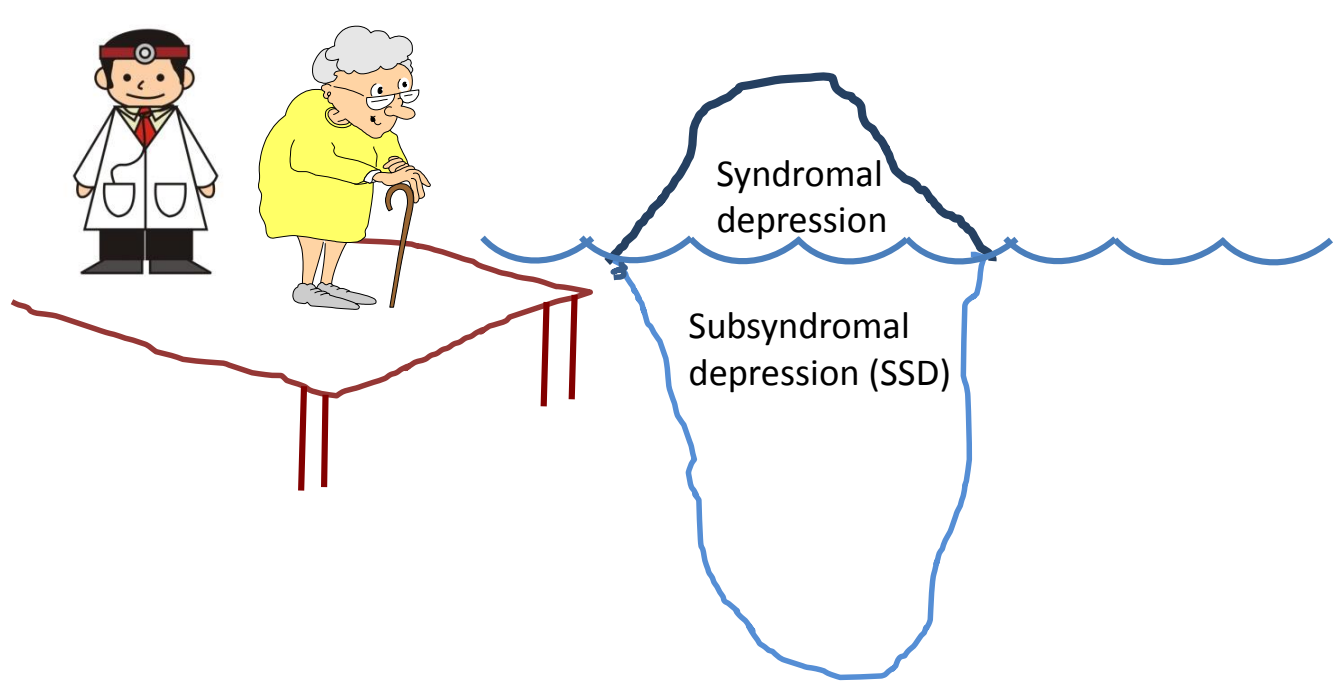

Figure 11. The metaphor of the iceberg, as a way to illustrate that SSD is more common but less recognized in clinical practice, compared to syndromal depression.

Possibly SSD is even more significant in the elderly compared to younger ages, as some studies have indicated that SSD is more common in old age [89, 223]. However, even if the populationattributable fraction of health problems is larger for SSD than for syndromal depression, that does not necessarily mean that SSD should be diagnosed or treated.

\subsubsection{Normality, medicalization and diagnostic practice}

To get a diagnosis might be beneficial for the individual, as both medical treatments and the insurance systems build on medical diagnoses. However, it is not self-evident that we should diagnose and treat SSD just because it is associated with lower quality of life, more social problems, and more physical and psychiatric morbidity. The importance of such associations might be minor for some individuals, while there might be disadvantages of both diagnosis and treatment. The disadvantages of a diagnosis can be the social stigma of mental illness, the consequence that the individual is passivated or maybe starts practicing a victim role within the sickness role. The disadvantages of treatment would be that the person with SSD and a mental illness diagnosis receives antidepressive medications that often have undesirable effects - in rare cases they lead to somatic or psychiatric inpatient care, or even death [127, 224-226].

In this context we can remind ourselves that disorders have at least three different aspects: the medical positivist or the objective aspect (disease), the subjective aspect (illness) and the social aspect (sickness) in relation to other individuals, groups and culture [225, 226]. Whether SSD should be regarded as a disorder to diagnose is thus not self-evident. Traditionally, the consequence of passing the boundary to a disorder, and getting the label of a diagnosis, has been that the individual qualifies for treatment. This has been the fact in many areas internationally 
and is still true today. From a sociological perspective the social sickness aspect entails both duties and privileges [225]. Standards are linked to the disorder or the diagnosis, and examples of duty include being called sick, and to comply with the community's recommended treatment. Privileges on the other hand can include a greater legitimacy for rest and support that come with a diagnosis. Within the field of psychiatric disorders, compared to somatic disorders, the sickness role appears somewhat differently, as the social stigma (disapproval of a person based on social characteristics) is more pronounced, and the legitimacy for rest and support is less as the mental disorder is generally less visible compared to somatic disorders such as a hip fracture [226].

In addition, the interactions between the different aspects of a disorder might be stronger in mental compared to somatic disorders. Examples of such interactions can be when a physician adjusts the choice of diagnosis for a medical certificate to what the insurance system promotes [personal experience], whereby social sickness is formed which in turn can lead to subjective illness for the individual. Another example would be when a person's subjective illness is mistakenly regarded as a disease, which leads to a diagnosis and consequent social sickness.

According to the theory formation of social constructionism, our discussions and perceptions of diagnoses and disorders correspond to a continuous constructing and reconstructing of the disorders in society [227, 228]. In this way, perceptions of a disease are constructed both in the sick person and in surrounding persons, in a dialog or a negotiation process between different persons. In today's society this dialog has changed compared with previously, as today it is more often conducted in social media. The changing content and form of the dialog influences the resulting sickness perception, for example when even elderly people increasingly communicate their psychiatric diagnoses with each other on Facebook and similar social media [229, 230]. Thus, by defining a phenomenon as abnormal or as a sickness, the phenomenon transforms from normality to pathology in its consequences through the social interaction (the so-called Thomas theorem [231]). Subjective illness is interpreted as objective disease, which leads to social sickness, which in turn changes the original aspects of illness and disease. Turning back to SSD, we would thus link a set of social standards (with duties and privileges) to the condition if we called this disease or pathology.

The tendency for a growing number of phenomena of our society to be regarded as sickness or pathology instead of normality or normal health, has been called medicalization [232, 233]. The discussion about medicalization has been closely associated with the social constructionist theory, and critical voices have stated that by expanding the concept of disease, medicalization leads to the passivation of individuals as well as to the expanding power of healthcare in society. As another possible example of this supposed expansion of healthcare in society (or medicalization), it was recently noted in the journal Lancet Psychiatry that people increasingly use the concept of "mental health problems" instead of "mental illness" or "mental disorders" [234]. With a wider concept, more citizens or patients are included, and thus including SSD in the DSM in the future would probably mean a step toward further medicalization, with advantages 
and disadvantages. Probably, there is also a parallel and opposite tendency in our society, which could be named demedicalization.

The DSM system still today mostly corresponds to a prevailing categorical diagnostic paradigm in psychiatry internationally, and it therefore resembles the classification system of Carl von Linné, in which different entities are classified in separate categories like buckets next to each other [5]. The alternative dimensional perspective on psychiatric disorders indicates the problem of distinguishing between normality and disease, but it also indicates the problem of comorbidity in psychiatry. The extent of comorbidity in psychiatry is large in general, which for the individual can mean that he or she receives different psychiatric diagnoses from year to year, even if the clinical picture is broadly similar, or otherwise (depending on the practice of the individual physician) that the individual receives several diagnoses at the same time [27, 235].

From an epidemiological perspective this is an important contributing factor to the widely varying numbers of prevalence of psychiatric diseases. For example the prevalence of depression in a study depends on whether psychiatric comorbidity (for example dementia) is an exclusion factor or not in the collection of data. Critics have, popularly, compared the DSM system in the psychiatric field with McDonald's hamburgers in the hamburger industry: the best reliability is not necessarily the best quality. As a continuation of the criticism of the DSM, hopes have been expressed that diagnostic registries in the future (ICD-11, DSM-6) will be built more on etiology than on topography [236]. Examples of such efforts to find a better basis for disorder classifications in the future are transdiagnostic studies with neurochemical, neuroanatomical and genetic categorizations in psychiatry, as well as the studies on the hexaflex model for psychological processes in psychotherapy (of Acceptance and Commitment Therapy (ACT)), although the processes are called a destructive normality and not disorders in ACT [235, 237, 238].

The terms 'transdiagnostic conditions', 'phenotypes' and 'subtypes of psychological problems' are used in order to disengage from the frames of the current DSM [16, 235]. Also, this thesis can be regarded as an effort to understand and describe psychological problems from a transdiagnostic perspective, or at least beyond the boundaries of normality and syndromal depression. Thereby, this thesis also contributes to a continuous social construction and reconstruction of our society, with parallel tendencies of medicalization and demedicalization according to the discussion above.

The relationship between advocates of different perspectives in the controversies about the hegemonic diagnosis models, the understanding of disorders and the process of medicalization has recurrently been tense, and the criticism of the prevailing paradigm of psychiatry has been called antipsychiatry [239]. As the antipsychiatric movement historically has been defined by representatives of psychiatry itself, and as psychiatry is a very wide field, the antipsychiatric movement naturally has recurrently been described as heterogeneous. During long periods this debate has also led to reduced cooperation between psychiatry and adjoining disciplines 
(sociology, psychology) [232]. Also, within psychiatry there has been a similar debate about the problems of diagnostic boundaries, for example the debate about the border between normality and pathology. However, the matter on where to draw the line between normality and disease is not only applicable to psychiatry, but also to the domains of somatic healthcare where some boundaries change over time [30].

Following the above discussion about the boundary between normality and pathology, I draw the preliminary conclusion that SSD is not definitely normality or disease or disorder, as such a determination can be a matter of parlance, insurance practices, medical scientific findings, hegemonic diagnosis models and consequent interactions between objective, subjective and social aspects of a disorder. An alternative formulation would be that SSD in the individual case of very old persons can be regarded as concerning either normal aging or disease. But no matter which, this thesis indicates that SSD in very old persons has significance for the health and for morbidity of the individual over time. Considering that SSD and depression have a higher prevalence and in particular a higher incidence compared with many other diseases in the population, they have been compared with respiratory tract infections. Schaefer et al. 2017 rhetorically compared episodes of mental illness with infections such as bronchitis or influenza [240]. The picture of bronchitis can thus also contribute to the understanding of SSD from an epidemiological perspective (Figure 12).

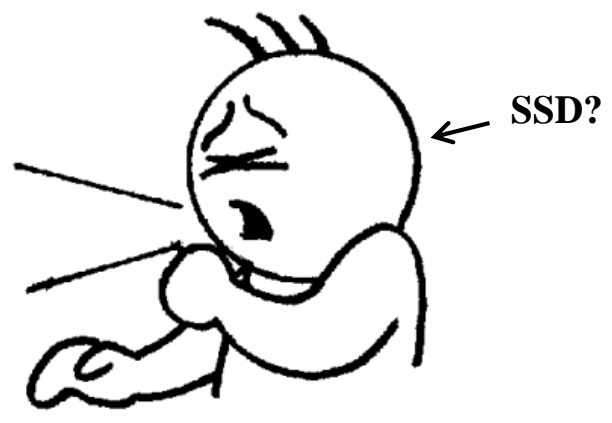

Figure 12. The metaphor of depressiveness for the soul or the psyche, which can be seen as an analogy to bronchitis for the body. The analogy builds on epidemiologic similarities between depressiveness and bronchitis.

\subsubsection{Prevention and treatment of SSD in very old persons}

To a certain extent, the significance of SSD in very old persons depends on the possibilities for intervention. If there were no interventions that made a difference in SSD, then it would be less relevant to identify this condition of mild depressiveness. There are several treatment options for SSD, but there is no generally accepted treatment model of SSD for the time being. 
Probably this is due partly to the lack of consensus about the definition of SSD, and partly also to the fact that few treatment studies for the condition have been undertaken [21]. Previous studies investigating for example CBT or the drug group SSRI indicate that these treatments work for SSD just as in more severe degrees of depressiveness, although the effect sizes are smaller for SSD than for syndromal depression [106-108]. For depression in the specific age group of very old persons there are no treatment guidelines either, although there are such for the larger category of elderly persons of age 65+ [109].

Common treatment options that have shown an effect for depression in elderly persons are CBT and the subtype problem-solving therapy, antidepressive medications, physical activity and collaborative care $[109,110]$. Because of the lack of evidence for the specific age group of very old persons, some physicians choose a nihilistic approach to the question of treatments, i.e. they argue that one can choose whichever treatment or no treatment at all with an equivalent scientific support. As in previous literature, Kok et al. 2017 advocates in the above-mentioned review an approach in which we extrapolate from evidence for treatment of younger ages to treatment of older ages [109, 122, 123].

Similar to our previous reasoning about heterogeneity in etiology and the clinical picture, and in addition to the guidelines for treatment of depressiveness in elderly persons, there are reasons to try to consider both comorbidity and transcultural aspects in the treatment choice for depressiveness. Also, evidence-based medicine means not only considering scientific findings but also the individual preferences for the choice of treatment [241, 242]. Thus, we would choose perhaps CBT or problem-solving therapy if there were psychosocial aspects in the medical history that could be handled constructively, or perhaps physical activity as a treatment if there were physical prerequisites, or else choose antidepressive medications if the depressive person preferred. Just as in syndromal depression and other psychiatric disorders, there can be good health economic and ethical reasons for choosing stepped care models in the design of prevention or treatment strategies for SSD in healthcare [27, 82, 117].

Also, there are reasons to choose more compound or multimodal treatment models of integrative character such as comprehensive geriatric care (CGA) or collaborative care, which have growing support in psychiatry, old age psychiatry, and geriatrics [110, 114, 116, 243]. These and similar treatment models seem particularly appropriate for elderly persons with SSD, as they build on holistic or person-centered care, which in turn are particularly appropriate for complex multifactorial conditions that are common in patients in old age psychiatry.

In summary, there is a lack of evidence for the prevention and treatment of SSD in very old persons, but extrapolation from treatment guidelines of younger age groups seems to be a fair and promising approach. This might include stepped care models, and the use of holistic and multimodal treatment models such as CGA and collaborative care. Improvement of mild depressive conditions can often be achieved with limited but individually adjusted interventions, while failure of therapy or more severe conditions demands more intensive interventions. 


\subsection{Methodological discussion}

The validity (consistency between reality and interpretation) of this thesis, and the question of whether the separate papers of the thesis project have contributed to the overall aims, are dependent on several factors. These will be commented upon in the following. The overall aim of the thesis was to investigate the unclear area between syndromal depression and non-depression in very old persons, and to investigate SSD or subthreshold depression in the very elderly. When initially formulating this overall aim, we assumed equivalence between the unclear area and SSD. However, I have gradually realized that SSD and the unclear area is not necessarily the same thing, which is why the validity of our definition of SSD and the validity of the thesis project are presented separately in the following.

\subsubsection{The validity of the definition of SSD in the thesis project}

The validity of our definition of the term SSD can be described by the following components [12]:

1. The content validity (i.e. whether the choice of domains and items is adequate for the aim, and how well the measurement instrument covers the subject in a convincing way) depends on the choice of GDS-15 (Appendix, annex 1) for the operationalization of SSD in the studies. To equalize SSD with a specific score range of GDS-15 is a simplification of reality, as SSD cannot definitely be caught by the instrument. Regarding the composition of items of the instrument, this has been well described previously, and the validity for measuring depression has been thoroughly investigated in many studies, although most studies were in other countries than Sweden [147, 148]. We chose to use the 15-item version of GDS instead of GDS-20 (which has been more common in clinical practice in Sweden) and instead of the original 30-item version of the instrument [150, $244,245]$. One aspect of the GDS-15 is that the instrument, like other scales, contains single items that are affected by bodily problems (even if the quest in the design of the scale was to avoid such items). For example items no. nine about doing new things, and no. 13 about energy are typically influenced in this way. This means there is a risk of getting an elevated score because of somatic comorbidity, despite our aim of investigating psychological or psychiatric problems. On the other hand, affective disorders have both somatic and psychological aspects, a fact that instead motivates the inclusion of some questions on somatic aspects in order to capture all aspects of the condition. In order to increase validity considering the dynamic character of depressive conditions, in paper 2 we chose to define the SSD group from two separate measurements of GDS-15. Thus, paper 2 differs from the other papers regarding the content validity. Also the cutoff between ND and SSD was changed from $1 / 2 p$ to $2 / 3 p$ for GDS-15 for papers 2-4 compared to paper 1 , which also means there is a variation of content validity between the studies. 
2. Criterion validity (or empirical validity, consisting of concurrent validity and more aspects):

- Concurrent validity: as the use of a depression screening scale for defining categories of depressiveness is a well-established method according to the literature, this seemed to be an effective and practical way to define SSD in the ELSA85 study, and in the separate papers [21]. A critical remark would be that a consequent use of DSM criteria for defining categories of depressiveness would be a more valid way, as DSM is often regarded as the gold standard. As there is no definition of SSD in this registry, the DSM was not an option. From the dimensional perspective on psychiatric disorders, screening scales also have advantages compared to a diagnostic structured interview, as they naturally measure the affective conditions in degrees or numbers. A principal disadvantage of GDS-15 is that this scale was not principally constructed to screen for SSD or to measure degrees of depressiveness, but to determine the presence of syndromal depression (and to do this from a categorical perspective). Using the scale for another purpose than that originally intended means a change in validity [12]. In addition, the positive predictive value is generally dependent on the prevalence of the condition in the sample, which is also different between SSD and syndromal depression. Thus, using GDS-15 for defining SSD was important for the criterion validity. Despite the advantages of using GDS-15, the fact that this scale was not constructed to measure SSD but something else (depression) consequently meant a risk that we might study something slightly different to what we intended.

3) The construct validity (the degree to which the screening instrument relates to other instruments and concepts) was not a central matter for the thesis project, even if such aspects were discussed within the frame of this thesis and the single papers.

\subsubsection{Internal validity for the thesis project as a whole:}

\subsubsection{Quantitative criteria for the assessment of validity}

The validity of the single papers or of the thesis project corresponds to how well the studies investigated the intended study object, which also means their degree of bias. There are at least two principal types of bias in the papers:

1. Selection bias:

- Non-participation was a substantial problem for the cohort study ELSA85 as $24 \%$ $(154 / 650)$ of the eligible population chose to refrain from participating. Whether this selection of participants was differential or not is unclear. In comparison with peers for the whole country, the participants had a similar distribution of sex, but a slightly lower educational level (paper 4). Thus, we cannot surely know if the sample was representative of very old persons in the country, although demographic data (Table 2 of this thesis frame, and Table 1 of papers 1-4) at 
baseline in general indicated a reasonable representability compared with very old persons in the country.

- Item non-response was generally a small problem for the thesis, as the response rate was high for most variables of the cohort study. For paper 4, two variables had a lower response rate, and these were handled with multiple imputations as a way of minimizing selection bias for the analyses. For the rest of the analyses, non-response was handled with listwise exclusion.

- Loss to follow-up was a methodological problem (particularly for papers 3 and 4) as in many longitudinal studies of very old persons, because of frailty and death. In paper 4 a detailed analysis of the attrition for the whole cohort study was made (Table 3), and it turned out that attrition was associated with lower ADL and lower cognitive function, a higher proportion of adapted housing, and more depressiveness. This differential attrition meant an increased risk of type two errors, i.e. an underestimation of real associations [167].

2. Information bias:

- Information bias was prevented in paper 1 through blinding for the category of depressiveness in steps 1-3 in the content analysis.

- Reproduction of preconceptions was prevented in study 1 through the rigor of the methodology in general, and through the efforts to increase reflexiveness.

- Recall bias was prevented by the longitudinal design with several measure waves instead of a cross-sectional design, and by using register data. Principal risks of using register data are the risks of under-reporting (sensitivity) and incorrect categorization (specificity). However the included register data were of good quality and these sources of error were considered small for the project.

- Misclassification bias was probably a relevant problem for the thesis, which corresponds to the sensitivity and specificity of the GDS-15 for defining SSD (described above). However, using GDS-15 principally means a risk of nondifferential misclassification with a risk of underestimation of the associations, which methodologically though is less serious than a differential misclassification [246].

- Response bias or reporting bias: under-reporting or over-reporting feelings of guilt or other symptoms are common in questions about alcohol consumption or about depressiveness. This type of information bias could have resulted in a misclassification bias if participants denied depressive symptoms despite having them. For paper 1, latent content analysis was used, which prevented this risk as the method entails interpretation of subtle or unspoken messages from the interviews. For the other papers the importance of this type of information bias was considered small, given a generally low to moderate degree of social stigma from depressive symptoms in the current cultural context.

As a way of preventing more general bias in the thesis project, different methods have been used in different papers (e.g. supplemental qualitative and quantitative methods, and different statistical methods in papers 2-4), which might be called triangulation of methods, or mixed 
methods in a wide sense [157, 247, 248]. However this triangulation of methods was not intended to compensate for any specific methodological problem, but rather to make the thesis project as versatile as possible.

\subsubsection{Qualitative criteria for the assessment of the validity}

In qualitative methodology there are partly different criteria for the assessment of a scientific study. Trustworthiness has been described as a more general criterion, containing the four components of confirmability, dependability, credibility and transferability [249].

1. Confirmability concerns how consistent the results are with collected data, i.e. whether a correct interpretation was made, whether appropriate statistical methods were used, and whether the researchers were neutral in the analyses. Did the researchers reproduce their preconceptions, or did they have an appropriate naturalistic openness to the data?

2. Dependability is the stability and instrumental consistency in the data collection and analysis over time.

3. Credibility concerns whether the results correspond to a reliable and accurate interpretation of data, and how well the study phenomenon is focused upon and the context considered. Credibility also includes the aspect of whether alternative interpretations have been considered.

4. Transferability is roughly the same as external validity or generalizability, which is commented upon in a separate section below, with comments on the research design and sample.

Of these four assessment criteria of qualitative methodology, dependability was considered a small problem for the thesis project, and measures were taken in the separate papers to increase the confirmability and the credibility (described in section 3.4 above). In paper 1, the confirmability and the risk of reproducing preconceptions was a particular challenge, which was prevented by taking field notes, by making reflexive notes before and between the interviews, by proofreading of the transcripts, by analysis according to a well-established method, and by validation discussions in the research group. The credibility was promoted by producing the manuscripts of the single papers in dialog between the different authors, by presentation of citations in paper 1 and tables and figures in the other papers, and by presenting the interpretation of findings in context in each manuscript.

Other criteria assessing quality or trustworthiness in qualitative methodology which have been proposed by Malterud 2001 are reflexiveness, relevance and validity [250]:

- Reflexiveness (how the research process rather than preconceptions has influenced the results and the efforts of the researchers to be aware of their preconceptions and perspectives): Particular field notes were written for paper 1, and a broad literature review with different theoretical perspectives was undertaken for all the papers. In addition, reflexiveness was promoted by writing the manuscripts in a dialog between the authors. 
- Validity (described by Malterud as a high quality of design, data collection and analysis, with a systematical method and the addressing of potential bias): section 5.4.1 above described some of the measures taken to promote the quality of data collection and analysis. Other measures were taken in the planning of the cohort study of ELSA85, in which I participated very little in the design, but more in the data collection. The population sample, the use of high quality data registers, and the long period of follow-up were strengths of the design as regards the validity. The combination of qualitative and quantitative methodology within the thesis project also strengthened the validity. In papers 2-4 several statistical methods were used in parallel, which contributed to addressing specific sources of bias. Examples of this were the adjustment for multiple comparisons in paper 3 , and the detailed analysis of missing data in paper 4 .

- Relevance (do the findings add something new or useful in relation to previous theory and knowledge): we based our planning of the design, data collection and analyses on previous literature, but we also made an effort to problematize our own findings in relation to previous literature. In general, our studies added new knowledge, as they were based on the identified knowledge gap about SSD in very old age, according to the introduction section 1.7. As several of our findings were in line with previous literature (on younger ages), our critical discussion of the findings in context was perhaps particularly important for increasing their relevance.

\subsubsection{External validity, generalizability or transferability:}

In the above, different aspects of internal validity are described for our operationalization of SSD and for the thesis project as a whole. The external validity (or generalizability or transferability) is also important for the interpretation of the thesis project as a whole, and corresponds to the degree which our research findings are applicable or transferable to other persons, outside our specific sample. As all four papers build on a population study, this means that the findings should be transferable to other similar populations around the world, which mainly means peers of men and women with the same degrees of depressiveness.

The generalizability was limited by selection bias (described more in section 5.4.2.1) with especially non-participation and differential loss to follow-up as two relevant problems, which together with the moderate sample size means that transferring the findings to other populations should be done with caution. In addition, depressiveness should be understood in a context of cultural and structural societal factors, so transferring the study findings to other cultural contexts could be problematic. For example, depressiveness can be triggered by other cultural symbols in another geographical area, which would change the relative significance of different markers for SSD (paper 2), or it can be associated with other health economic effects in a country with a different organization of healthcare. By presenting demographic data, describing the setting, and discussing the findings in their context, we have tried to clarify the possibilities to generalize for potential readers, or the possibilities to reproduce the studies by other researchers. Roughly, the samples and the design of the different papers offer great possibilities to generalize the results 
and the conclusion to the age group of very old persons with SSD in Sweden and neighboring countries.

\subsubsection{Reliability of the data collection in the thesis}

In addition to the internal and the external validity described above, the reliability or measurement noise also affects the quality of the study results. For paper 1 the reliability was increased by our efforts to ensure an effective and thoughtful interview technique, an appropriate design of the interview guide, and accuracy in the proofreading and analysis of the interview transcripts. For the quantitative measurement the reliability was ensured by training research coworkers to perform the data collection, and by using well-established assessment instruments (GDS-15, EQ-5D, MMSE and others) for the measurements.

A specific problem concerning reliability in psychiatric research is the participants' varying ability to understand the questions, and to recall things and report correctly. One factor that is assumed to have increased the reliability of the GDS-15 instrument is that the questions were posed orally by an occupational therapist at home, instead of the participants reading the questions. This procedure made it possible to clarify the meaning of the questions during the conversation. Also, the decision to use GDS-15 instead of other depression scales is assumed to have contributed to the reliability, as the instrument is constructed to be easily understood even for persons with mild cognitive impairments in old age. One inescapable problem regarding the reliability in studies of very old persons is the naturally occurring communication difficulties because of impairments of hearing, vision, speech and cognitive functions. As all co-workers involved in the data collection had a background of working in geriatric care, such communication difficulties were considered to be of minor importance for the data collection.

\subsubsection{Some comments on causality for the thesis project}

In studies of SSD in very old persons, as in epidemiological studies in general, there is a focus on identifying causality, as such knowledge is crucial for the prevention of illness in society. In order to identify a cause or an etiologic agent associated with a form of illness, a first step is to assess if there is an association according to a hypothesis, and if such an association is valid or spurious. Only then, and with an adequate research design, is it possible to assess whether the association is causal or better explained by confounders, and what type of causality it is. Most psychiatric disorders have the type of causal associations with agents termed 'non-necessary and non-sufficient', which also corresponds to webs of causation (described in section 5.2.2 above). Although we used four measure waves over a long period of eight years, our studies were not designed to assess temporality between SSD and other factors, as the time intervals between the measure waves were so long and irregular. It appears probable that the degree of depressiveness varied substantially in between the measure waves, so the temporalities of associations were uncertain. However, the findings from our longitudinal studies indicate valid associations over longer periods. In addition, as previous studies on persons of younger ages have had results indicating causality between depressiveness and the same factors (by dose-response, replication 
of findings, biological plausibility, and more [21, 31, 251-253]) it appears probable that the identified associations of our studies were at least partly causal.

In order to be able to assess the causality aspect, future studies should use more measure waves and closer time intervals between the waves, so that determinants for the dynamics of depressiveness will appear more clearly. In addition, more detailed diagnostic procedures compared with those used for our definition of SSD (by studying single depressive symptoms or by using specific transdiagnostic methods) would improve precision when identifying relevant phenotypes and studying associations on a more detailed level. Although the causal relations in mental illness are interwoven in complex networks, the scientific progress in the field gives reasons for optimism. 


\section{Conclusions and future perspectives}

This thesis had a general aim of investigating the unclear area between syndromal depression and non-depression in very old persons, and to investigate SSD or subthreshold depression in very old persons.

Papers 1 and 2 described experiences of being among persons with SSD in very old age, and the factors associated with SSD from a cross-sectional perspective. Paper 1 described SSD and compared it to ND and syndromal depression among the very old, through interviews characterized by naturalistic openness. By means of qualitative content analysis, four themes were identified which together give a comprehensive picture of how SSD is experienced in very old age. In the comparison of SSD, ND and syndromal depression, there were many similarities among all the categories, while differences were larger between SSD and depression compared with SSD and ND. This finding was interpreted as supporting the perception of SSD as something qualitatively (not just quantitatively) different from syndromal depression. Hopefully this study and future supplemental studies can contribute to a better understanding of SSD, indirectly clarify motives for interventions, and also lead to ideas about how to design interventions for SSD.

Paper 2 contributed to identifying factors associated with SSD among very old persons from a cross-sectional perspective, and according to the multivariate logistic and linear regressions, the hypothesized four domains (sociodemographic factors, declining physical functioning, neuropsychiatric factors, and existential factors) were significantly associated with SSD. One interpretation of the findings was that some markers for SSD are not included in the depression diagnosis criteria of DSM or ICD, and therefore it is important to be aware that there may be other signs or symptoms, apart from the classical ones, in order not to overlook significant depressiveness. By awareness of such other markers we can increase the chances of identifying depressiveness when comorbidity and transcultural aspects make the clinical picture complex.

Papers 3 and 4 showed that very old persons with SSD compared to ND were associated with negative outcomes of lower self-perceived health, elevated healthcare costs, and morbidity over a long period. The mean total direct healthcare costs per month of survival over five years were 1.45 times higher for persons with SSD at either baseline or the one-year follow-up compared to $\mathrm{ND}$, which according to our hypotheses was significant even when adjusting for somatic multimorbidity. Contrary to our hypotheses, cognitive dysfunction, chronic pain, lower ADL function, and lower physical function were not significantly associated with future healthcare costs in our multivariate regression.

According to our hypotheses, SSD compared to ND was associated with lower basic ADL and IADL, lower self-perceived health, lower cognitive function, a higher frequency of loneliness, and a higher degree of depressiveness in each of the four measure waves in eight years of follow-up. 
Contrary to our hypotheses, lower cognitive function was not significantly associated with SSD when adjusting for other covariate factors. Also contrary to our hypotheses, mortality over nine years was not elevated for very old persons with SSD compared to ND when adjusting for relevant covariates.

Previous studies have indicated that SSD is common in society - perhaps in particular among elderly persons - and our study findings indicate that SSD in very old persons is significant for the patients, for healthcare and for society. Even if the diagnostic registry DSM currently does not include SSD as a separate diagnosis, the condition is associated with both suffering and functional decline which both could motivate interventions for the single individual. Such interventions for this target group have been insufficiently studied. However, it is probable that the same kind of interventions as those for syndromal depression would also be appropriate for SSD, although both diagnostics and treatment should be adjusted for the individual and for the very old person's conditions. We have discussed from an epidemiological and from a social constructionist perspective whether SSD corresponds to disease and pathology or instead to normal aging, and a preliminary conclusion was that SSD should not be regarded as either normality or pathology in general. On the basis of the findings from the four papers of this thesis project, and of the literature in the subject field I make the following interpretation of SSD in very old persons, according to a biopsychosocial stress-diathesis model (Figure 13).

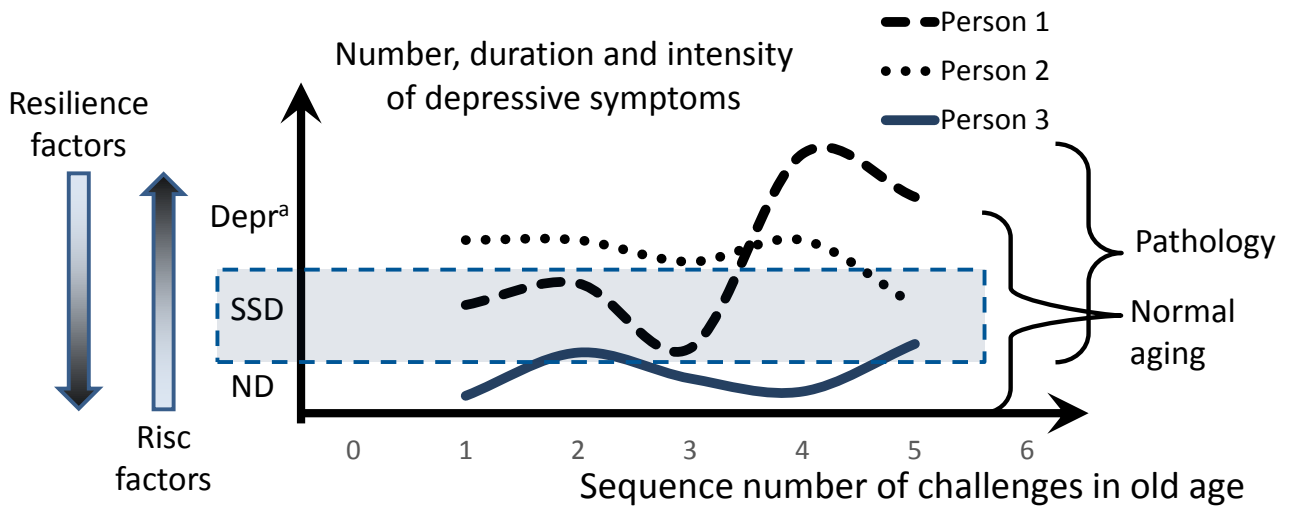

Figure13. An interpretation of SSD in very old persons according to the principles of the biopsychosocial stress-diathesis model, inspired by Aggernæs et al. 2017 [254]. The number, duration and intensity of depressive symptoms presented as a function of sequence number of challenges in aging. Resilience factors decrease the vulnerability of the individual, while risk factors increase it. SSD is situated in an area of the diagram where pathology and normal aging are overlapping. Note: ${ }^{a}=$ Depr stands for syndromal depression in the Figure. 
How we respond affectively to different challenges in old age is individually different as a result of individual resilience, risk factors and previous experiences. Therefore, the change (size and direction of the change of the individual curve in the diagram) in terms of number, duration and intensity of depressive symptoms, is different between individuals as a result of a specific challenge. SSD in one person at a certain time can be part of normal aging, while SSD with the same number of symptoms, intensity and duration in another person or another time, can mean pathology. Part of the depression area of the diagram might even correspond to normal aging, as the areas of normal aging and pathology overlap. An alternative view of SSD beyond these boundaries (perhaps when considering the general tendency of mood fluctuations for a person over a period of more than one year) would be that SSD corresponds to a general vulnerability (the sum of resilience and risk factors together), and this can be treated as a basic rule.

Different treatments would then fit different individuals depending on the type of vulnerability and on which agents has triggered a deterioration of the state of health. When existential matters as a form of risk factor contribute the most to the current vulnerability, then psychotherapy with elements of reminiscence therapy, problem-solving therapy or other CBT interventions could be good alternatives. When neurochemical mechanisms as another form of risk factor, contribute the most to the vulnerability, then antidepressive medications would be appropriate. Making an effort to assess the specific story of the very old person would thus facilitate a tailored intervention (as is increasingly used in the field of CBT), and would also ameliorate the diagnostic assessment. In many cases a combination of different treatment alternatives would also be appropriate. In addition, interventions to promote health or increase resilience more generally, by interventions such as behavioral activation or physical activity, would decrease vulnerability. According to our previous discussion, a stepped care model of interventions, collaborative care and the CGA model also appear to be good alternatives in the care of SSD and depressiveness as these models are all used with consideration of the complex and multifactorial aspects of how a very old person presents SSD.

The practical implications of this thesis are that organizations and personnel in healthcare and municipal care need to have an awareness and openness towards SSD in very old persons, as it may be important both for the health of the individual and society. With such awareness, physicians, nurses and other occupational categories in healthcare and municipal care could become better at identifying depressiveness, and could then, after a comprehensive assessment, decide what measures to take. In order to make a correct assessment of the health problems of a very old person, it is crucial for both diagnostics and treatment to consider comorbidity, transcultural aspects and the individual's thoughts and preferences altogether. By considering scientific evidence, clinical knowledge and the unique situation and preferences of the individual, the healthcare provided will be evidence-based and tailored for the individual. This would probably help the very old person to achieve a higher quality of life, a higher resilience, as well as a lower morbidity over time. 
Future studies could extend our understanding of possible causal aspects of the relationships among depressive symptoms and morbidity in old age by using tighter measure waves while also controlling for mediating factors clearly defined a priori. A more thorough analysis of single depressive symptoms or the use of transdiagnostic models in research could also improve the possibilities of disentangling moderators or relevant phenotypes in the heterogeneity of SSD and syndromal depression. Future qualitative studies could also deepen our understanding of SSD by investigating heterogeneity within and between categories of depressiveness, which is of relevance for diagnostics and treatment. In addition, there is a need for prevention studies of SSD in old persons, to assess whether interventions might reduce morbidity, societal costs and improve quality of life. 


\section{Tack (Acknowledgments)}

Till min huvudhandledare, docent Anna Milberg, för ditt fantastiska jobb som handledare. Du har uppmuntrat och inspirerat mig, och du har lärt mig det fina hantverket forskning på detaljnivå. Med ihärdighet, konstruktiva frågor och synpunkter, och med mycket beröm har du sporrat mig att läsa, undersöka, skriva och revidera. Det var precis vad jag behövde (:)! Det har varit ett stort nöje att ta del av din stora kompetens inom olika former av forskningsmetod, förutom att jag också mycket uppskattat våra samtal om vardagen, universitets- och sjukvårdsorganisation, familjelivet, och naturupplevelser.

Till min bihandledare, professor Jan Marcusson, för inspiration, för din kreativitet och dina visioner som hjälpt mig att utmana mig själv lite mer, att tro på mig själv, och att tänka lite friare. Du har även varit en inspiration när det gäller frågan om hur man kombinerar forskning, kliniskt arbete, fysisk och mental träning med estetik. Tack för det!

Till forskningsledare och min medförfattare docent Ewa Wressle, som fungerat som en bihandledare fastän du inte varit handledare formellt inom doktorandprojektet. Vilken generositet av dig! Tack för allt förarbete, huvudarbete och efterarbete i ELSA85-projektet, och för din hjälp som vägledare för mig i forskningsvärlden. Tack också för alla morgnar på geriatriska mottagningen, då du varit först på jobbet och satt på kaffebryggaren åt oss andra - underbart!

Till Mats Fredriksson vid Forum Östergötland, Linköping Universitet, som bistått mig många gånger med statistisk rådgivning på ett utvecklande sätt, och till min medförfattare Lars Bernfort för god utbildning och inspirerande och trevligt samarbete i den hälsoekonomiska analysen.

Till alla övriga medarbetare som varit med och samlat in data till ELSA85-projektet, och till alla studiedeltagare som ville delta i projektet och som därmed bidragit till kunskapsutvecklingen, och i förlängningen till en bättre vård, omsorg och ett bättre samhälle.

Till mina forskningskollegor Elisabet Classon, Katarina Fällman, Maria Johansson, Yvonne Johansson, Camilla Nilsberth, Katarina Nägga, Johanna Simmons, Björn Westerlind och Nicolina Wiklund på avdelningen för Geriatrik vid Linköpings universitet för trevligt och givande samarbete vid forskningsseminarier och andra tillställningar.

Till mina chefer som bidragit till denna forskning genom att ge mig tjänstledighet och stöd för forskningen: Marita Ström och Bengt-Olof Bengtsson vid Psykiatriska kliniken, och Kerstin Arbring, Sabina Olin Skoglund, Cilla Dobrov och Anne Ekdahl vid Geriatriska enheten av Universitetssjukhuset i Linköping.

Till min kliniska handledare inom psykiatrin, Jenö Lückl, som varit en klippa för mig när mitt jobb stundtals varit rörigt och splittrat mellan olika engagemang inom psykiatri, geriatrik, forskning, utbildning och psykoterapi. Till min rumskamrat Emil Gustafsson som förgyllt morgnar och eftermiddagar på jobbet genom små roliga betraktelser, skoj och uppmuntran i 
vardagens jobb: livet är en fest! Till alla fina kollegor inom geriatrisk och psykiatrisk sjukvård, vilka gör mitt jobb i vardagen så trevligt varje dag.

Till mina vänner Johan Lindkvist och Ambjörn Furenhed, vilka under många år bjudit mig på jättemånga fina och spännande samtal av nyfikenhet, filosofi, estetik, levnadsvisdom och roliga skämt. Tänk vad härligt att få träffa er regelbundet. Ni har bidragit till denna avhandling på ovanstående sätt, och genom mekanismer som ingen av oss helt kan förstå!

Till mina vänner och läkarkollegor Ted Cabreira, Oskar Lundgren och Mikael Nilsson som hjälpt mig med perspektiv, stöd och utveckling i jobb, fritid och forskning genom åren.

Till mina föräldrar Ulla och Johnny Ludvigsson för all den kärlek och allt stöd som ni givit mig under hela mitt liv. Till mina syskon Jonas, David, Mattias och Johanna - ni är och har varit mina fantastiska följeslagare, var och en av er är inspirerande förebilder för mig på sitt sätt.

Till min älskade Kattis för all kärlek och allt stöd du ger mig, och för alla fina stunder. Du ifrågasätter, och hjälper mig att ta nya steg i min utveckling - på ett uppfriskande, underhållande och härligt sätt. Du hjälper mig att tycka mer om mig själv.

Till mina barn Kajsa och Olle för att ni är er själva, för alla härliga stunder, och för att ni är mina läromästare i livet. Den här avhandlingen har jag skrivit med er kärlek och ert stöd. Tack för den hjälpen! 


\section{References}

1. Pauser, H., J. Lundmark, and B. Lindgren, Ny geropsykiatrisk vårdmodell möjliggör snabbt omhändertagande av äldre - en femårsrapport. Läkartidningen, 1989. 86(30-31): p. 2600-2603.

2. Horwitz, A.V., J.C. Wakefield, and L. Lorenzo-Luaces, History of depression, in The Oxford handbook of mood disorders R.J. DeRubeis and D.R. Strunk, Editors. 2016, Oxford University Press: New York.

3. Dewhurst, W.G., Melancholia and depression: from hippocratic times to modern times. J. Psychiatry Neurosci, 1992. 17: p. 81-83.

4. Richet, C., An Address ON ANCIENT HUMORISM AND MODERN HUMORISM: Delivered at the International Congress of Physiology held in Vienna, September 27th to 30th. Br Med J, 1910. 2(2596): p. 921-6.

5. von Linné, C., Linnés Systema morborum. Uppsala universitets årsskrift. 1957: Lundequist.

6. Bujalkova, M., S. Straka, and A. Jureckova, Hippocrates' humoral pathology in nowaday's reflections. Bratisl Lek Listy, 2001. 102(10): p. 489-92.

7. World Health Organization, ICD-10 Classification of Mental and Behavioural Disorders (The): Diagnostic Criteria for Research. 1993: World Health Organization.

8. Suris, A., R. Holliday, and C.S. North, The Evolution of the Classification of Psychiatric Disorders. Behav Sci (Basel), 2016. 6(1).

9. Kawa, S. and J. Giordano, A brief historicity of the Diagnostic and Statistical Manual of Mental Disorders: issues and implications for the future of psychiatric canon and practice. Philos Ethics Humanit Med, 2012. 7: p. 2.

10. American Psychiatric Association. Diagnostic and statistical manual of mental disorders : DSM-5. 2013; 5th ed.:[

11. Kendler, K.S., R.A. Munoz, and G. Murphy, The development of the Feighner criteria: a historical perspective. Am J Psychiatry, 2010. 167(2): p. 134-42.

12. Goldstein, J.M., S. Cherkerzian, and J.C. Simpson, Validity: Definitions and Applications to Psychiatric Research, in Textbook of Psychiatric Epidemiology, M.T. Tsuang, M. Tohen, and P.B. Jones, Editors. 2011, John Wiley \& Sons, Ltd.

13. Robins, E. and S.B. Guze, Establishment of diagnostic validity in psychiatric illness: its application to schizophrenia. Am J Psychiatry, 1970. 126(7): p. 983-7.

14. Goldberg, D., Plato versus Aristotle: categorical and dimensional models for common mental disorders. Compr Psychiatry, 2000. 41(2 Suppl 1): p. 8-13.

15. Judd, L.L., Dimensional paradigm of the long-term course of unipolar major depressive disorder. Depress Anxiety, 2012. 29(3): p. 167-71.

16. Forbes, M.K., et al., Beyond comorbidity: Toward a dimensional and hierarchical approach to understanding psychopathology across the life span. Dev Psychopathol, 2016. 28(4pt1): p. 971986.

17. Judd, L.L., et al., Subsyndromal symptomatic depression: a new mood disorder? J Clin Psychiatry, 1994. 55 Suppl: p. 18-28.

18. Sadek, N. and J. Bona, Subsyndromal symptomatic depression: a new concept. Depress Anxiety, 2000. 12(1): p. 30-9.

19. Judd, L.L., H.S. Akiskal, and M.P. Paulus, The role and clinical significance of subsyndromal depressive symptoms (SSD) in unipolar major depressive disorder. J Affect Disord, 1997. 45(1-2): p. 5-17; discussion 17-8.

20. Lyness, J.M., et al., The clinical significance of subsyndromal depression in older primary care patients. Am J Geriatr Psychiatry, 2007. 15(3): p. 214-23. 
21. Meeks, T.W., et al., A tune in "a minor" can "b major": a review of epidemiology, illness course, and public health implications of subthreshold depression in older adults. J Affect Disord, 2011. 129(1-3): p. 126-42.

22. Rodriguez, M.R., et al., Definitions and factors associated with subthreshold depressive conditions: a systematic review. BMC Psychiatry, 2012. 12: p. 181.

23. Cuijpers, P., et al., Differential mortality rates in major and subthreshold depression: metaanalysis of studies that measured both. Br J Psychiatry, 2013. 202(1): p. 22-7.

24. Sheikh, J.A. and J.A. Yeasavage, Geriatric Depression Scale (GDS): recent findings and development of a shorter version., in Clinical Gerontology: A Guide to Assessment and Intervention, T.L. Brink, Editor. 1986, Howarth Press: New York.

25. Chachamovich, E., et al., Impact of major depression and subsyndromal symptoms on quality of life and attitudes toward aging in an international sample of older adults. Gerontologist, 2008. 48(5): p. 593-602.

26. Murphy, J.M., Symptom Scales and Diagnostic Schedules in Adult Psychiatry, in Textbook of Psychiatric Epidemiology, M.T. Tsuang, M. Tohen, and P.B. Jones, Editors. 2011, John Wiley \& Sons, Ltd.

27. Cross, S.P. and I. Hickie, Transdiagnostic stepped care in mental health. Public Health Res Pract, 2017. 27(2).

28. Gordis, L., Epidemiology. 2014, Elsevier/Saunders: Philadelphia, PA p. 21-22.

29. Insel, T.R., Translating scientific opportunity into public health impact: a strategic plan for research on mental illness. Arch Gen Psychiatry, 2009. 66(2): p. 128-33.

30. Schwartz, L.M. and S. Woloshin, Changing disease definitions: implications for disease prevalence. Analysis of the Third National Health and Nutrition Examination Survey, 1988-1994. Eff Clin Pract, 1999. 2(2): p. 76-85.

31. Ayuso-Mateos, J.L., et al., From depressive symptoms to depressive disorders: the relevance of thresholds. Br J Psychiatry, 2010. 196(5): p. 365-71.

32. Braam, A.W., et al., Depression, subthreshold depression and comorbid anxiety symptoms in older Europeans: results from the EURODEP concerted action. J Affect Disord, 2014. 155: p. 26672.

33. Forsell, Y., A three-year follow-up of major depression, dysthymia, minor depression and subsyndromal depression: results from a population-based study. Depress Anxiety, 2007. 24(1): p. 62-5.

34. Beck, A., et al., Severity of depression and magnitude of productivity loss. Ann Fam Med, 2011. 9(4): p. 305-11.

35. Beekman, A.T., et al., The natural history of late-life depression: a 6-year prospective study in the community. Arch Gen Psychiatry, 2002. 59(7): p. 605-11.

36. Han, L., et al., 12-month cognitive outcomes of major and minor depression in older medical patients. Am J Geriatr Psychiatry, 2008. 16(9): p. 742-51.

37. Laborde-Lahoz, P., et al., Subsyndromal depression among older adults in the USA: prevalence, comorbidity, and risk for new-onset psychiatric disorders in late life. Int I Geriatr Psychiatry, 2014.

38. Glassock, R., A. Denic, and A.D. Rule, When kidneys get old: an essay on nephro-geriatrics. J Bras Nefrol, 2017. 39(1): p. 59-64.

39. Keller, J.N., Age-related neuropathology, cognitive decline, and Alzheimer's disease. Ageing Res Rev, 2006. 5(1): p. 1-13.

40. Salthouse, T.A., Neuroanatomical substrates of age-related cognitive decline. Psychol Bull, 2011. 137(5): p. 753-84.

41. Pink, A., et al., Cortical Thickness and Depressive Symptoms in Cognitively Normal Individuals: The Mayo Clinic Study of Aging. J Alzheimers Dis, 2017. 58(4): p. 1273-1281. 
42. Mather, M., The Affective Neuroscience of Aging. Annu Rev Psychol, 2016. 67: p. 213-38.

43. Bewernick, B.H. and T.E. Schlaepfer, Chronic depression as a model disease for cerebral aging. Dialogues Clin Neurosci, 2013. 15(1): p. 77-85.

44. Skoog, I., Bridge Over Troubled Water. Am J Geriatr Psychiatry, 2017. 25(4): p. 340-341.

45. Almeida, D.M., et al., The speedometer of life: Stress, health and aging. , in Handbook of the psychology of aging, K.W. Schaie and S.L. Willis, Editors. 2011, Elsevier Academic Press: San Diego, CA, US. p. pp. 191-206.

46. Blanchflower, D.G. and A.J. Oswald, Is well-being U-shaped over the life cycle? Soc Sci Med, 2008. 66(8): p. 1733-49.

47. Statistics", O.f.N. Measuring National Well-being : At what age is Personal Well-being the highest? 2016 [cited 2018 May 18th].

48. Kunzmann, U., T.D. Little, and J. Smith, Is age-related stability of subjective well-being a paradox? Cross-sectional and longitudinal evidence from the Berlin Aging Study. Psychol Aging, 2000. 15(3): p. 511-26.

49. Ouwehand, C., D.T. de Ridder, and J.M. Bensing, A review of successful aging models: proposing proactive coping as an important additional strategy. Clin Psychol Rev, 2007. 27(8): p. 873-84.

50. Nygren, B., et al., Resilience, sense of coherence, purpose in life and self-transcendence in relation to perceived physical and mental health among the oldest old. Aging Ment Health, 2005. 9(4): p. 354-62.

51. Charles, S.T. and L.L. Carstensen, Social and emotional aging. Annu Rev Psychol, 2010. 61: p. 383409.

52. Allen, A.B. and M.R. Leary, Self-Compassion, Stress, and Coping. Soc Personal Psychol Compass, 2010. 4(2): p. 107-118.

53. Audulv, A., et al., Coping, adapting or self-managing - what is the difference? A concept review based on the neurological literature. J Adv Nurs, 2016. 72(11): p. 2629-2643.

54. Bjorklof, G.H., et al., Coping and depression in old age: a literature review. Dement Geriatr Cogn Disord, 2013. 35(3-4): p. 121-54.

55. Atkinson, P.A., C.R. Martin, and J. Rankin, Resilience revisited. J Psychiatr Ment Health Nurs, 2009. 16(2): p. 137-45.

56. Tusaie, K. and J. Dyer, Resilience: a historical review of the construct. Holist Nurs Pract, 2004. 18(1): p. 3-8; quiz 9-10.

57. MacLeod, S., et al., The impact of resilience among older adults. Geriatr Nurs, 2016. 37(4): p. 26672.

58. Shen, $\mathrm{K}$. and Y. Zeng, The association between resilience and survival among Chinese elderly. Demogr Res, 2010. 23(5): p. 105-116.

59. Hayman, K.J., N. Kerse, and N.S. Consedine, Resilience in context: the special case of advanced age. Aging Ment Health, 2017. 21(6): p. 577-585.

60. Lundman, B., et al., Inner strength--a theoretical analysis of salutogenic concepts. Int J Nurs Stud, 2010. 47(2): p. 251-60.

61. Eriksson, M. and B. Lindstrom, Validity of Antonovsky's sense of coherence scale: a systematic review. J Epidemiol Community Health, 2005. 59(6): p. 460-6.

62. Wadensten, B., An analysis of psychosocial theories of ageing and their relevance to practical gerontological nursing in Sweden. Scand J Caring Sci, 2006. 20(3): p. 347-54.

63. Bowling, A., Aspirations for older age in the 21st century: what is successful aging? Int J Aging Hum Dev, 2007. 64(3): p. 263-97.

64. Wadensten, B., Introducing older people to the theory of gerotranscendence. J Adv Nurs, 2005. 52(4): p. 381-8. 
65. Vahia, I.V., et al., Developing a dimensional model for successful cognitive and emotional aging. Int Psychogeriatr, 2012. 24(4): p. 515-23.

66. Cosco, T.D., et al., Operational definitions of successful aging: a systematic review. Int Psychogeriatr, 2014. 26(3): p. 373-81.

67. Rowe, J.W. and R.L. Kahn, Successful aging. Gerontologist, 1997. 37(4): p. 433-40.

68. Carver, L.F. and D. Buchanan, Successful aging: considering non-biomedical constructs. Clin Interv Aging, 2016. 11: p. 1623-1630.

69. Charles, S.T., Strength and vulnerability integration: a model of emotional well-being across adulthood. Psychol Bull, 2010. 136(6): p. 1068-91.

70. Hinck, S., The lived experience of oldest-old rural adults. Qual Health Res, 2004. 14(6): p. 779-91.

71. Sjoberg, L., et al., Secular changes in the relation between social factors and depression: a study of two birth cohorts of Swedish septuagenarians followed for 5 years. J Affect Disord, 2013. 150(2): p. 245-52.

72. Christensen, K., et al., Ageing populations: the challenges ahead. Lancet, 2009. 374(9696): p. 1196-208.

73. Falk, H., et al., Functional disability and ability 75-year-olds: a comparison of two Swedish cohorts born 30 years apart. Age Ageing, 2014. 43(5): p. 636-41.

74. NIH, N.I.o.A., Why Population Aging Matters: A Global Perspective. 2007: National Institute on Aging, National Institutes of Health, U.S. Department of Health and Human Services. United States. .

75. Collerton, J., et al., Health and disease in 85 year olds: baseline findings from the Newcastle 85+ cohort study. BMJ, 2009. 339: p. b4904.

76. Baltes, P.B. and J. Smith, New frontiers in the future of aging: from successful aging of the young old to the dilemmas of the fourth age. Gerontology, 2003. 49(2): p. 123-35.

77. Mathers, C.D. and D. Loncar, Projections of global mortality and burden of disease from 2002 to 2030. PLoS Med, 2006. 3(11): p. e442.

78. Global Burden of Disease Study, C., Global, regional, and national incidence, prevalence, and years lived with disability for 301 acute and chronic diseases and injuries in 188 countries, 19902013: a systematic analysis for the Global Burden of Disease Study 2013. Lancet, 2015. 386(9995): p. 743-800.

79. IsHak, W.W., et al., Quality of life: the ultimate outcome measure of interventions in major depressive disorder. Harv Rev Psychiatry, 2011. 19(5): p. 229-39.

80. Cassano, P. and M. Fava, Depression and public health: an overview. J Psychosom Res, 2002. 53(4): p. 849-57.

81. Socialstyrelsen, Nationella riktlinjer för vård vid depression och ångestsyndrom - Stöd för styrning och ledning: 2017-12-4. 2017: Socialstyrelsen.

82. (NICE)", T.N.I.f.H.a.C.E. Depression in adults: recognition and management. Clinical guideline [CG90]. 2009 April 2018 13th of May, 2018].

83. Beekman, A.T., J.R. Copeland, and M.J. Prince, Review of community prevalence of depression in later life. Br J Psychiatry, 1999. 174: p. 307-11.

84. Steel, Z., et al., The global prevalence of common mental disorders: a systematic review and meta-analysis 1980-2013. Int J Epidemiol, 2014. 43(2): p. 476-93.

85. Ferrari, A.J., et al., Global variation in the prevalence and incidence of major depressive disorder: a systematic review of the epidemiological literature. Psychol Med, 2013. 43(3): p. 471-81.

86. Sjoberg, L., et al., Prevalence of depression: Comparisons of different depression definitions in population-based samples of older adults. J Affect Disord, 2017. 221: p. 123-131.

87. Skoog, I., Psychiatric disorders in the elderly. Can J Psychiatry, 2011. 56(7): p. 387-97. 
88. Fiske, A., J.L. Wetherell, and M. Gatz, Depression in older adults. Annu Rev Clin Psychol, 2009. 5: p. 363-89.

89. Haigh, E.A.P., et al., Depression Among Older Adults: A 20-Year Update on Five Common Myths and Misconceptions. Am J Geriatr Psychiatry, 2018. 26(1): p. 107-122.

90. Bergdahl, E., et al., Depression among the oldest old: the Umea 85+ study. Int Psychogeriatr, 2005. 17(4): p. 557-75.

91. Sigstrom, R., et al., Depressive spectrum states in a population-based cohort of 70-year olds followed over 9 years. Int J Geriatr Psychiatry, 2018.

92. Tsopelas, $\mathrm{C}$., et al., Neuropathological correlates of late-life depression in older people. $\mathrm{Br} \mathrm{J}$ Psychiatry, 2011. 198(2): p. 109-14.

93. Tadayonnejad, R. and O. Ajilore, Brain network dysfunction in late-life depression: a literature review. J Geriatr Psychiatry Neurol, 2014. 27(1): p. 5-12.

94. Alexopoulos, G.S., Depression in the elderly. Lancet, 2005. 365(9475): p. 1961-70.

95. Lebedeva, A., et al., Structural brain changes associated with depressive symptoms in the elderly with Alzheimer's disease. J Neurol Neurosurg Psychiatry, 2014. 85(8): p. 930-5.

96. Gothe, F., et al., Cerebrovascular diseases and depression: epidemiology, mechanisms and treatment. Panminerva Med, 2012. 54(3): p. 161-70.

97. Gulmann, N.C., Depressionssjukdomar och andra förstämningssyndrom, in Gerontopsykiatri, N.C. Gulmann, Editor. 2003, Studentlitteratur: Lund. p. 134-151.

98. Amore, M., et al., Beyond nosography of depression in elderly. Arch Gerontol Geriatr, 2007. 44 Suppl 1: p. 13-22.

99. Mehta, M., et al., Depressive symptoms in late life: associations with apathy, resilience and disability vary between young-old and old-old. Int J Geriatr Psychiatry, 2008. 23(3): p. 238-43.

100. Pantzar, A., et al., Cognitive deficits in unipolar old-age depression: a population-based study. Psychol Med, 2014. 44(5): p. 937-47.

101. Lapierre, S., et al., A systematic review of elderly suicide prevention programs. Crisis, 2011. 32(2): p. 88-98.

102. Alexopoulos, G.S., et al., Assessment of late life depression. Biol Psychiatry, 2002. 52(3): p. 16474.

103. Herrmann, L.L., G.M. Goodwin, and K.P. Ebmeier, The cognitive neuropsychology of depression in the elderly. Psychol Med, 2007. 37(12): p. 1693-702.

104. Sachs-Ericsson, N., et al., A longitudinal study of differences in late- and early-onset geriatric depression: depressive symptoms and psychosocial, cognitive, and neurological functioning. Aging Ment Health, 2013. 17(1): p. 1-11.

105. Hegeman, J.M., et al., Phenomenology of depression in older compared with younger adults: meta-analysis. Br J Psychiatry, 2012. 200(4): p. 275-81.

106. Barbui, C., et al., Efficacy of antidepressants and benzodiazepines in minor depression: systematic review and meta-analysis. Br J Psychiatry, 2011. 198(1): p. 11-6, sup 1.

107. Cuijpers, P., et al., Psychotherapy for subclinical depression: meta-analysis. Br J Psychiatry, 2014. 205(4): p. 268-74.

108. Cherubini, A., et al., Subthreshold depression in older subjects: an unmet therapeutic need. J Nutr Health Aging, 2012. 16(10): p. 909-13.

109. Kok, R.M. and C.F. Reynolds, 3rd, Management of Depression in Older Adults: A Review. JAMA, 2017. 317(20): p. 2114-2122.

110. Gilbody, S., et al., Effect of Collaborative Care vs Usual Care on Depressive Symptoms in Older Adults With Subthreshold Depression: The CASPER Randomized Clinical Trial. JAMA, 2017. 317(7): p. 728-737. 
111. Socialstyrelsen, Personligt ombud för personer med psykiska funktionshinder - En sexårsuppföljning av tio försöksverksamheter 2004.

112. Thota, A.B., et al., Collaborative care to improve the management of depressive disorders: a community guide systematic review and meta-analysis. Am J Prev Med, 2012. 42(5): p. 525-38.

113. Grochtdreis, T., et al., Cost-effectiveness of collaborative care for the treatment of depressive disorders in primary care: a systematic review. PLoS One, 2015. 10(5): p. e0123078.

114. Ellis, G., et al., Comprehensive geriatric assessment for older adults admitted to hospital. Cochrane Database Syst Rev, 2017. 9: p. CD006211.

115. Ekerstad, N., et al., Is the acute care of frail elderly patients in a comprehensive geriatric assessment unit superior to conventional acute medical care? Clin Interv Aging, 2017. 12: p. 1-9.

116. Blazer, D.G., Psychiatry and the oldest old. Am J Psychiatry, 2000. 157(12): p. 1915-24.

117. Van't Veer-Tazelaar, P., et al., Cost-effectiveness of a stepped care intervention to prevent depression and anxiety in late life: randomised trial. Br J Psychiatry, 2010. 196(4): p. 319-25.

118. Silfvernagel, K., et al., Individually tailored internet-based cognitive behaviour therapy for older adults with anxiety and depression: a randomised controlled trial. Cogn Behav Ther, 2017: p. 115.

119. Beyer, J.L. and K.G. Johnson, Advances in Pharmacotherapy of Late-Life Depression. Curr Psychiatry Rep, 2018. 20(5): p. 34.

120. Kukreja, S., et al., Polypharmacy in psychiatry: a review. Mens Sana Monogr, 2013. 11(1): p. 8299.

121. Sadavoy, J., An integrated model for defining the scope of psychogeriatrics: the five Cs. Int Psychogeriatr, 2009. 21(5): p. 805-12.

122. Karlsson, I., Depressiv sjukdom vid åldrandet. Äldrepsykiatri -Kliniska riktlinjer för utredning och behandling, ed. K. Sparring Björkstén. 2013: Svenska Psykiatriska Föreningen (SPF) och Gothia Fortbildning $A B$.

123. Steffens, D.C. and D.G. Blazer, Mood Disorders, in Essentials of Geriatric Psychiatry, D.G. Blazer and D.C. Steffens, Editors. 2012, American Psychiatric Publishing.

124. Parker, G., et al., Defining melancholia: A core mood disorder. Bipolar Disord, 2017. 19(3): p. 235237.

125. Kydd, A. and A. Fleming, What doctors need to know: Prescribing or not for the oldest old. Maturitas, 2016. 90: p. 9-16.

126. Maj, M., When does depression become a mental disorder? Br J Psychiatry, 2011. 199(2): p. 85-6.

127. Wakefield, J.C., False positives in psychiatric diagnosis: implications for human freedom. Theor Med Bioeth, 2010. 31(1): p. 5-17.

128. Heok, K.E. and R. Ho, The many faces of geriatric depression. Curr Opin Psychiatry, 2008. 21(6): p. 540-5.

129. Pepersack, T., et al., Correlates of unrecognized depression among hospitalized geriatric patients. J Psychiatr Pract, 2006. 12(3): p. 160-7.

130. Hedberg, P., et al., Purpose in life over a five-year period: a longitudinal study in a very old population. Int Psychogeriatr, 2011. 23(5): p. 806-13.

131. Katon, W.J., et al., Increased medical costs of a population-based sample of depressed elderly patients. Arch Gen Psychiatry, 2003. 60(9): p. 897-903.

132. Unutzer, J., et al., Depressive symptoms and the cost of health services in HMO patients aged 65 years and older. A 4-year prospective study. JAMA, 1997. 277(20): p. 1618-23.

133. Leibson, C.L., et al., Direct medical costs and source of cost differences across the spectrum of cognitive decline: a population-based study. Alzheimers Dement, 2015. 11(8): p. 917-32.

134. Reuben, D.B., et al., The effect of self-reported and performance-based functional impairment on future hospital costs of community-dwelling older persons. Gerontologist, 2004. 44(3): p. 401-7. 
135. Lazkani, A., et al., Healthcare costs associated with elderly chronic pain patients in primary care. Eur J Clin Pharmacol, 2015. 71(8): p. 939-47.

136. Pitkala, K.H., et al., Effects of psychosocial group rehabilitation on health, use of health care services, and mortality of older persons suffering from loneliness: a randomized, controlled trial. J Gerontol A Biol Sci Med Sci, 2009. 64(7): p. 792-800.

137. Hajek, A., et al., Disentangling the complex relation of disability and depressive symptoms in old age - findings of a multicenter prospective cohort study in Germany. Int Psychogeriatr, 2017. 29(6): p. 885-895.

138. Callahan, C.M., et al., Longitudinal study of depression and health services use among elderly primary care patients. J Am Geriatr Soc, 1994. 42(8): p. 833-8.

139. Houtjes, W., et al., The impact of an unfavorable depression course on network size and loneliness in older people: a longitudinal study in the community. Int J Geriatr Psychiatry, 2014. 29(10): p. 1010-7.

140. Nagga, K., et al., Health-related factors associated with hospitalization for old people: comparisons of elderly aged 85 in a population cohort study. Arch Gerontol Geriatr, 2012. 54(2): p. 391-7.

141. EuroQol, G., EuroQol--a new facility for the measurement of health-related quality of life. Health Policy, 1990. 16(3): p. 199-208.

142. Grimby, G., et al., Dependence and perceived difficulty in daily activities in community-living stroke survivors 2 years after stroke: a study of instrumental structures. Stroke, 1998. 29(9): p. 1843-9.

143. Folstein, M.F., S.E. Folstein, and P.R. McHugh, "Mini-mental state". A practical method for grading the cognitive state of patients for the clinician. J Psychiatr Res, 1975. 12(3): p. 189-98.

144. Regard, M., Cognitive rigidity and flexibility: A neuropsychological study. 1981, University of Victoria. p. PhD. Dissertation.

145. Reitan, R.M., Trail Making Test: manual for administration and scoring. 1992, Tucson, AZ: Reitan Neuropsychology Laboratory.

146. Nordlund, A., et al., The Goteborg MCl study: mild cognitive impairment is a heterogeneous condition. J Neurol Neurosurg Psychiatry, 2005. 76(11): p. 1485-90.

147. de Craen, A.J., T.J. Heeren, and J. Gussekloo, Accuracy of the 15-item geriatric depression scale (GDS-15) in a community sample of the oldest old. Int J Geriatr Psychiatry, 2003. 18(1): p. 63-6.

148. Pocklington, C., et al., The diagnostic accuracy of brief versions of the Geriatric Depression Scale: a systematic review and meta-analysis. Int J Geriatr Psychiatry, 2016. 31(8): p. 837-57.

149. Stek, M.L., et al., Natural history of depression in the oldest old: population-based prospective study. Br J Psychiatry, 2006. 188: p. 65-9.

150. Yesavage, J.A., et al., Development and validation of a geriatric depression screening scale: a preliminary report. J Psychiatr Res, 1982. 17(1): p. 37-49.

151. Montorio, I. and M. Izal, The Geriatric Depression Scale: a review of its development and utility. Int Psychogeriatr, 1996. 8(1): p. 103-12.

152. Rabin, R. and F. de Charro, EQ-5D: a measure of health status from the EuroQol Group. Ann Med, 2001. 33(5): p. 337-43.

153. Fortin, M., et al., A systematic review of prevalence studies on multimorbidity: toward a more uniform methodology. Ann Fam Med, 2012. 10(2): p. 142-51.

154. Iverson, G.L., Interpretation of Mini-Mental State Examination scores in community-dwelling elderly and geriatric neuropsychiatry patients. Int J Geriatr Psychiatry, 1998. 13(10): p. 661-6.

155. Park, N.S., et al., The mediating role of loneliness in the relation between social engagement and depressive symptoms among older Korean Americans: do men and women differ? J Gerontol B Psychol Sci Soc Sci, 2013. 68(2): p. 193-201. 
156. Wirehn, A.B., H.M. Karlsson, and J.M. Carstensen, Estimating disease prevalence using a population-based administrative healthcare database. Scand J Public Health, 2007. 35(4): p. 42431.

157. Patton, M.Q., Qualitative Research \& Evaluation Methods. Third ed. 2002, Thousand Oaks: SAGE Publications Inc

158. Graneheim, U.H. and B. Lundman, Qualitative content analysis in nursing research: concepts, procedures and measures to achieve trustworthiness. Nurse Educ Today, 2004. 24(2): p. 105-12.

159. Gahleitner, S.B., Zwischen Differenz und Dekonstruktion. Methodische Überlegungen zur Überschreitung des biploraren Geschlechterdualismus in der enderforschung nach einem Verfahren von Hagemann-White [Between difference and deconstruction. Thinking about methodological strategies for overcoming bipolar gender dualism in gender research using a method proposed by Hagemann-White]. in Gender methodologisch. Empirische Forschung in der Informationsgesellschaft vor neuen Herausforderungen, S. Buchen, C. Helfferich, and M.S. Maier, Editors. 2004, VS Verlag für Sozialwissenschaften: Wiesbaden. p. pp. 283-292.

160. Gildemeister, R., Gender Studies, in A Companion to Qualitative Research, U. Flick, E. von Kardoff, and I. Steinke, Editors. 2004, SAGE Publications: London. p. 126-127.

161. Graneheim, U.H., B.M. Lindgren, and B. Lundman, Methodological challenges in qualitative content analysis: A discussion paper. Nurse Educ Today, 2017. 56: p. 29-34.

162. Wirehn, A.B., et al., Age-specific direct healthcare costs attributable to diabetes in a Swedish population: a register-based analysis. Diabet Med, 2008. 25(6): p. 732-7.

163. EUnetHTA, E.N.f.H.t.A., EUnetHTA JA 2 WP7. Methods for health economic evaluations - $A$ guideline based on current practices in Europe. Guideline. 2015.

164. Akobundu, E., et al., Cost-of-illness studies : a review of current methods. Pharmacoeconomics, 2006. 24(9): p. 869-90.

165. Benjamini, Y., Discovering the false discovery rate. Journal of the Royal Statistical Society: Series B (Statistical Methodology) 2010. 72(4): p. 405-416.

166. Newman, A.B., An overview of the design, implementation, and analyses of longitudinal studies on aging. J Am Geriatr Soc, 2010. 58 Suppl 2: p. S287-91.

167. Graham, J.W., Missing data analysis: making it work in the real world. Annu Rev Psychol, 2009. 60: p. 549-76.

168. World Medical, A., World Medical Association Declaration of Helsinki: ethical principles for medical research involving human subjects. JAMA, 2013. 310(20): p. 2191-4.

169. Gupta, U.C. and S. Kharawala, Informed consent in psychiatry clinical research: A conceptual review of issues, challenges, and recommendations. Perspect Clin Res, 2012. 3(1): p. 8-15.

170. Roberts, L.W. and B. Roberts, Psychiatric research ethics: an overview of evolving guidelines and current ethical dilemmas in the study of mental illness. Biol Psychiatry, 1999. 46(8): p. 1025-38.

171. Wittink, M.N., et al., How older adults combine medical and experiential notions of depression. Qual Health Res, 2008. 18(9): p. 1174-83.

172. Barg, F.K., et al., A mixed-methods approach to understanding loneliness and depression in older adults. J Gerontol B Psychol Sci Soc Sci, 2006. 61(6): p. S329-39.

173. Switzer, J.F., et al., "Pull yourself up by your bootstraps": a response to depression in older adults. Qual Health Res, 2006. 16(9): p. 1207-16.

174. Allan, J. and A. Dixon, Older women's experiences of depression: a hermeneutic phenomenological study. J Psychiatr Ment Health Nurs, 2009. 16(10): p. 865-73.

175. Fischer, R.S., A. Norberg, and B. Lundman, Embracing opposites: meanings of growing old as narrated by people aged 85. Int J Aging Hum Dev, 2008. 67(3): p. 259-71.

176. Wiberg, P., et al., Secular trends in the prevalence of dementia and depression in Swedish septuagenarians 1976-2006. Psychol Med, 2013. 43(12): p. 2627-34. 
177. McCormack, B., Person-centredness in gerontological nursing: an overview of the literature. J Clin Nurs, 2004. 13(3a): p. 31-8.

178. Geiselmann, B. and M. Bauer, Subthreshold depression in the elderly: qualitative or quantitative distinction? Compr Psychiatry, 2000. 41(2 Suppl 1): p. 32-8.

179. Lee, C.T., et al., Latent class-derived subgroups of depressive symptoms in a community sample of older adults: the Cache County Study. Int J Geriatr Psychiatry, 2012. 27(10): p. 1061-9.

180. van Loo, H.M., et al., Data-driven subtypes of major depressive disorder: a systematic review. BMC Med, 2012. 10: p. 156.

181. Fried, E.I. and R.M. Nesse, Depression is not a consistent syndrome: An investigation of unique symptom patterns in the STAR*D study. J Affect Disord, 2015. 172: p. 96-102.

182. Carragher, N., et al., Subtypes of depression in a nationally representative sample. J Affect Disord, 2009. 113(1-2): p. 88-99.

183. Trivedi, M.H., et al., The Inventory of Depressive Symptomatology, Clinician Rating (IDS-C) and Self-Report (IDS-SR), and the Quick Inventory of Depressive Symptomatology, Clinician Rating (QIDS-C) and Self-Report (QIDS-SR) in public sector patients with mood disorders: a psychometric evaluation. Psychol Med, 2004. 34(1): p. 73-82.

184. Wakefield, J.C. and M.F. Schmitz, Severity of complicated versus uncomplicated subthreshold depression: New evidence on the "Monotonicity Thesis" from the national comorbidity survey. J Affect Disord, 2017. 212: p. 101-109.

185. Piver, A., L.N. Yatham, and R.W. Lam, Bipolar spectrum disorders. New perspectives. Can Fam Physician, 2002. 48: p. 896-904.

186. Kalk, N.J. and A.H. Young, Footnotes to Kraepelin: changes in the classification of mood disorders with DSM-5. BJPsych Open, 2017. 3(3): p. e1-e3.

187. Adams, K.B., Depressive symptoms, depletion, or developmental change? Withdrawal, apathy, and lack of vigor in the Geriatric Depression Scale. Gerontologist, 2001. 41(6): p. 768-77.

188. Ballenger, J.C., et al., Consensus statement on transcultural issues in depression and anxiety from the International Consensus Group on Depression and Anxiety. J Clin Psychiatry, 2001. 62 Suppl 13: p. 47-55.

189. Statistics Sweden. The Total Population Register. Sweden: Statistics Sweden (Statistiska Centralbyrån, SCB) . 2015 [cited 2016.

190. Sveriges Kommuner och Landsting, Ekonomirapporten, maj 2017. Om kommunernas och landstingens ekonomi 2017.

191. Luppa, M., et al., Direct costs associated with depressive symptoms in late life: a 4.5-year prospective study. Int Psychogeriatr, 2013. 25(2): p. 292-302.

192. Bock, J.O., et al., Excess health care costs of late-life depression - Results of the AgeMooDe study. J Affect Disord, 2016. 199: p. 139-47.

193. Bock, J.O., et al., The Impact of Depressive Symptoms on Healthcare Costs in Late Life: Longitudinal Findings From the AgeMooDe Study. Am J Geriatr Psychiatry, 2017. 25(2): p. 131141.

194. Donohue, J.M. and H.A. Pincus, Reducing the societal burden of depression: a review of economic costs, quality of care and effects of treatment. Pharmacoeconomics, 2007. 25(1): p. 7-24.

195. Luppa, M., et al., Cost-of-illness studies of depression: a systematic review. J Affect Disord, 2007. 98(1-2): p. 29-43.

196. Byers, A.L., P.A. Arean, and K. Yaffe, Low use of mental health services among older Americans with mood and anxiety disorders. Psychiatr Serv, 2012. 63(1): p. 66-72.

197. Sussman, T., et al., Improving the management of late-life depression in primary care: barriers and facilitators. Depress Res Treat, 2011. 2011: p. 326307. 
198. Tarricone, R., Cost-of-illness analysis. What room in health economics? Health Policy, 2006. 77(1): p. 51-63.

199. Luppa, M., et al., Healthcare costs associated with recognized and unrecognized depression in old age. Int Psychogeriatr, 2008. 20(6): p. 1219-29.

200. Cepoiu, M., et al., Recognition of depression in older medical inpatients. J Gen Intern Med, 2007. 22(5): p. 559-64.

201. Wittayanukorn, S., J. Qian, and R.A. Hansen, Prevalence of depressive symptoms and predictors of treatment among U.S. adults from 2005 to 2010. Gen Hosp Psychiatry, 2014. 36(3): p. 330-6.

202. Anell, A., A. Glenngård, and S. Merkur, Sweden: Health system review. Health Systems in Transition. 2012.

203. Socialstyrelsen, Elderly need of mental health care and support (Äldres behov av psykiatrisk vård och stöd). 2012-2-22. 2012.

204. Hoeft, T.J., et al., Directions for Effectiveness Research to Improve Health Services for Late-Life Depression in the United States. Am J Geriatr Psychiatry, 2016. 24(1): p. 18-30.

205. Barry, L.C., et al., Longitudinal association between depressive symptoms and disability burden among older persons. J Gerontol A Biol Sci Med Sci, 2009. 64(12): p. 1325-32.

206. Holwerda, T.J., et al., Impact of loneliness and depression on mortality: results from the Longitudinal Ageing Study Amsterdam. Br J Psychiatry, 2016. 209(2): p. 127-34.

207. Stek, M.L., et al., Is depression in old age fatal only when people feel lonely? Am J Psychiatry, 2005. 162(1): p. 178-80.

208. Rapp, M.A., et al., Depression predicts mortality in the young old, but not in the oldest old: results from the Berlin Aging Study. Am J Geriatr Psychiatry, 2008. 16(10): p. 844-52.

209. Blazer, D.G., C.F. Hybels, and C.F. Pieper, The association of depression and mortality in elderly persons: a case for multiple, independent pathways. J Gerontol A Biol Sci Med Sci, 2001. 56(8): p. M505-9.

210. Walker, E.R., R.E. McGee, and B.G. Druss, Mortality in mental disorders and global disease burden implications: a systematic review and meta-analysis. JAMA Psychiatry, 2015. 72(4): p. 334-41.

211. Hill, A.B., The Environment and Disease: Association or Causation? Proc R Soc Med, 1965. 58: p. 295-300.

212. Lewis, G., Introduction to Epidemiologic Research Methods, in Textbook of Psychiatric Epidemiology, M. Tsuang, M. Tohen, and P.B. Jones, Editors. 2011. p. 6.

213. Bresnahan, M., et al., Peering into the Future of Psychiatric Epidemiology, in Textbook of Psychiatric Epidemiology, M.T. Tsuang, M. Tohen, and P.B. Jones, Editors. 2011.

214. Ventriglio, A., A. Bellomo, and D. Bhugra, Web of causation and its implications for epidemiological research. Int J Soc Psychiatry, 2016. 62(1): p. 3-4.

215. March, D. and E. Susser, The eco- in eco-epidemiology. Int J Epidemiol, 2006. 35(6): p. 1379-83.

216. Ormel, J., et al., Temporal and reciprocal relationship between IADL/ADL disability and depressive symptoms in late life. J Gerontol B Psychol Sci Soc Sci, 2002. 57(4): p. P338-47.

217. Koenig, A.M., et al., Neuropsychological functioning in the acute and remitted States of late-life depression. J Alzheimers Dis, 2015. 45(1): p. 175-85.

218. Chen, C.M., et al., The longitudinal relationship between depressive symptoms and disability for older adults: a population-based study. J Gerontol A Biol Sci Med Sci, 2012. 67(10): p. 1059-67.

219. Fishleder, S., et al., Trajectories of depressive symptoms in community-dwelling older adults: $A$ six-month longitudinal study with monthly assessment. J Affect Disord, 2016. 198: p. 171-7.

220. Gorwood, P., et al., Toxic effects of depression on brain function: impairment of delayed recall and the cumulative length of depressive disorder in a large sample of depressed outpatients. Am J Psychiatry, 2008. 165(6): p. 731-9. 
221. Malykhin, N.V. and N.J. Coupland, Hippocampal neuroplasticity in major depressive disorder. Neuroscience, 2015. 309: p. 200-13.

222. McIntyre, R.S., D. Cha, and J.K. Soczynska, Cognition in Major Depressive Disorder. Oxford Psychiatry Library. 2014: Oxford University Press.

223. Judd, L., Schettler, P.J., Akiskal, H.S., The prevalence, clinical relevance, and public health significance of subthreshold depressions. The Psychiatric Clinics Of North America 2002. 25(4): p. 685-98.

224. Wakefield, J.C., The concept of mental disorder. On the boundary between biological facts and social values. Am Psychol, 1992. 47(3): p. 373-88.

225. Hayes, J. and E.L. Hannold, The road to empowerment: a historical perspective on the medicalization of disability. J Health Hum Serv Adm, 2007. 30(3): p. 352-77.

226. Perry, B.L., The labeling paradox: stigma, the sick role, and social networks in mental illness. J Health Soc Behav, 2011. 52(4): p. 460-77.

227. Berger, P. and T. Luckmann, The Social Construction of Reality: A Treatise in the Sociology of Knowledge. 1966, Penguin Books.

228. Conrad, P. and K.K. Barker, The social construction of illness: key insights and policy implications. J Health Soc Behav, 2010. 51 Suppl: p. S67-79.

229. O'Dea, B. and A. Campbell, Online social networking amongst teens: friend or foe? Stud Health Technol Inform, 2011. 167: p. 133-8.

230. Li, A., D. Jiao, and T. Zhu, Detecting depression stigma on social media: A linguistic analysis. J Affect Disord, 2018. 232: p. 358-362.

231. Smith, R.S., Contested memory: Notes on Robert K. Merton's"the Thomas Theorem and the Matthew Effect". The American Sociologist, 1999. 30(2): p. 62-67.

232. Pilgrim, D. and R. Bentall, The medicalisation of misery: A critical realist analysis of the concept of depression. Journal of Mental Health, 1999. 8(3): p. 261-274.

233. van Dijk, W., et al., Medicalisation and Overdiagnosis: What Society Does to Medicine. Int J Health Policy Manag, 2016. 5(11): p. 619-622.

234. Bhugra, D., A. Ventriglio, and K.S. Bhui, What's in a name? Reclaiming mental illness. Lancet Psychiatry, 2016. 3(12): p. 1100-1101.

235. Lilienfeld, S.O. and M.T. Treadway, Clashing Diagnostic Approaches: DSM-ICD Versus RDoC. Annu Rev Clin Psychol, 2016. 12: p. 435-63.

236. Fanous, A.H., Can genomics help usher schizophrenia into the age of RDoC and DSM-6? Schizophr Bull, 2015. 41(3): p. 535-41.

237. Hayes, S.C., K.D. Strosahl, and K.G. Wilson, Acceptance and Commitment Therapy, Second Edition: The Process and Practice of Mindful Change. 2nd ed. 2012, London: The Guilford Press.

238. Insel, T., et al., Research domain criteria (RDoC): toward a new classification framework for research on mental disorders. Am J Psychiatry, 2010. 167(7): p. 748-51.

239. Berlim, M.T., M.P. Fleck, and E. Shorter, Notes on antipsychiatry. Eur Arch Psychiatry Clin Neurosci, 2003. 253(2): p. 61-7.

240. Schaefer, J.D., et al., Enduring mental health: Prevalence and prediction. J Abnorm Psychol, 2017. 126(2): p. 212-224.

241. Lewis-Fernandez, R., et al., Feasibility, acceptability and clinical utility of the Cultural Formulation Interview: mixed-methods results from the DSM-5 international field trial. Br J Psychiatry, 2017. 210(4): p. 290-297.

242. Govindarajan, R. and P. Narayanaswami, Evidence Based Medicine for Every day, Everyone and Every Therapeutic Study. Muscle Nerve, 2018.

243. Van den Broeck, K., et al., Collaborative care regarding major depressed patients: A review of guidelines and current practices. J Affect Disord, 2016. 200: p. 189-203. 
244. Gottfries, G.G., S. Noltorp, and N. Norgaard, Experience with a Swedish version of the Geriatric Depression Scale in primary care centres. Int J Geriatr Psychiatry, 1997. 12(10): p. 1029-34.

245. Jongenelis, K., et al., Diagnostic accuracy of the original 30-item and shortened versions of the Geriatric Depression Scale in nursing home patients. Int J Geriatr Psychiatry, 2005. 20(11): p. 1067-74.

246. Gordis, L., Epidemiology. 2014, Elsevier/Saunders: Philadelphia, PA p. 264-265.

247. Ostlund, U., et al., Combining qualitative and quantitative research within mixed method research designs: a methodological review. Int J Nurs Stud, 2011. 48(3): p. 369-83.

248. Kettles, A.M., J.W. Creswell, and W. Zhang, Mixed methods research in mental health nursing. J Psychiatr Ment Health Nurs, 2011. 18(6): p. 535-42.

249. Lincoln, Y.S., Y.S.L.E.G. Guba, and E.G. Guba, Naturalistic Inquiry. 1985: SAGE Publications.

250. Malterud, K., Qualitative research: standards, challenges, and guidelines. Lancet, 2001. 358(9280): p. 483-8.

251. Schillerstrom, J.E., D.R. Royall, and R.F. Palmer, Depression, disability and intermediate pathways: a review of longitudinal studies in elders. J Geriatr Psychiatry Neurol, 2008. 21(3): p. 183-97.

252. Trivedi, M.H. and T.L. Greer, Cognitive dysfunction in unipolar depression: implications for treatment. J Affect Disord, 2014. 152-154: p. 19-27.

253. Stegenga, B.T., et al., Depression, anxiety and physical function: exploring the strength of causality. J Epidemiol Community Health, 2012. 66(7): p. e25.

254. Aggernaes, B., Autism: a transdiagnostic, dimensional, construct of reasoning? Eur J Neurosci, 2018. 47(6): p. 515-533. 


\section{Papers 1-4.}





\section{Papers}

The papers associated with this thesis have been removed for copyright reasons. For more details about these see:

http://urn.kb.se/resolve?urn=urn:nbn:se:liu:diva-149813 
ANNEX 



\section{Appendix}

\section{Annex 1. The 15-item Geriatric Depression Scale (GDS-15)}

Choose the best answer for how you have felt over the past week:

1. Are you basically satisfied with your life? YES / NO

2. Have you dropped many of your activities and interests? YES / NO

3. Do you feel that your life is empty? YES / NO

4. Do you often get bored? YES / NO

5. Are you in good spirits most of the time? YES / NO

6. Are you afraid that something bad is going to happen to you? YES / NO

7. Do you feel happy most of the time? YES / NO

8. Do you often feel helpless? YES / NO

9. Do you prefer to stay at home, rather than going out and doing new things? YES / NO

10. Do you feel you have more problems with memory than most? YES / NO

11. Do you think it is wonderful to be alive now? YES / NO

12. Do you feel pretty worthless the way you are now? YES / NO

13. Do you feel full of energy? YES / NO

14. Do you feel that your situation is hopeless? YES / NO

15. Do you think that most people are better off than you are? YES / NO

Reference: Sheikh JA,Yeasavage JA: Geriatric Depression Scale (GDS): recent findings and development of a shorter version., in Clinical Gerontology: A Guide to Assessment and Intervention. Edited by Brink TL. New York, Howarth Press, 1986, pp. 